\title{
Towards the development of an integrated modelling framework underpinned by \\ mineralogy
}

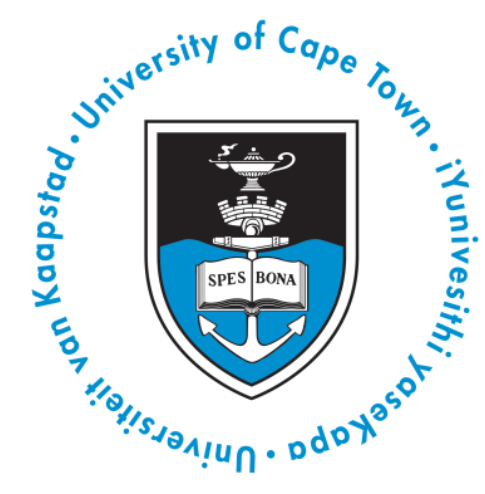

\section{Sithembiso Ntlhabane}

Dissertation in fulfilment of the degree of Master of Science in Chemical

Engineering

\section{October 2018}

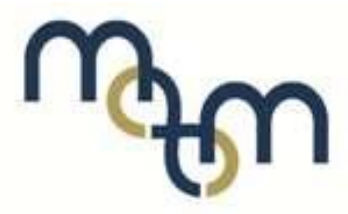

minerals to metals

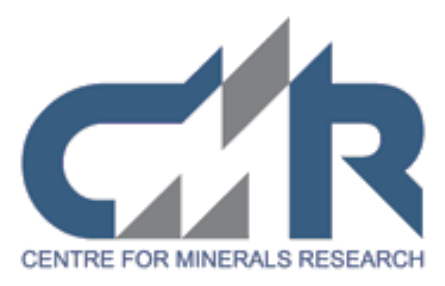


The copyright of this thesis vests in the author. No quotation from it or information derived from it is to be published without full acknowledgement of the source. The thesis is to be used for private study or noncommercial research purposes only.

Published by the University of Cape Town (UCT) in terms of the non-exclusive license granted to UCT by the author. 


\section{Declaration}

I declare that this thesis is my own work. It is being submitted for the degree of Master of Science (MSc) in the University of Cape Town. This thesis has not been submitted before for any degree or examination in any other university.

Signed by candidate

Sithembiso Ntlhabane

October 2018 


\begin{abstract}
The mining industry is under increased pressure from many stakeholders to be forward thinking in its approach to sustainability. This requires a holistic approach to address techno-economic, environment and social issues, rather than just focusing on individual aspects of sustainability practice. The ability to do so requires an integrated modelling framework, underpinned by mineralogy so that the effect of ore variability on one or more of these factors can be simultaneously evaluated and optimised. This study focuses on the steps towards the development of this proposed framework using a case study of a polymetallic sulfide ore flotation circuit. The initial focus in the framework development is on integrating the techno-economic and the environmental aspects of sustainability. Thereafter the framework is used to consider a variety of scenarios evaluating the balance between techno-economic value and environmental burden.
\end{abstract}

A sampling exercise was conducted around the intermediate and terminal streams of the flotation circuit processing polymetallic sulfide ore. All samples were characterised using both chemical assays and mineralogy (QEMSCAN). This formed the input data for the development of an ore specific element to mineral conversion (EMC) recipe that converts chemical assays to mineral grades. The EMC technique has the advantage of being fast, inexpensive and can be used on a routine basis. The recipe for this specific polymetallic sulfide ore was designed to calculate nine minerals in four different rounds, using least square method in the first two rounds and non-negative least square in the last two rounds. Sulfide minerals (chalcopyrite, galena and sphalerite) were calculated in the first round, barite was estimated in the second round, silicate minerals (garnet, biotite and quartz) were determined in the third round and pyrrhotite and magnetite were calculated on the last round. Data validation for EMC was performed by comparing calculated mineral grades against the measured mineral grades obtained from QEMSCAN. The accuracy was determined by evaluating the $\mathrm{R}^{2}$ value, the results were comparable as the $\mathrm{R}^{2}$ value was above 0.95 for all minerals.

Mineral grades obtained from EMC of the assayed streams were used to carry out a mineral mass balanced of the flotation circuit. From the results, mineral grade and recovery were calculated and were used to evaluate metallurgical performance across the flotation circuit. The chalcopyrite (copper) concentrate was diluted with pyrrhotite (26 wt. \%). The sphalerite concentrate (zinc) had the highest grade (94 wt. \%) followed by galena (lead) with a concentrate grade of 85 wt. \%. Sphalerite and galena achieved high recoveries over $90 \%$. From analysis of the flotation performance of the circuit, the results demonstrate an opportunity to improve the copper (chalcopyrite) concentrate quality. The diluted concentrate is likely to attract penalties during downstream processing (e.g. smelter) due to the presence of impurities (pyrrhotite). The concentrate can be upgraded by rejecting pyrrhotite in the first stage of the copper circuit. In addition, the mass balanced mineralogy results were used to calculate a theoretical 
potential of the final tailings to generate acid rock drainage (ARD). The ARD method used is based on the relative abundance of acid generating sulfide minerals (chalcopyrite, galena, sphalerite and pyrrhotite) and other minerals with the theoretical potential to neutralise the acid generated. The net mineralogically calculated acid producing potential was estimated as $46.4 \mathrm{~kg} \mathrm{H}_{2} \mathrm{SO}_{4} /$ ton.

To further demonstrate the usefulness of the framework, a mineral splitter function was used to model the flotation circuit and test different hypothetical scenarios. Two hypothetical scenarios were investigated relative to the current operating condition of the flotation circuit. A sensitivity analysis on both scenarios was conducted to assess the effect of feed ore variability. The pyrrhotite feed grade was varied between 10 and $100 \%$ of the base case and all sulfide mineral recoveries were kept constant. Scenario I considered improving $\mathrm{Cu}$ (chalcopyrite) concentrate grade in the $\mathrm{Cu}$ circuit by rejecting pyrrhotite. A Monte Carlo simulation was carried out by varying the pyrrhotite recovery to concentrate from a minimum of $2 \%$ to a maximum of $18 \%$ in the mineral splitter function. The results showed an increase in pyrrhotite grade in the final zinc tailings and an increase in the mineralogically calculated ARD potential (up to $53.9 \mathrm{~kg} \mathrm{H}_{2} \mathrm{SO}_{4} / \mathrm{t}$ for tailings). Scenario II considered the installation of a magnetic separator to concentrate pyrrhotite in the final tailings and achieved a net acid producing potential of $15.2 \mathrm{~kg} \mathrm{H}_{2} \mathrm{SO}_{4} / \mathrm{t}$, which was lower than scenario I. The sensitivity analysis of scenario I showed a correlation between increased pyrrhotite feed grade with mineralogically calculated ARD potential (89.6 $\mathrm{kg} \mathrm{H}_{2} \mathrm{SO}_{4} / \mathrm{t}$ ). The results from sensitivity analysis of scenario II were lower were than scenario I (28.6 $\mathrm{kg} \mathrm{H}_{2} \mathrm{SO}_{4} / \mathrm{t}$ ). This shows that installation of a magnetic separator has the potential to mitigate ARD formation and produce a potential economic magnetite concentrate by-product.

In conclusion this study has shown how mineralogy can be integral in developing an integrated modelling framework for simultaneously assessing techno-economic and environmental performance. The developed framework demonstrated the possibility of simultaneously balancing the trade-off, improving grade and mitigating the risk of ARD formation. It is a conceptual starting point for a new approach to traditional process mineralogy studies to start implementing sustainable development aspects on the operational level. 


\section{Acknowledgments}

I would first like to thank God for keeping me strong and this all through His grace.

For every one of us that succeeds, it is because there is somebody there to show you the way out Oprah Winfrey. To my supervisors: Associate Professor Megan Becker, Dr Edson Charikinya, Professor Robert Schouwstra and Professor Dee Bradshaw, thank you all for the support, constructive criticism and advice, I wouldn't be able to rise to the occasion without the latter. To Associate Professor Megan Becker, thank you for accepting my application to study at UCT, I will forever be grateful for this journey as it became one of the best gifts in my life. I appreciate your technical input in mineralogy, presentation, writing skills and the time you give to your students. To Dr Edson Charikinya, thank you for the vast knowledge in simulation software, your input in understanding HSC Chemistry, running the different scenario analysis and the patience in explaining how the software operates. I would like to thank you for your contribution in writing and presentation skills. To Professor Robert Schouwstra, thank you for the vast knowledge in process mineralogy, the constructive criticism and to see the holistic picture of my project. To Professor Dee Bradshaw, thank you for the initial funding and the vast contribution of knowledge to the project. Thank you for helping me to find and tap into my purpose and giving me the foundation to prepare myself for it, this has made me find meaning in my life.

I would like to acknowledge the National Research Foundation of South Africa (Grant Number 86054), and by the South African Research Chairs Initiative (SARChI Chair in Minerals Beneficiation) of the Department of Science and Technology and National Research Foundation of South Africa for funding the project. Any opinions, findings and conclusions or recommendations expressed in any publication generated by the NRF supported research is that of the author(s), and the NRF accepts no liability whatsoever in this regard

I would like to acknowledge the staff in the department of Chemical Engineering at UCT- Gaynor Yorath, Andrea Molifie, Lorraine Nkemba, Monde Bekaphi, Kenneth Maseko, Mussa Lisso, Dr Paul Bepswa and Nicole Uys. To Gaynor and Andrea for analysing the samples with QEMSCAN and availability to help in processing the data. To Lorraine for preparing samples for QEMSCAN analysis. To Monde and Kenneth for always assisting in the lab whenever help was required. To Mussa for successfully managing the sample campaign. To Dr Bepswa, thank you for transferring the knowledge on sampling. To Nicole, thank you very much for proof reading my thesis and providing valuable suggestions.

I would like to thank the metallurgist (Camilla, Tumi, Tim, Tshepo and Langa) from the mine for assisting with the sample campaign, packaging the samples and providing necessary information on the process. 
I would like to thank Fredrik Axelsson, for assisting in the project and passing the knowledge of HSc Chemistry. I would like to thank Dr Lund from Luleå University of Technology for assisting in setting up the EMC recipe and understanding and aiding in the interpretation of results obtained.

To UCT Toastmaster, for giving me the platform to build my confidence in public speaking.

I would like to thank Theo, Keith and Nobuhle for helping me to settle in Cape Town, you guys made me feel at home away from home.

To Liabo, Marcy, Leanne and Tom thank you for making my time memorable in Cape Town.

To Christina, thank you for allowing us to come to your meeting to meet Professor Phakeng, I will always be grateful for that moment. To Professor Phakeng, thank you for giving your time in your busy schedule, your presence is serene but yet bold and daring and that is admirable.

To my hearts; my parents, brother, extended family members and friends. Thank you for the strength, emotional support and comfort you provided throughout the journey.

Lastly but not least, thank you Sithembiso (Sthe) Ntlhabane, for allowing yourself to come out of your comfort zone, for your vulnerability that became your strength in time of need and the courage to face your fears. The two year journey affirmed, that fortune always favours the brave. 


\section{List of publications and presentations}

Becker, M., Charikinya, E., Ntlhabane, S., Voigt, M., Broadhurst, J., Harrison, S., Bradshaw, D., 2018. An Integrated Mineralogy-based Modelling Framework For The Simultaneous Assessment Of Plant Operational Parameters With Acid Rock Drainage Potential Of Tailings, in: Wolkersdorfer, C., Sartz, L., Weber, A., Burgess, J., Tremblay, G. (Eds.), Proceedings of the 11th International Conference on Acid Rock Drainage. Pretoria, South Africa, pp. 309-314.

Ntlhabane, S., Becker, M., Charikinya, E., Schouwstra, R., and Bradshaw, D., 2017. Towards the development of an integrated modelling framework. Presented at: MEI Process Mineralogy '17, 20-21 March 2017, Cape Town.

Ntlhabane, S., Becker, M., Charikinya, E., Schouwstra, R., and Bradshaw, D., 2017. Towards the development of an integrated modelling framework. Presented at: Mineral Research Showcase, Southern African Institute of Mining \& Metallurgy Western Cape Branch, 3-4 August 2017, Cape Town.

Ntlhabane, S., Becker, M., Charikinya, E., Voigt, M., Schouwstra, R., Bradshaw, D., 2017. Towards the development of an integrated modelling framework underpinned by mineralogy. Miner. Eng. 116, 123-131. doi:10.1016/j.mineng.2017.09.013.

Ntlhabane, S., Becker, M., Charikinya, E., Schouwstra, R., Bradshaw, D., 2018. Developing a mineralogical acid rock drainage indicator for operational decision-making. Published in: Digby, C., Bradshaw, D., Mostert, B., Chicksen (Eds), Green Mining: Beyond the Myth. Perspectives of the future mining, $\mathrm{p} 75$. 


\section{Table of Contents}

$\begin{array}{lll}\text { Contents } & \text { Page }\end{array}$

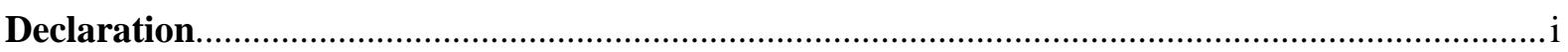

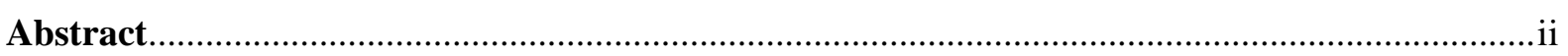

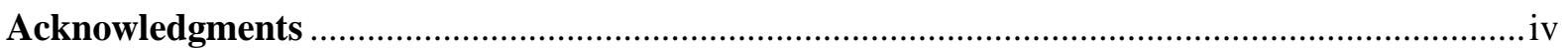

List of publications and presentations …………....................................................................

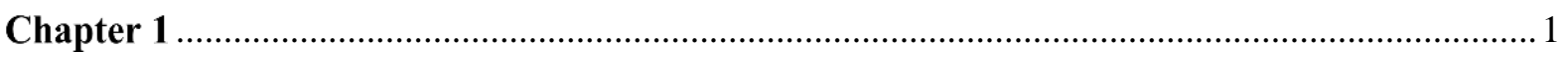

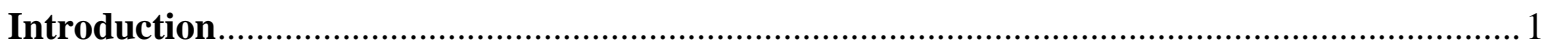

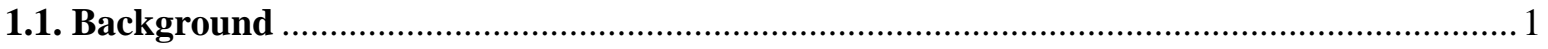

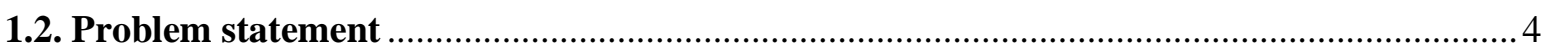

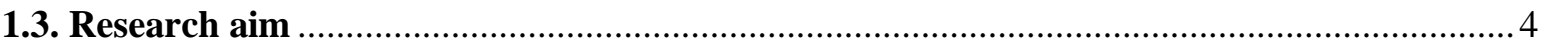

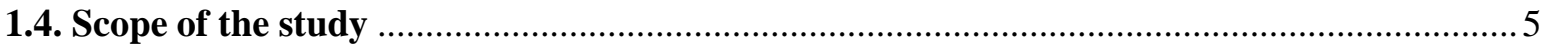

1.5. Thesis structure

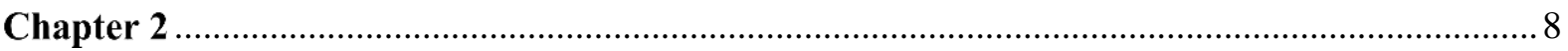

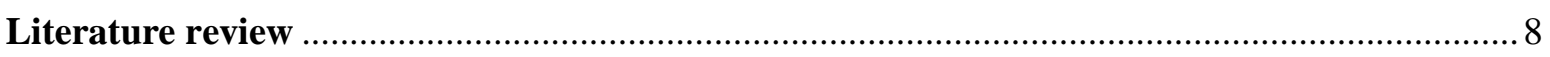

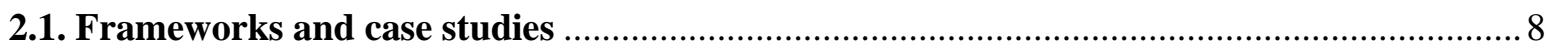

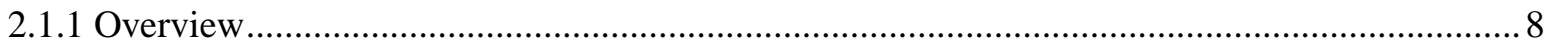

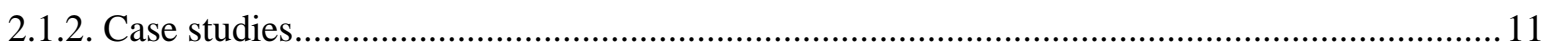

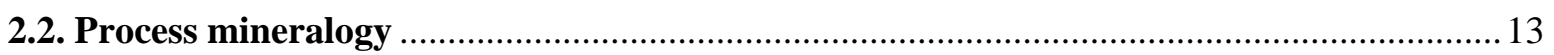

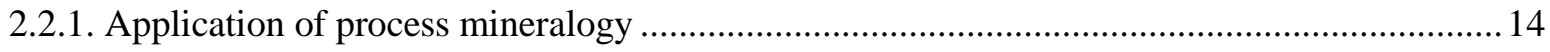

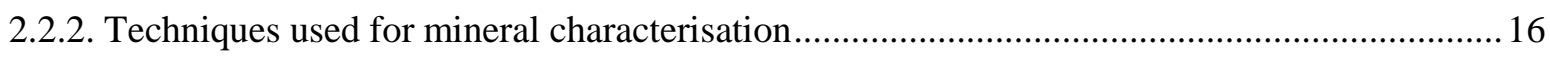

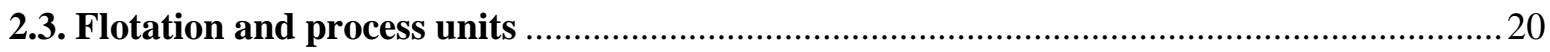

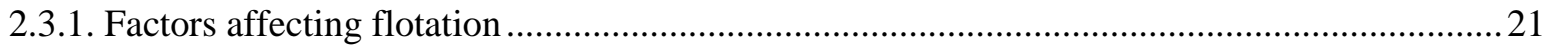

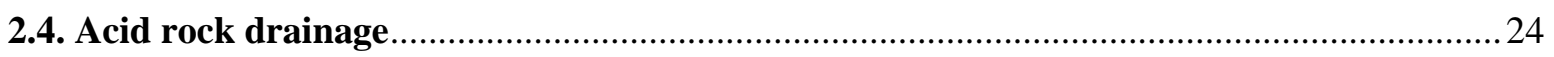

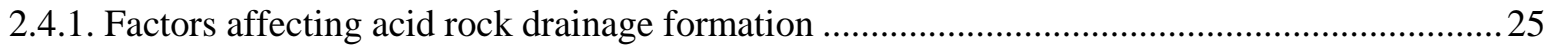

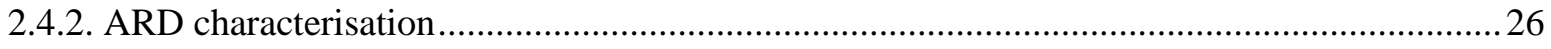

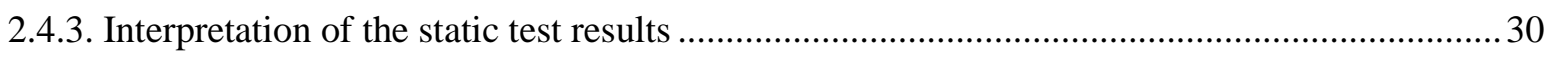


2.5. Modelling tools

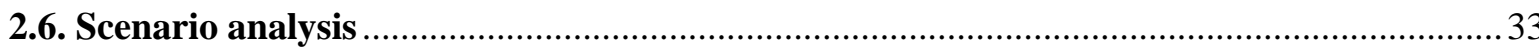

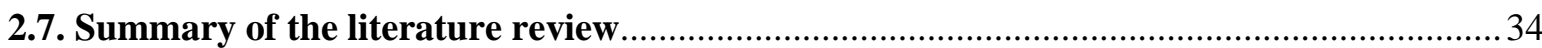

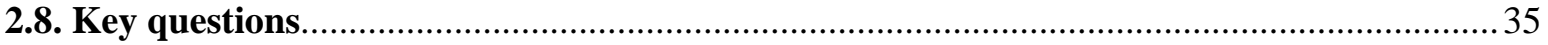

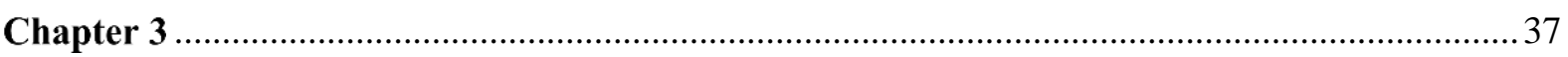

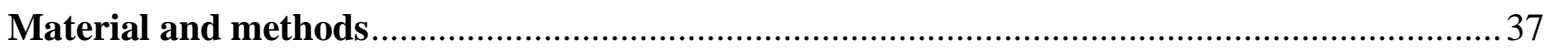

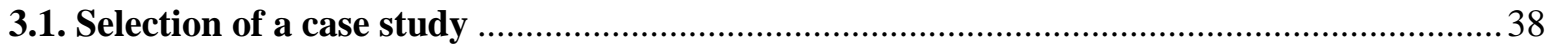

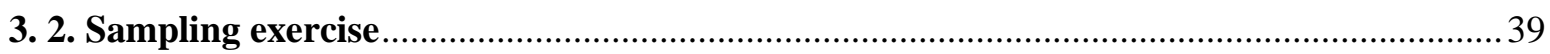

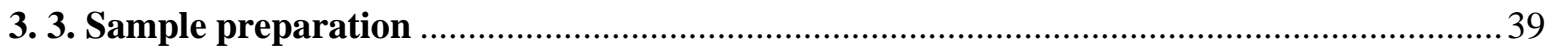

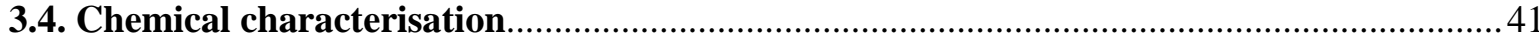

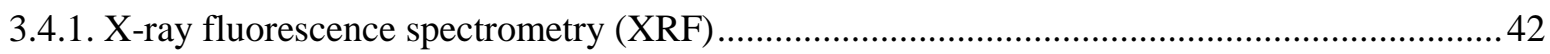

3.4.2. Inductively coupled plasma optical emission spectrometry (ICP-OES) ……........................ 42

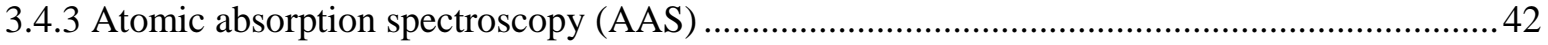

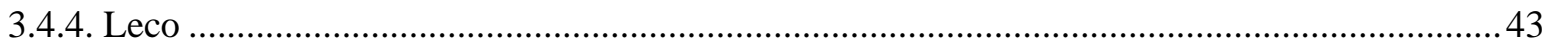

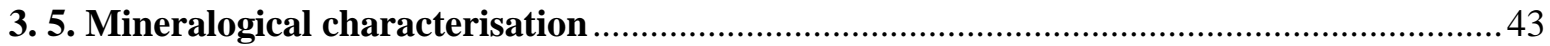

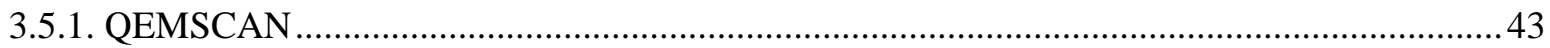

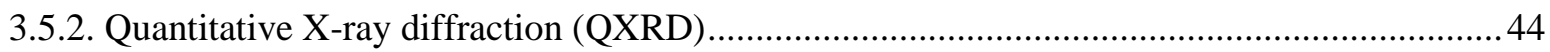

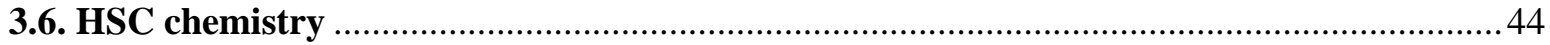

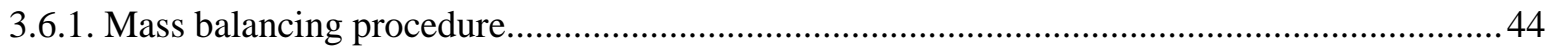

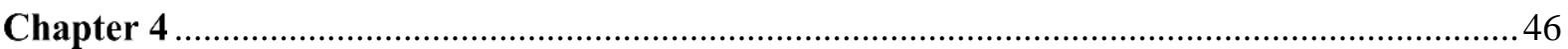

Developing a case study for an integrated modelling framework ........................................46

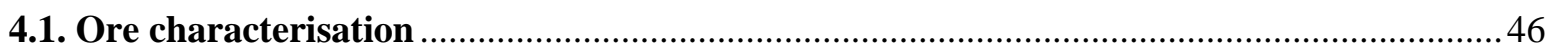

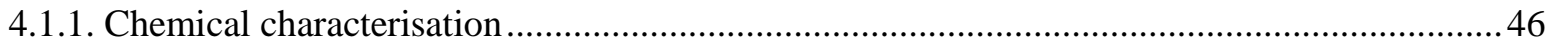

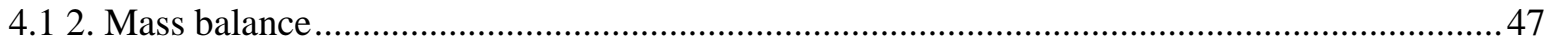

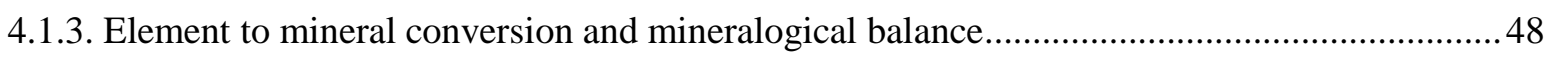

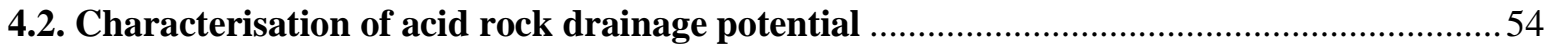

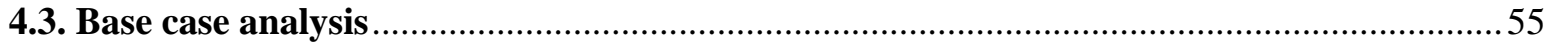

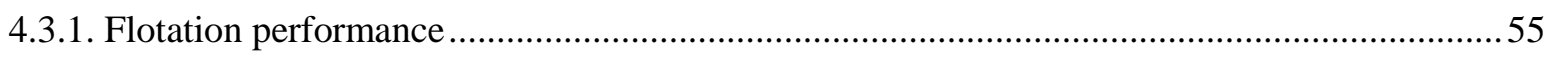

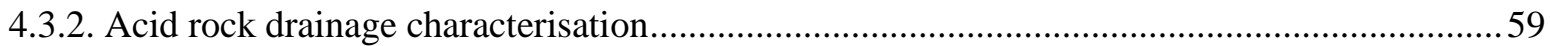


Chapter 5

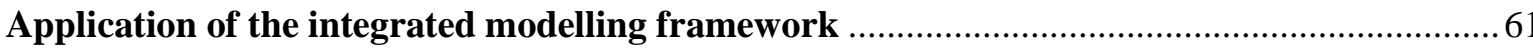

5.1. The effects of final copper grade on net smelter return ...................................................... 61

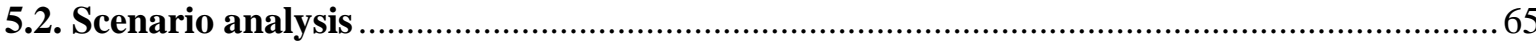

5.2.1 Scenario I: Improving copper (chalcopyrite) concentrate ...................................................... 66

5.2.2. Scenario II: Improving $\mathrm{Cu}$ (chalcopyrite) concentrate quality and installing a magnetic

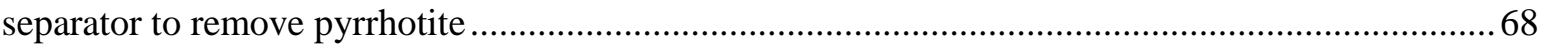

5.2.3. Sensitivity analysis of scenario I: Changes in feed ore variability ......................................... 71

5.2.4. Sensitivity analysis for scenario II- Changes in feed ore variability ...................................... 73

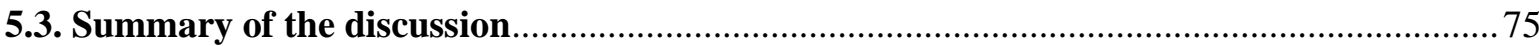

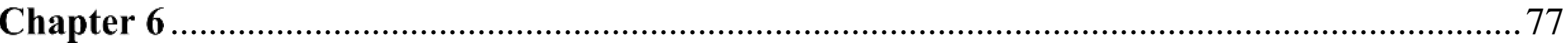

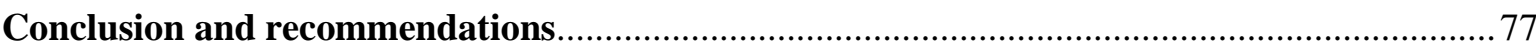

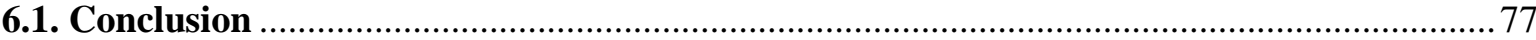

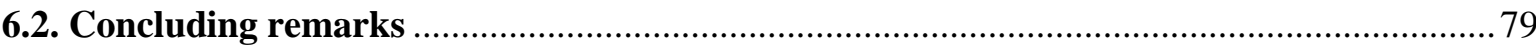

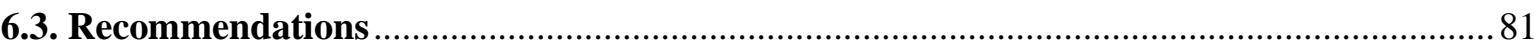

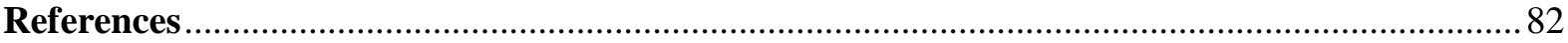

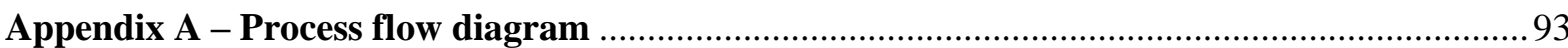

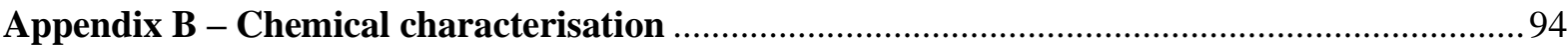

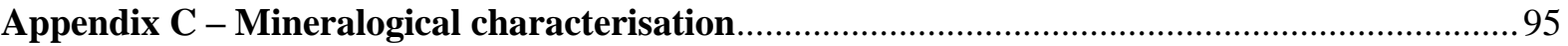

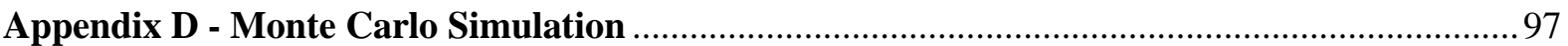




\section{List of figures}

Figure 1.1: General trend of declining ore grades for base and precious metals (Mudd, 2009)............ 1 Figure 1.2: A diagram illustrating the three pillars (social, economic and environment) of sustainable development - adapted from Barbier (1987), www.wikepedia.com.

Figure 1.3: Diagram illustrating an integrated approach of tailings management by linking the geochemistry of arsenic in the waste material back to arsenic in ore mineralogy and identifying possible points of intervention where the effects of the orebody can be tested (Edraki et al., 2014).................. 4

Figure 1.4: Illustration of the scope and boundaries of the study ...................................................... 6

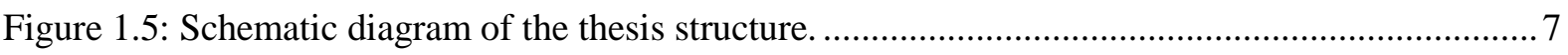

Figure 2.1: Components of the proposed sustainability integration methodology (Tuazon et al., 2012).

Figure 2.2: A comparison of zinc recovery and liberation before and after installing IsaMill technology at the Mt Isa Mines from 1981 to 1996 (Young et al., 1997).

Figure 2.3: Comparison of bulk mineralogy of copper $(\mathrm{Cu})$ concentrate before and after upgrading of (top) and that of Nickel (Ni) concentrate before and after upgrading (bottom) (Evans et al., 2011).... 15 Figure 2.4: Conceptual approach to mitigate acid rock drainage in the waste material (Hesketh et al.,

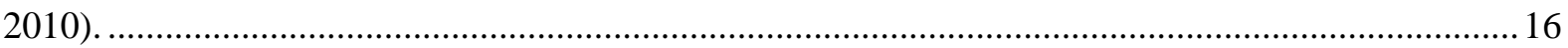

Figure 2.5: A diagram of the process of froth flotation (Wills and Napier-Munn, 2006).................... 21 Figure 2.6: Theoretical grade-recovery curve. The picture on the left demonstrates that high recovery can be a combination of valuable and gangue minerals which that reduces the grade of the concentrate. The picture on the right shows that if the actual grade and recovery is lower than the theoretical, then it might be required to change operational conditions to improve this (1). If grade or recovery are above the theoretical curve, then the texture of the feed will be required to change (2) (Cropp et al., 2013).

Figure 2.7: Conventional route of mineral recovery according to the particle size (Runge et al., 2013).

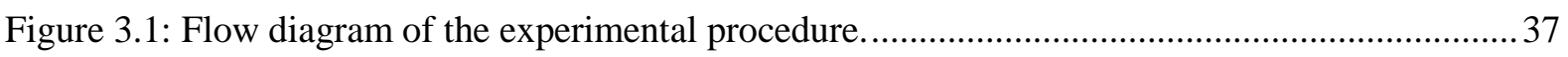

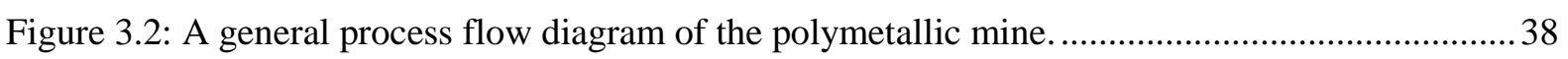

Figure 3.3: Flowsheet of the case study flotation circuit with key sampling points annotated..............39

Figure 3.4: Photographs of equipment used in the sampling campaign and sample preparation. .........40

Figure 3.5: Particle Size Distribution of the samples collected across the flotation circuit. Conc refers to concentrate. 
Figure 4.1: Comparison of the unbalanced chemical assays analysed by techniques with balanced chemical assay analysed by techniques for all samples. The associated $\mathrm{R}^{2}$ value is included for each element.

Figure 4.2: Comparison of the unbalanced chemical assays with the QEMSCAN calculated chemical assay for all samples. The associated $\mathrm{R}^{2}$ value is included for each element.

Figure 4.3: Comparison of the unbalanced EMC calculated mineralogy with the unbalanced QEMSCAN measured mineral grades for all samples.

Figure 4.4: Comparison of the unbalanced EMC calculated mineralogy with the balanced EMC measured mineral grades for all samples.

Figure 4.5: Balanced mineral grades across the flotation circuit, calculated using the EMC method..56

Figure 5.1:Payments and charges with concentrate grade (Wills and Napier-Munn, 2006).....

Figure 5.2: The elemental composition of a concentrate produced from the base case.

Figure 5.3: The relationship between final copper concentrate grade and percentage payable $\mathrm{Cu}$ concentrate of the base case. The asterisk indicates the copper content of the base case. .64

Figure 5.4: Matrix of the different scenario analysis considered for the study.

Figure 5.5: Correlation between predicted ARD potential and increased pyrrhotite grade in the final zinc tails for scenario I.

Figure 5.6: The elemental composition of a concentrate produced from the simulated $\mathrm{Cu}$ concentrate for scenario $\mathrm{I}$.

Figure 5.7: The relationship between final copper concentrate grade and percentage payable $\mathrm{Cu}$ concentrate for scenario I. The asterisk indicates the copper content of the simulated $\mathrm{Cu}$ concentrate for scenario I. .68

Figure 5.8: Flowsheet of the case study flotation circuit with a magnetic separator for scenario II.....69 Figure 5.9: Correlation between predicted ARD potential and increased pyrrhotite grade in the final magnetic tails for scenario II.

Figure 5.10: The elemental composition of a concentrate produced from the simulated $\mathrm{Cu}$ concentrate with a magnetic separator for scenario II. .70

Figure 5.11: The relationship between final copper concentrate grade and percentage payable $\mathrm{Cu}$ concentrate for scenario II. The asterisk indicates the copper content of the improved $\mathrm{Cu}$ concentrate with a magnetic separator for scenario II. .71

Figure 5.12: Correlation of modelled ARD potential and increased pyrrhotite grade in the feed for sensitivity analysis of scenario I.

Figure 5.13: The elemental composition of a concentrate produced from the changes in ore variability for sensitivity analysis of scenario I.

Figure 5.14: The relationship between final copper concentrate grade and percentage payable $\mathrm{Cu}$ concentrate for sensitivity analysis of scenario I. The asterisk indicates the copper content of the $\mathrm{Cu}$ concentrate when considering changes in ore variability for sensitivity analysis of scenario I. .73 
Figure 5.15: Correlation of modelled ARD potential and increased pyrrhotite grade in the feed with the installation of a magnetic separator for sensitivity analysis of scenario II.

Figure 5.16: The elemental composition of a concentrate produced from the changes in ore variability magnetic separator for sensitivity analysis of scenario II. .74

Figure 5.17: The relationship between final copper concentrate grade and percentage payable $\mathrm{Cu}$ concentrate for sensitivity analysis of scenario II. The asterisk indicates the copper content of the $\mathrm{Cu}$ concentrate when considering the changes in ore variability with the magnetic separator for sensitivity analysis of scenario II. .75

Figure 6.1: Overview of the integrated framework development. .79 


\section{List of tables}

Table 2.1:Summary of the case studies discussed in this section. 13

Table 2.2: Methods for mineralogical characterisation (Adapted from Lamberg et al., 2013)............. 20

Table 2.3: Summary of reagents and their purpose (Wills and Napier Munn, 2006). .22

Table 2.4: Grouping of minerals according to their reactivity at $\mathrm{pH} 5$ adopted from (Lawrence and Scheske, 1997). .26

Table 2.5: Parameters considered when calculating mineralogical acid rock drainage (Paktunc, 1999).

Table 2.6: Mineralogical ANC methods (Plante et al., 2012)......

Table 2.7: Guidelines for ARD classification using different static chemical tests (Smart et al., 2002; Stewart et al., 2006).

Table 3.1: Detection limit of the chemical techniques and it is applicable for both sized and bulk samples

Table 4.1: Chemical composition of the different streams samples analysed by the different analytical techniques, given in wt. \%. (Unbalanced data).

Table 4.2: Overall mass balance across the flotation circuit. The mass balance data was obtained from HSC SIM flowsheet module. .48

Table 4.3: Data reconciliation of the flotation circuit during the survey. 48

Table 4.4: QEMSCAN bulk mineralogy of the different samples. Note results shown are unbalanced and the data is expressed as wt. \%.

Table 4.5: Mineral chemistry of the sulfide minerals where the standard deviation is given in brackets. The number of analyses is also reported. (From Rudnick, 2018, Pers. Comm). .51 Table 4.6: Mineral chemistry for silicate minerals where the standard deviation is given in brackets. The number of analyses is also reported. (From Rudnick, 2018, Pers. Comm).

Table 4.7: Mineral chemistry based on the stoichiometric composition of the minerals (Data taken from HSC database).

Table 4.8: Element to mineral conversion recipe used for the study. LS indicates least squares, NNLS indicates non-negative least squares.

Table 4.9: Summary of the relative potential contribution of the various minerals in terms of their acid forming or neutralising capacity.

Table 4.10: Balanced valuable mineral grade and recovery. Mineral grades were obtained from EMC and the recovery was calculated from SIM mass balance module.

Table 4.11: Common causes for low grade and recovery in the flotation circuit. They are demonstrated relative to particle size (Cropp et al., 2013).

Table 4.12: Mineral recoveries across the different streams within the flotation circuit. Mineral recovery is expressed in \%. 
Table 4.13: Acid rock drainage potential of the final tailings calculated using balanced, EMC results. Pyrite AP contribution is grouped under pyrrhotite 60

Table 4.14: Acid rock drainage potential of the final tailings calculated using unbalanced QEMSCAN data. Pyrite AP contribution is calculated separately. 60

Table 5.1: Copper concentrate maximum impurity levels and approximate penalties (Salomon-de-

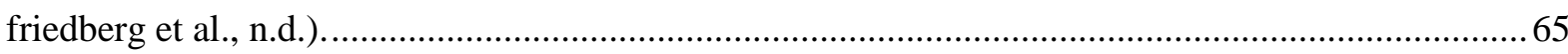

Table 5.2: Summary of the scenario analysis. .75 


\section{Acronyms and units}

ABA

AMD

AP

ARD

ARDI

EMC

EPMA

GDP

ICP-OES

LS

MPA

NAF

NNLS

$\mathrm{NP}$

PAF

PSD

QEMSCAN

RMSD

SEM

SIP

XRD

XRF

$\mathrm{t} / \mathrm{hr}$

Wt. \%
Acid base accounting

Acid mine drainage

Acid potential

Acid rock drainage

Acid rock drainage index

Element to mineral conversion

Electron probe micro-analyser

Gross domestic product

Inductively coupled plasma optical-emission spectroscopy

Least square

Maximum potential acidity maximum

Non-acid forming

Non-negative least square

Neutralising potential

Potentially acid forming

Particle size distribution

Quantitative Evaluation of Minerals by Scanning Electron Microscope

Root mean square deviation

Scanning Electron Microscope

Species identification protocol

$\mathrm{X}$-Ray diffraction

$\mathrm{X}$-ray fluorescence spectrometry

tons per hour

Weight percentage 


\section{Mineral names and formulas}

Annite

Anorthite

Barite

Biotite

Chalcopyrite

Calcite

Chamosite

Dolomite

Forsterite

Garnet

Galena

Grunerite

Magnetite

Pyrrhotite

Quartz

Sphalerite

Spessartine
$\mathrm{KFe}_{3}{ }^{2+} \mathrm{AlSi}_{3} \mathrm{O}_{10}(\mathrm{OH}, \mathrm{F})_{2}$

$\mathrm{CaAl}_{2} \mathrm{Si}_{2} \mathrm{O}_{8}$

$\mathrm{BaSO}_{4}$

$\mathrm{KFe}_{3} \mathrm{AlSi}_{3} \mathrm{O}_{10}(\mathrm{OH})_{2}$

$\mathrm{CuFeS}_{2}$

$\mathrm{CaCO}_{3}$

$\left(\mathrm{Fe}_{5} \mathrm{Al}\right)\left(\mathrm{AlSi}_{3}\right) \mathrm{O}_{10}(\mathrm{OH})_{8}$

$\mathrm{CaMg}\left(\mathrm{CO}_{3}\right)_{2}$

$\mathrm{Mg}_{2} \mathrm{SiO}_{4}$

$\mathrm{Mn}_{3} \mathrm{FeAl}_{2}(\mathrm{SiO} 4)_{3}$

$\mathrm{PbS}$

$\mathrm{Fe}_{7} \mathrm{Si}_{8} \mathrm{O}_{22}(\mathrm{OH})_{2}$

$\mathrm{Fe}_{3} \mathrm{O}_{4}$

$\mathrm{Fe}_{7} \mathrm{~S}_{8}$

$\mathrm{SiO}_{2}$

$\mathrm{Zn}_{0.9} \mathrm{Fe}_{0.1} \mathrm{~S}$

$\mathrm{Mn}_{3} \mathrm{Al}_{2} \mathrm{Si}_{3} \mathrm{O}_{12}$ 


\section{Chapter 1}

\section{Introduction}

\subsection{Background}

The mining industry is faced with numerous multifaceted challenges-within the realms of technoeconomic, environmental and social issues (Deloitte, 2014; Bradshaw, 2014; WEF, 2015). Key challenges to the mining industry within the techno-economic space consist of rising operating costs alongside volatile metal markets where the balance between supply and demand is tenuous (Deloitte, 2014; Baxter, 2016) and declining ore grades (Figure 1.1). Technical difficulties in processing low grade, heterogeneous and mineralogically complex ores often necessitate the development of innovative technology that will address any shortfalls to access low grade ores (Mudd, 2009; Prior et al., 2012; Baum, 2013; Powell, 2013). In many cases, low-grade, complex ores require significant energy inputs for size reduction to liberate very fine grained disseminated valuable minerals (Pease et al., 2006; Norgate and Haque, 2009; Mudd, 2010; Prior et al., 2012).

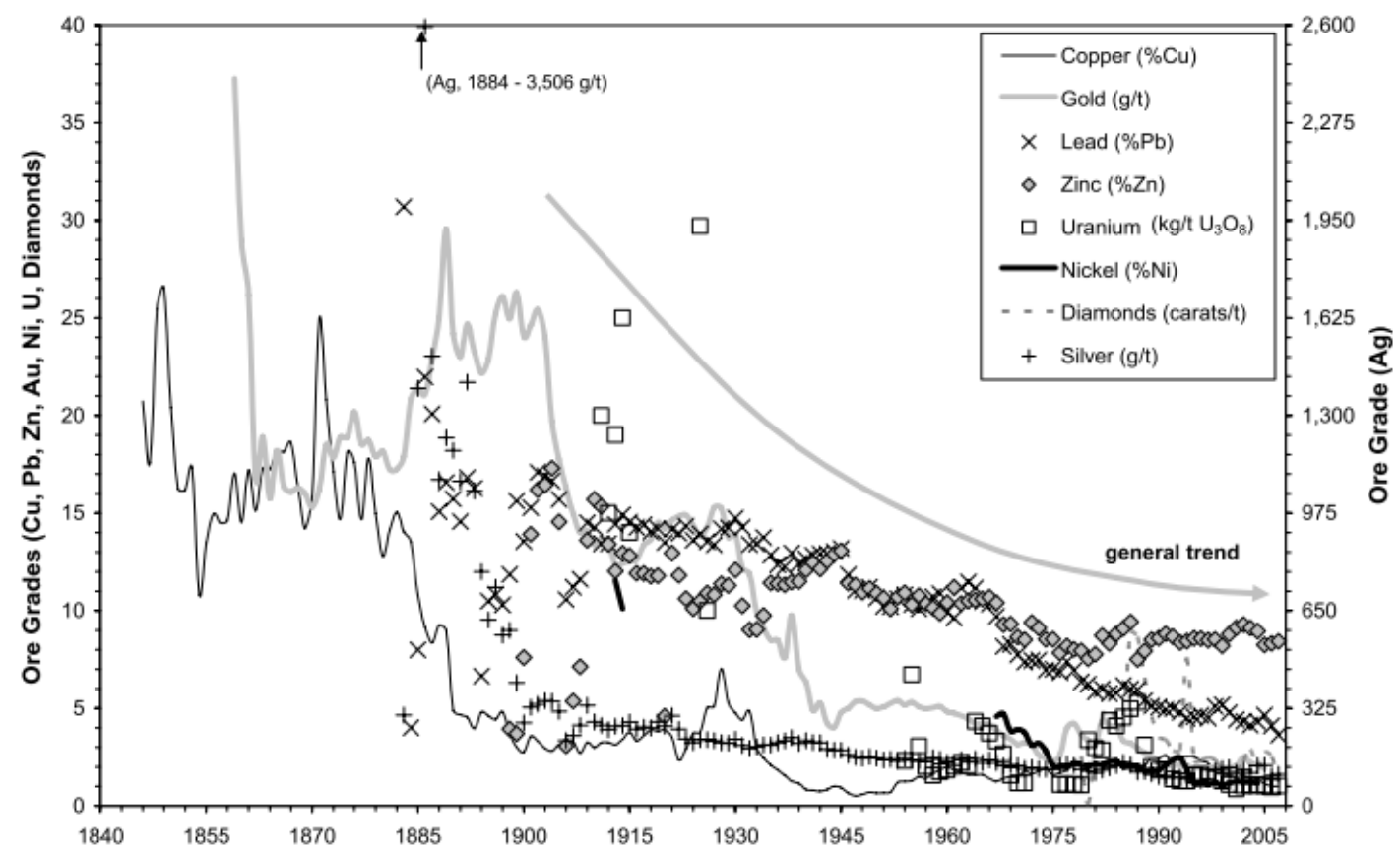

Figure 1.1: General trend of declining ore grades for base and precious metals (Mudd, 2009).

During liberation separation and recovery processes of valuable minerals, there may be unintended associated environmental consequences such as acid rock drainage (ARD). Acid rock drainage is derived from mining activities and it is currently one of the most significant environmental problems facing the mining industry (Hesketh et al., 2010; Dold, 2014; Naidoo, 2017). Acid rock drainage is 
produced when sulfur-rich rocks are oxidised to form low $\mathrm{pH}$ waters with high sulfate contents and high concentrations of dissolved often toxic elements (Parbhakar-Fox et al., 2011). This results in the direct contamination of water resources within the vicinity of the mine and has far-reaching consequences to the surrounding communities, especially those residing in remote and arid areas (Ochieng et al., 2010; IFC, 2014). Due to the lack of municipal water, communities residing in a remote area are highly dependent on the availability of potable borehole water (Durand, 2012) with water contamination being the cause of a wide range of health problems and disorders in livestock and humans. The development of technology and skills that allow for the prediction, prevention and mitigation of ARD into perpetuity are therefore pressing concerns for the industry (Akcil and Koldas, 2006; Mudd, 2010; Prior et al., 2012; Parbhakar-Fox et al., 2015).

Mining companies are pressurised by community and government to respond to these challenges in order to have a continued licence to operate (WBCSD and IIED, 2002; Azapagic, 2003; Laurence, 2011; Pimentel et al., 2015). It is important for the mining industry to address these challenges, as it contributes in growing the economy of a country. Global society is economically and socially dependant on mining as it is a source of job creation (Azapagic, 2003; Deloitte, 2014; Baxter, 2016). The production of minerals provides the raw materials used in a variety of industries and are essential in manufacturing of products used by humans (Azapagic, 2003; Worrall et al., 2009; Becker et al., 2017). In 2015 mining contributed $7.7 \%$ to gross domestic product (GDP) and 1.4 million jobs in South Africa (Baxter, 2016).

In the context of addressing these overarching multifaceted challenges, an adoption of thinking towards sustainable development is required by the mining industry. "Sustainable development meets the needs of the present without compromising the ability of future generations to meet their own needs" (Brundtland, 1987). Figure 1.2 depicts the components of sustainable development. "Bearable" meaning the bridge between social and environment attributes, the economic activities are not well defined, but the environment and society pillars have proper established platforms. "Viable" considers economic and environment, there is a strong economy and environmental performance but issues that have a negative impact on society are neglected. "Equitable" consist of social and economic spheres, however, whereas there are strong economic activities and social development programmes, the environment is at risk from being exploited. "Sustainable" integrates social, environment and economic and this is the triple bottom line - the sweet spot of sustainability. 


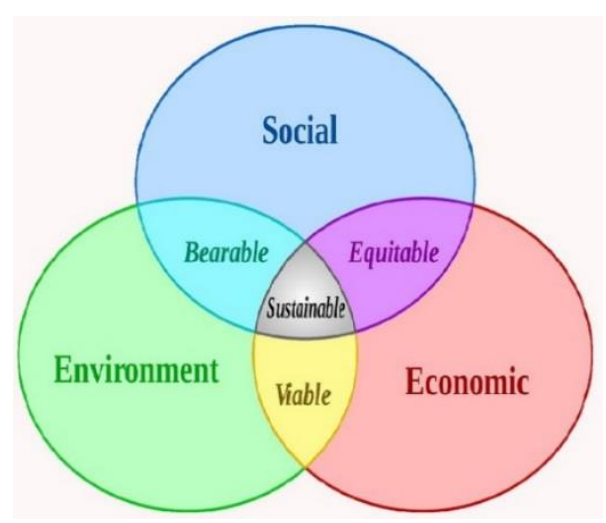

Figure 1.2: A diagram illustrating the three pillars (social, economic and environment) of sustainable development - adapted from Barbier (1987), www.wikepedia.com.

This holistic approach allows for a series of unit operations or an entire circuit to be simultaneously optimised by considering the interrelated techno-economic, environment and social factors. In the mining industry, this means that the investment should be profitable, technically appropriate, environmental and social responsible (Guerin, 2000). The review paper by Edraki et al. (2014) on 'designer mine tailings' considered some of the more integrated approaches that have been proposed using a modelling tool to predict the characteristics of tailings produced at various processing units (Figure 1.3). Other examples of integrated approaches are:

- The application of a two stage flotation process to the processing of fine coal discards allowing the recovery of a clean, saleable coal product, a small volume pyrite-rich product, and a high volume benign tailings product (Mbamba et al., 2012), or

- A computational approach in comparing the benefits of different circuit configurations in the flotation of high arsenic ores (Montenegro et al., 2013).

What these and other studies (e.g. Azapagic et al., 2006) have in common is their conceptual approach in addressing these interrelated sustainability challenges in the decision making process at both plant design stage and operation. However most of these studies place limited focus on the role of mineralogical information and its acquisition and link to downstream environmental impacts. An integrated modelling framework underpinned by mineralogy makes it possible to link back ore variability to improved recoveries or grade and/or environmental impacts. 


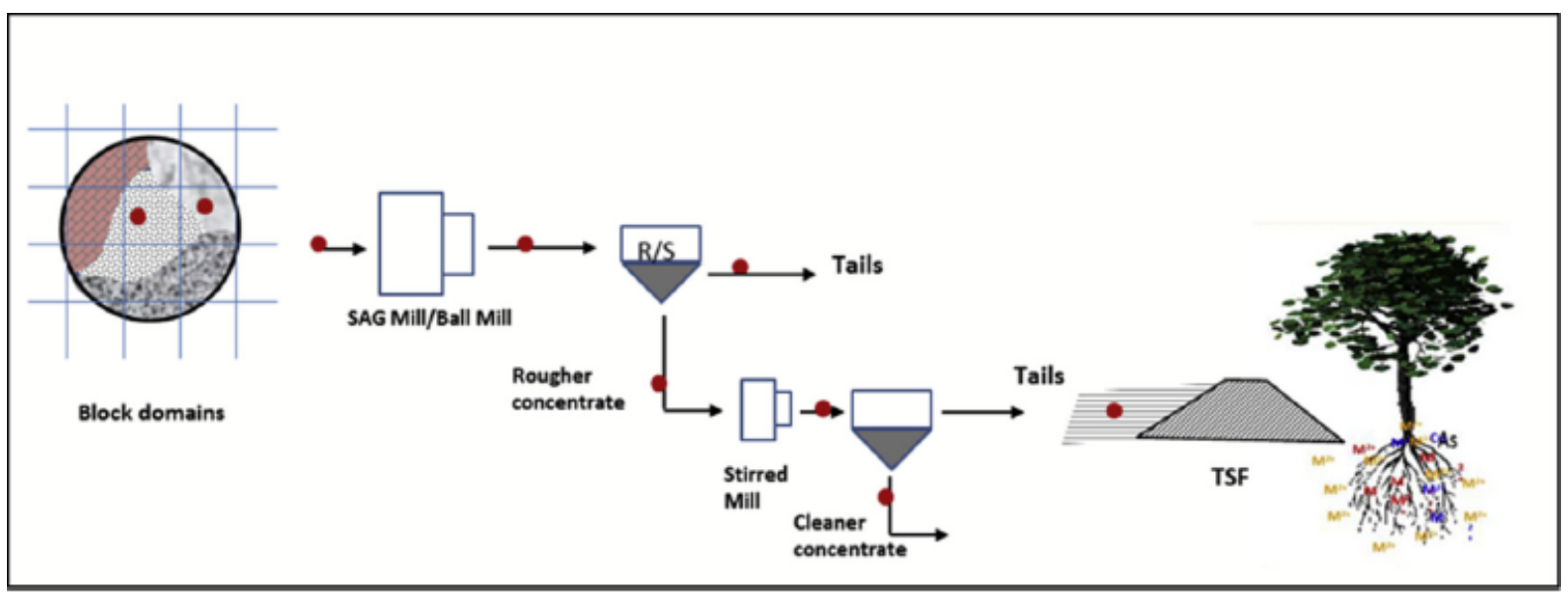

Figure 1.3: Diagram illustrating an integrated approach of tailings management by linking the geochemistry of arsenic in the waste material back to arsenic in ore mineralogy and identifying possible points of intervention where the effects of the orebody can be tested (Edraki et al., 2014).

The best route in achieving sustainability is understanding the behaviour of the ore throughout the process, because according to Hope et al. (2001) characterisation of minerals is important in the development and operation of mining and mineral processing systems. Furthermore, Becker et al. (2017) suggest that coming up with innovations and technology that considers environment and social issues during the operation of the mine, requires a better understanding of the orebody to develop such strategies.

\subsection{Problem statement}

The mining industry is faced with multifaceted challenges within techno-economic, environment and social spheres. The industry is therefore encouraged to demonstrate a forward thinking towards sustainability. This can be achieved by having a holistic approach to address all facets of sustainability at the operational level. This requires an integrated modelling framework underpinned by mineralogy, so that the varying composition of the ore on one or more of these factors can be simultaneously evaluated and optimised. The framework should incorporate sustainability principles for enhanced decision making (Charikinya et al., 2017). The existing frameworks do not address all aspects of sustainability on the operational level (Labuschagne et al., 2007).

\subsection{Research aim}

The overarching aim of this thesis is to develop the first phase of an integrated modelling framework of the entire minerals value chain using mineralogy. This first phase comprises the interface between techno-economic and environmental aspects for a single unit operation (flotation) at an operational level. The developed model should allow for a single component of ore variability on mineral 
processing performance (grade, recovery) to be assessed and to evaluate the potential for the flotation tailings to generate acid rock drainage.

\subsection{Scope of the study}

This study focuses on the initial phases of the development of an integrated framework underpinned by mineralogy to evaluate mineral processing performance (grade and recovery) and environment indicator (acid rock drainage) at an operational level. A case study of a polymetallic sulfide ore flotation circuit is used. The framework will incorporate a combination of simple empirical mineral splitter function, theoretical mineralogical predictions, and the element to mineral conversion (EMC) methodology to quantify bulk mineralogy. The scope and limitation of this study are illustrated in Figure 1.4. The intermediate and terminal streams are the only aspects considered in the flotation circuit. Other flotation parameters such as the presence of a froth phase, electrochemistry and pulp rheology, are all beyond the scope of this study. The study is also limited to quantifying bulk mineralogy calculated using the element to mineral conversion (EMC) methodology and does not consider other attributes of mineralogy such as particle size, texture and liberation. Acid rock drainage characterisation (ARD) is limited to acid base accounting whereby the ARD potential is evaluated using a theoretical calculation based on the mineralogical composition of the waste material. 


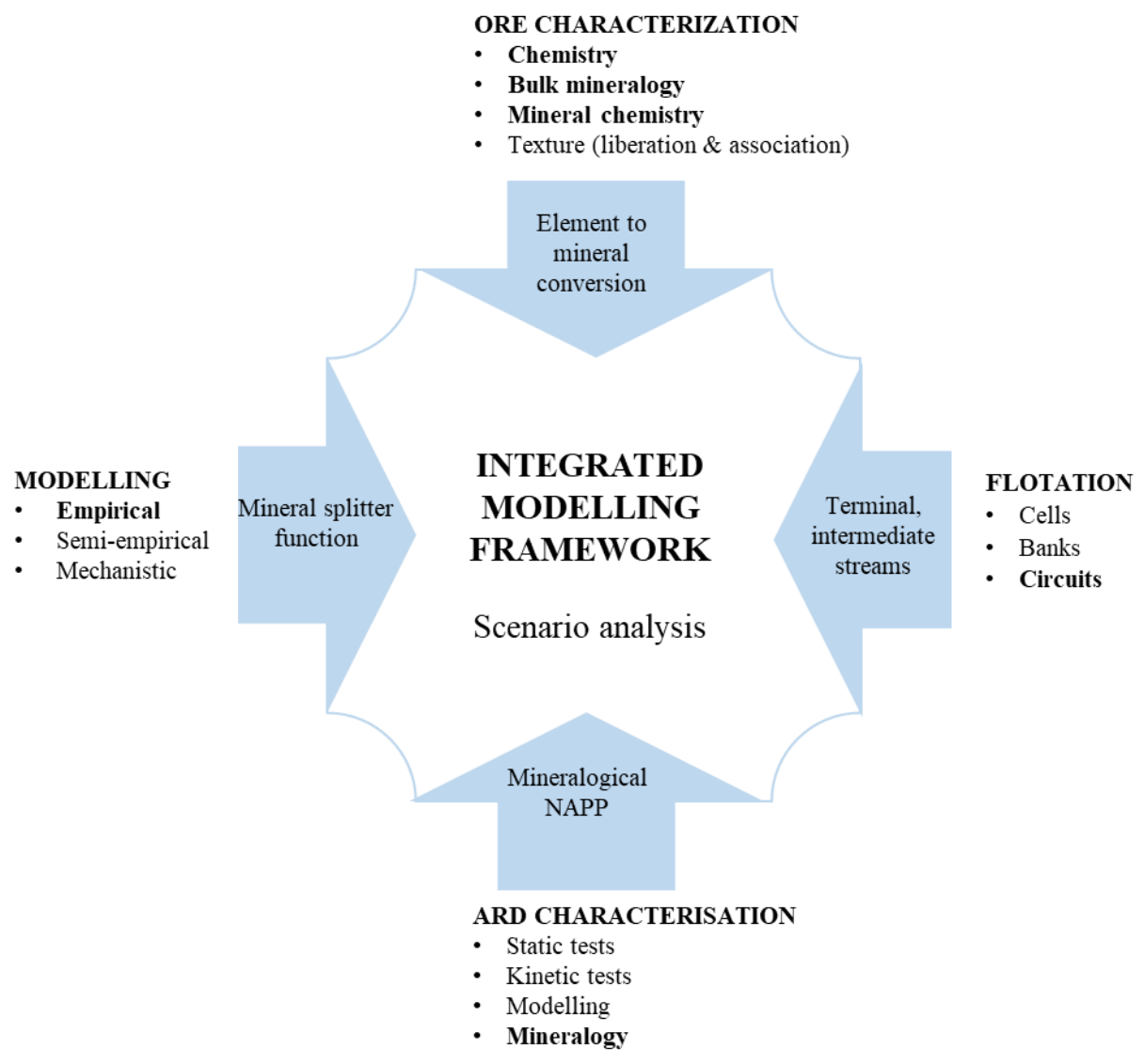

Figure 1.4: Illustration of the scope and boundaries of the study.

\subsection{Thesis structure}

The thesis consists of six chapters: Chapter 1 is an introduction which provides the background, context to the study, problem statement, research aim and the scope of this study. Chapter 2 gives an in-depth literature review on a) integrated frameworks accompanied with case studies, b) process mineralogy, c) flotation process unit d) acid rock drainage, e) modelling tools, f) scenario analysis and e) summary of the literature review. Chapter 3 outlines the case study sampling, details of analytical instrumentation for chemical and mineralogical characterisation, and mass balancing carried out in the study. Chapter 4 presents the steps undertaken to develop the framework. Chapter 5 demonstrates how the framework can be applied at the operational level using several scenarios. Chapter 6 highlights the conclusions and recommendations for further research. The outline of the thesis is demonstrated in Figure 1.5. 


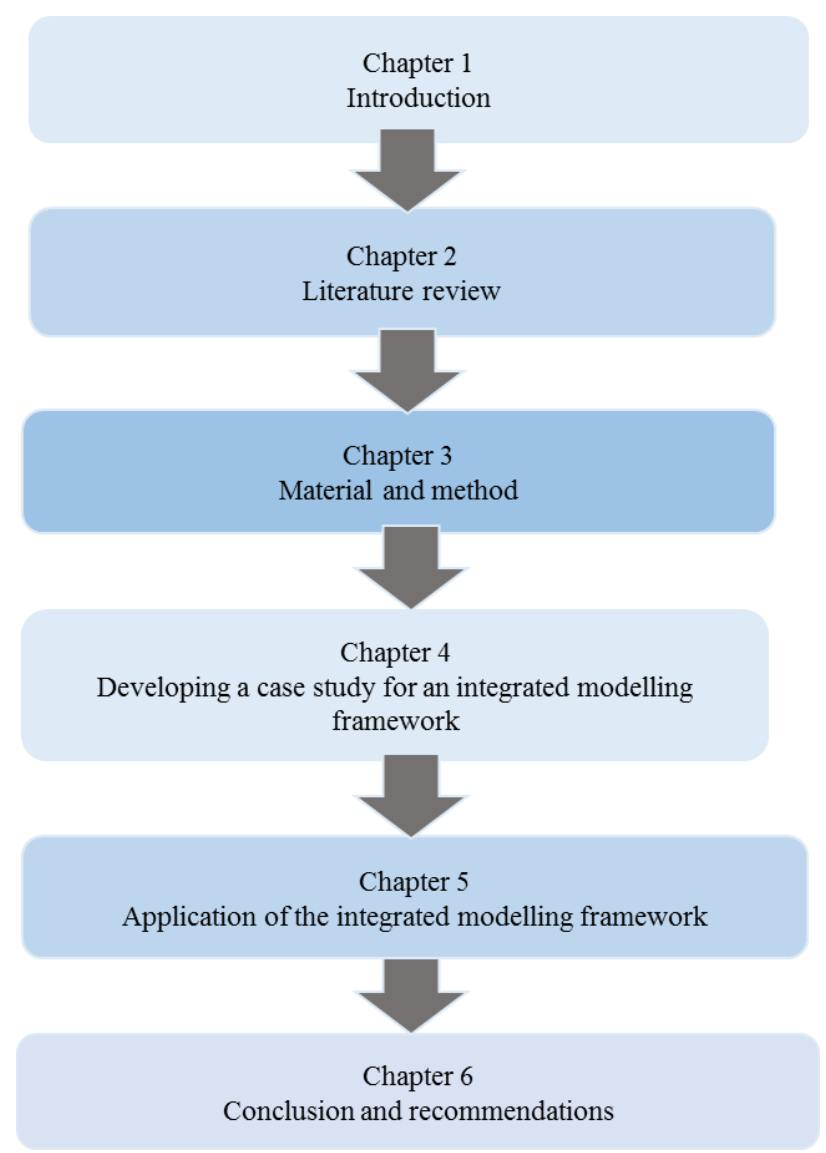

Figure 1.5: Schematic diagram of the thesis structure. 


\section{Chapter 2}

\section{Literature review}

This chapter is a critical analysis of the relevant literature within the scope of the study. It starts with a description of integrated frameworks with some accompanying case studies. This is proceeded by a critical review of the necessary inputs of the frameworks: process mineralogy, the flotation process unit and environmental indicators (acid rock drainage), as well as the application of the framework for scenario analysis. The chapter concludes with a critical summary of the literature.

\subsection{Frameworks and case studies}

\subsubsection{Overview}

Sustainable development in mineral processing can be achieved by selecting processes that produce minerals with improved technical and economic benefits, but also with reduced environmental and social impacts (Charikinya et al., 2017). Integrated modelling tools are useful platforms that can allow consideration of the triple pillars of sustainable development, in order to obtain a deeper comprehension of the complexity within sustainability (Laurence, 2011). This is a mathematical model that has indicators to assess, track uncertainties and to evaluate outcomes of a specific process and considers stakeholders interests and their interactions (Hacking and Guthrie, 2007; Welsh et al., 2013). An indicator is a variable used to develop an understanding of a complex system or an unmeasurable criterion allowing effective decision making in line with the global objectives (e.g. sustainability in the mining sector) (Mitchell, 1997). Indicators can be classified as both simple indicators, which are obtained from measurements and estimation (e.g. model) and composite indicators that are derived from the aggregation of a variety of variables or simple indicators (Girardin et al., 1999).

The majority of integrated frameworks within the minerals industry focus on finite resources such as energy and water, as well as to control waste and minimise harmful emissions (Nikolopoulou and Ierapetritou, 2012; Tuazon et al., 2012; Pimentel et al., 2015). The missing gap in most of the studies is that they do not consider the role of mineralogy (ore composition). It is critical that the role of mineralogy is considered since the mineralogical properties of the ore ultimately determine the beneficiation and upgrading process of the minerals (Ghorbani et al., 2013; Tungpalan et al., 2015) and also many of the negative environmental impacts (Parbhakar-Fox et al., 2011; Edraki et al., 2014). The use of mineralogy as an input into process unit models can result in reducing environmental and social impacts at the mining and processing sites (Norgate and Haque, 2009; Tuazon et al., 2012). Integrating 
sustainable development indicators as part of the decision making process during operation requires a methodical, detailed procedure of identification, qualification of problems and opportunities in each technical phase (Tuazon et al., 2012). The following steps should be considered when developing an integrated framework (see also Figure 2.1).

a) Definition of the operational and sustainable development goals for the operation as well as the scope of the study. Operational goals include production targets whilst sustainable goals consider evaluating measures to mitigate risk associated with the process. Scoping the project involves defining the battery limits, e.g. determine if the study will focus on the entire production process or operational units or the input or output of the process.

b) Determination of sustainable development opportunities or issues by examining defined battery limits. This exercise is governed by a series of indicators or possible 'what-if' scenarios. The identified sustainable development issues can be quantified and evaluated to determine how the issues can be prevented or be fully addressed.

c) Formulation of a business case which describes how the issues will be addressed as well as their priorities, benefits and the cost of each option. This is known as problem formation and option generation.

It is important that the proposed methodology of implementing sustainability principles should be tested at the operation with the goal to determine areas of improvements, new opportunities and initiatives with sustainability standards that fulfil operational performance (Tuazon et al., 2012). 

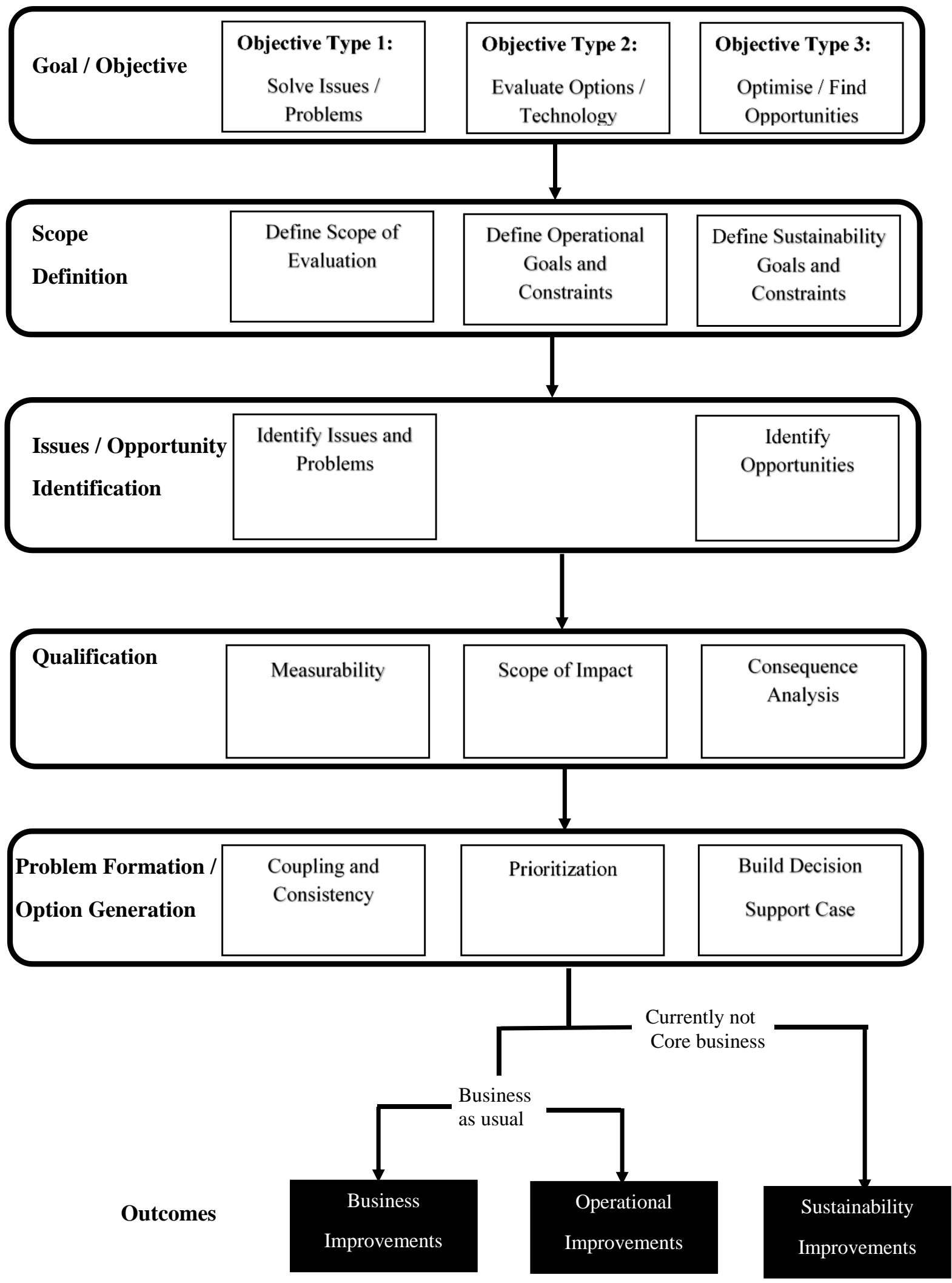

Figure 2.1: Components of the proposed sustainability integration methodology (Tuazon et al., 2012). 


\subsubsection{Case studies}

This section describes some of the exceptions of case studies in the literature that have utilised integrated frameworks at the operational level as part of the decision-making process.

The first case study focused on a mathematical model of a smelter operation (Caldentey and Mondschein, 2003). It comprised of two components: the first was a non-linear integer model that optimized smelter operations and investment decisions, and the second a network flow model that determined the economic performance of the sulfuric acid market. The first component was based on smelting capacity and controlling pollution emission. It used the price of sulfuric acid to determine optimal smelter operations and investment decisions were based on production of copper and sulfuric acid, including pollution emission from the operation and cost of treating these pollutants. The second component considered sulfuric acid produced to evaluate the price of the product and distribution of the acid relative to the demand. The components interacted with each other to produce acid in the most efficient manner, minimizing pollution and transportation cost associated with the shipment of the acid. This framework considered techno-economic and environmental aspects, as it was able to predict expected profit and was capable of minimizing pollution from the production. The downfall was the inability to evaluate if the pollution emitted had any negative impact on society (e.g. community and natural surroundings).

The second case study developed a linear programming model to minimize water requirements for a copper operation (Gunson et al., 2010). Key inputs to the framework included a mass balance, description of consumers and the main sources. From this information, the model was able to quantify sufficient water required by each consumer based on the water coming from the sources. The case study focused on the environmental aspect by minimizing water consumption but has a possibility to contribute to the social sphere by ensuring there is sufficient water for other consumers within the vicinity of the mine. In the near future, the framework will have to address the techno-economic aspect, as this determines if the mine can be financially sustainable in long run.

The third case study considered sustainable management system for a mine located in the water stricken environment (Freitas and Magrini, 2013). It used a stepwise methodology that integrated society and the environment into the decision-making process. The social aspect was an image criterion (image of the corporate) that represented the perception of individuals about the mine and it was obtained from surveys. The environmental aspects evaluated the impacts associated with water consumption, discharge and disposal. The Analytical Hierarchy Process (AHP) was utilised to determine the weights of each criterion through a pair-wise comparison of their relative importance. The best alternative identified was an installation of a pipe system to treat and reuse the water from the tailings dam. The integration of image criteria proved that the company was considerate of their surroundings and this 
can strengthen their relationship with the community. The use of surveys to measure image criteria prevents the framework from integrating the social aspects on a regular basis, as surveys require time and resources.

The fourth case study by Charikinya et al. (2017) developed an integrated modelling framework for a magnetic separator, underpinned by mineralogy to assess sustainable development indicators. Mineralogy was the main input to the model and was used to evaluate the effect of ore variability on the diverse pillars of sustainable development. The case study was based on three different iron ore types (low, medium and high grade) and eleven sustainable development indicators were proposed. Each of the indicators was accordingly weighted from 0 to 10 based on the importance of the sustainability indicator. The analytic hierarchy process (AHP) and weighted sum method (WSM) were used to assess the weighting of each indicator by assessing the overall score of processing a particular ore type. The results demonstrated that out of the eleven indicators carbon dioxide $\left(\mathrm{CO}_{2}\right)$ emissions, water use, noise and job creation ratings were the least affected by ore variability. The grade recovery deviation index (GRDI), rotational energy transfer efficiency (RETE), electricity cost, particle emissions and waste generation ratings were more dependent on the ore type. This framework was able to evaluate techno-economic, environment and social indicators and used mineralogy to assess how ore variability affects the different indicators. The use of mineralogy was something that has not been used in many case studies and it was useful in defining the behaviour of the ore. The downfall of the study was in that mineralogy was obtained using an automated SEM technique, which slows down data delivery. This prevents the framework to be used on daily basis to solve operational problems.

The abovementioned case studies provided a broad overview of how to incorporate sustainable development indicators as part of the decision-making process. The objective of incorporating sustainable development indicators at the operational level, was to provide information to mining companies on how they are or are not contributing towards sustainable development (Azapagic and Perdan, 2000). Majority of the abovementioned studies did not focus on all aspects of sustainability with Charikinya et al. (2017) being the only exception. They, therefore, failed to meet the full criteria of sustainable development, as it is a combination of techno-economic growth, enhanced socioeconomic development and minimising environmental impacts. The case studies focused on environmental and social impacts while Caldentey and Mondschein (2003), included techno-economic aspect. Social and environmental attributes play a critical role in today's mining industry, as failure to address these issues can lead to the mine losing their social license to operate. This could result through conflict with the surrounding community and incurring penalty cost for failing to comply with regulation governing emission of unwanted substances (pollution). The techno-economic aspect is important to consider as it derives the profitable sustainability of the mine, as it brings economic benefit such as job creation and generation of wealth (Azapagic, 2003). Table 2.1 summarises the case studies that have been discussed in this section. 
Table 2.1:Summary of the case studies discussed in this section.

\begin{tabular}{|c|c|c|c|}
\hline Case study & $\begin{array}{l}\text { Sustainability } \\
\text { indicators }\end{array}$ & Advantage & Disadvantage \\
\hline $\begin{array}{l}\text { Caldentey } \\
\text { and } \\
\text { Mondschein } \\
(2003)\end{array}$ & $\begin{array}{l}\text { Techno- } \\
\text { economic and } \\
\text { environmental }\end{array}$ & $\begin{array}{l}\text { The framework was able to } \\
\text { predict expected profit and } \\
\text { minimize pollution. }\end{array}$ & $\begin{array}{l}\text { The inability to evaluate if the } \\
\text { environment was affected by } \\
\text { the pollution. }\end{array}$ \\
\hline $\begin{array}{l}\text { Gunson } \\
\text { et al. (2010) }\end{array}$ & Environment & $\begin{array}{l}\text { The contribution to the social } \\
\text { sphere by finding measures to } \\
\text { minimise water consumption, } \\
\text { although the indicator was } \\
\text { categorised under the } \\
\text { environmental aspect. }\end{array}$ & $\begin{array}{l}\text { The lack of techno-economic } \\
\text { assessment, so the operation } \\
\text { will be unable to measure their } \\
\text { financial sustainability in a long } \\
\text { run. }\end{array}$ \\
\hline $\begin{array}{l}\text { Freitas and } \\
\text { Magrini } \\
\text { (2013) }\end{array}$ & $\begin{array}{l}\text { Social and } \\
\text { environment }\end{array}$ & $\begin{array}{l}\text { The advantage was being } \\
\text { considerate to the surrounding } \\
\text { community. }\end{array}$ & $\begin{array}{l}\text { Social attribute was assessed } \\
\text { from collecting data thorough } \\
\text { surveys and this can be time- } \\
\text { consuming and can require } \\
\text { resources. }\end{array}$ \\
\hline $\begin{array}{l}\text { Charikinya } \\
\text { et al. (2017) }\end{array}$ & $\begin{array}{l}\text { Techno- } \\
\text { economic, } \\
\text { social and } \\
\text { environment }\end{array}$ & $\begin{array}{l}\text { Utilised mineralogy to } \\
\text { understand the deportment of } \\
\text { the ore throughout the process. }\end{array}$ & $\begin{array}{l}\text { The ore variability was } \\
\text { analysed using an expensive } \\
\text { and time-consuming technique. }\end{array}$ \\
\hline
\end{tabular}

\subsection{Process mineralogy}

Process mineralogy plays an important role in mineral processing, as it is used to identify, predict, diagnose and optimise how an ore deposit can be processed (Lotter, 2011). It is a practical study that focuses on problems associated with processing an ore deposit, as well as developing, optimising of process flowsheets, including consideration of management strategies for waste and the environment (Henley, 1983; Jones, 1987; Petruk, 2000). Process mineralogy is therefore useful in addressing issues such as processing low-grade complex ores and ensuring valuable minerals are produced in a sustainable manner (West, 2011; Evans et al., 2011; Becker, 2018). Key mineralogical components of interest to measure and quantify in process mineralogy are the element deportment (valuable and deleterious), mineral grades, grain size distribution, texture, association and liberation. However, the successful application of the discipline extends past simple measurement, into the appropriate interpretation of the results, the understanding of the implications of the measurements and the ability to implementing the desired changes to metallurgical flowsheets (Bradshaw, 2014; Lotter et al., 2017). This section reviews several different applications of process mineralogy, and then considers some of the key methods used to characterise and quantify mineralogy. 


\subsubsection{Application of process mineralogy}

\section{Circuit design and optimisation}

The case study by Cullinan et al. (1999) showed how mineralogy can be used for flowsheet design and optimisation at the Mount Isa lead-zinc concentrator in Australia. At the time of the study, the operation was achieving low recoveries of zinc (sphalerite) and lead (galena). A size by size mineralogical study was conducted, to identify the limiting factor to overall recovery. The data demonstrated that both sphalerite and galena were less than $10 \mu \mathrm{m}$ (fine-grained) and lost due to poor liberation. This ultimately motivated for the development of new innovative stirred milling technology (Pease et al., 2006), and subsequent installation of this fine grinding technology to the flotation circuit leading to the long term improvement of zinc recovery. Figure 2.2 shows a strong association between sphalerite liberation and zinc recovery at Mt Isa over a 15-year period, before and after the installation of fine grinding technology.

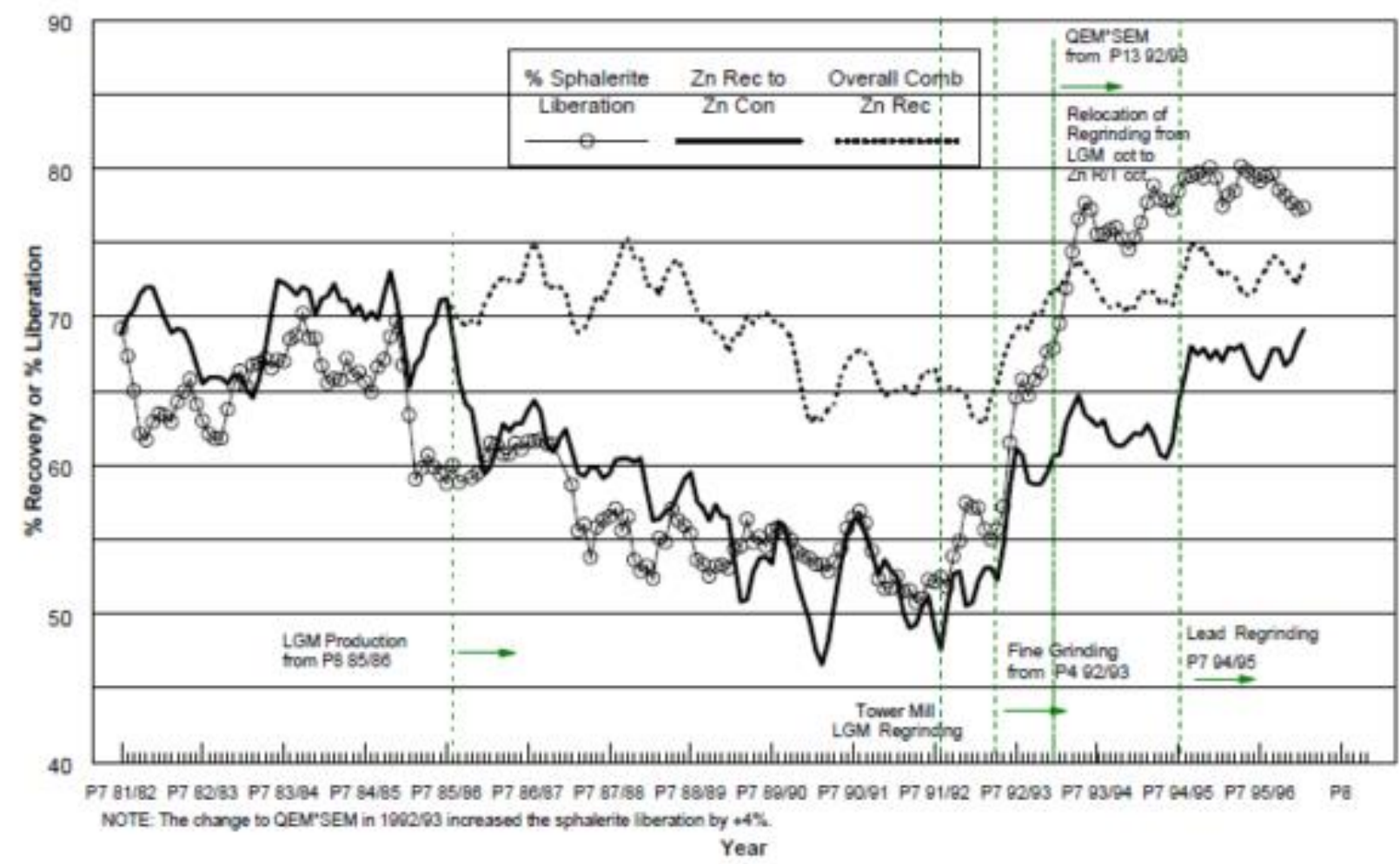

Figure 2.2: A comparison of zinc recovery and liberation before and after installing IsaMill technology at the Mt Isa Mines from 1981 to 1996 (Young et al., 1997).

\section{Benchmarking and optimisation}

The case study by Evans et al. (2011) considered a Cu-Ni sulfide ore concentrator in Canada to evaluate elemental deportment in the concentrate. The presence of $\mathrm{MgO}$-bearing minerals in the final flotation concentrate / smelter feedstock was identified as a problem to the downstream smelter energy efficiency. The study aimed to determine whether the concentrate should be further upgraded to reject 
the unwanted $\mathrm{MgO}$ bearing minerals and the implications thereof. Quantitative mineralogy results showed that the unwanted magnesium silicates needed additional liberation to further upgrade the concentrate. Subsequent modelling considered the balance between the energy costs for the additional grinding capacity versus the energy requirements of the smelter operation according to $\mathrm{MgO}$ grade. This case study successfully showed the key importance of mineralogy across several unit operations when considering sustainability. Figure 2.3 shows bulk mineralogy of the Ni-Cu concentrate before and after upgrading the concentrate.

\section{Copper $(\mathrm{Cu})$ concentrate}
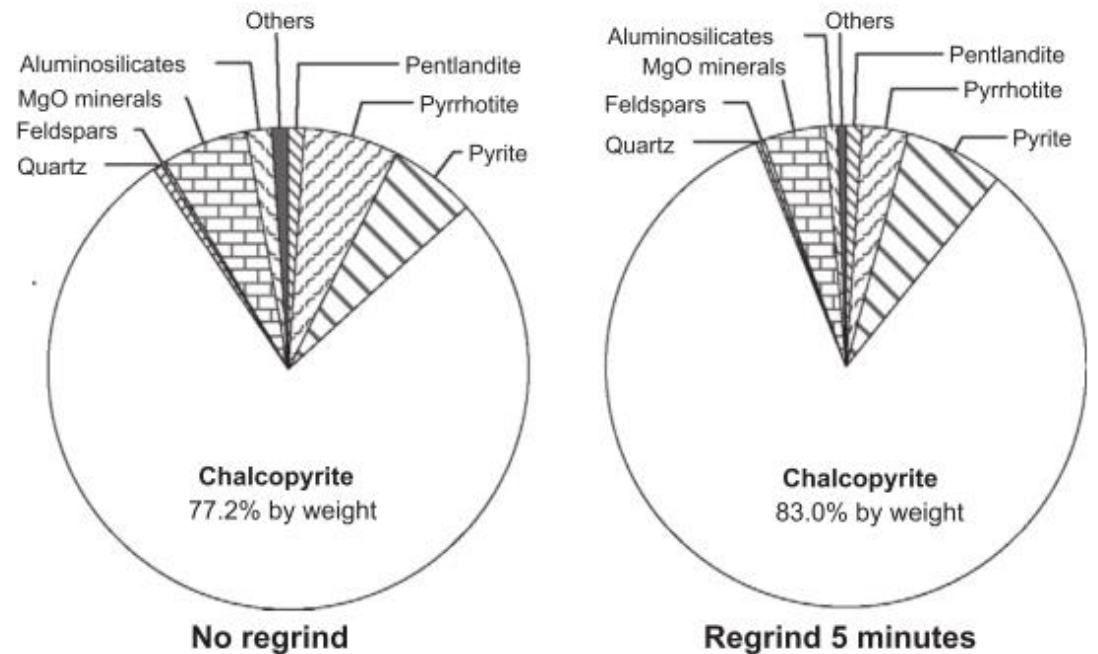

Regrind 5 minutes

Nickel ( $\mathrm{Ni}$ ) concentrate

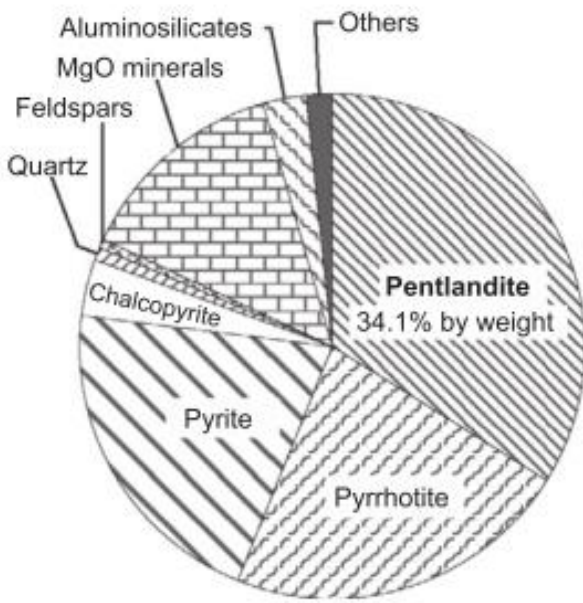

No regrind

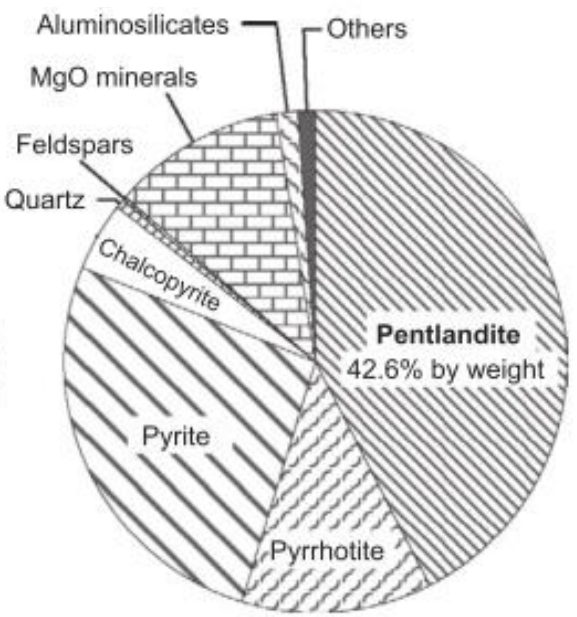

Regrind 5 minutes

Figure 2.3: Comparison of bulk mineralogy of copper $(\mathrm{Cu})$ concentrate before and after upgrading of (top) and that of Nickel (Ni) concentrate before and after upgrading (bottom) (Evans et al., 2011). 


\section{Integrated design approach}

A further application of mineralogy in design is the case study by Hesketh et al. (2010) that developed an integrated approach to mitigate acid rock drainage from waste material. The approach considered the potential to separate sulfide-rich gangue minerals (pyrite) from the tailings stream of a copper concentrator in the USA. Chemical assays, mineralogy, batch flotation tests and laboratory acid rock drainage characterisation tests were all used in the development of the concept. The study showed the technical potential to separate the tailings stream into a large volume non-acid forming waste stream, and a small volume acid forming waste stream that can be disposed of accordingly. This approach provides an opportunity to incorporate acid rock drainage mitigating systems in process design that is compatible with the principles of sustainable development. Figure 2.4 illustrate the conceptual approach of the case study.

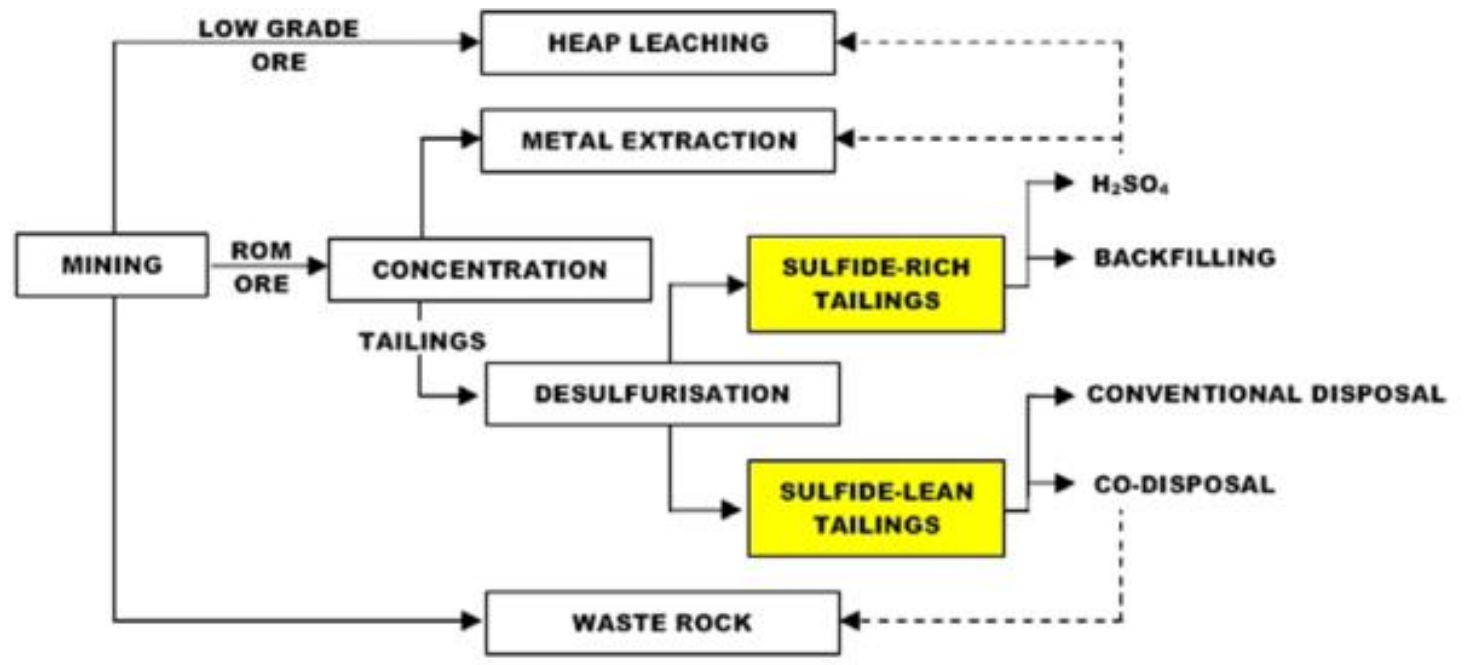

Figure 2.4: Conceptual approach to mitigate acid rock drainage in the waste material (Hesketh et al., 2010).

\subsubsection{Techniques used for mineral characterisation}

Mineralogical composition can be analysed using qualitative and quantitative analytical techniques which have advantages and disadvantages and they are presented in Table 2.2.

\section{Bulk chemical or elemental assays}

$\mathrm{X}$-ray fluorescence $(\mathrm{XRF})$ spectrometry method is applicable for analysing a wide spectrum of the element from sub-ppm to $100 \%$. Samples can be analysed as either loose powders or fused glass discs. Elemental composition is measured by secondary X-rays released from the sample whilst interacting with the primary X-ray beam. These resultant X-rays, emitted through this interaction, can be quantified according to the characteristic energy or wavelength, through energy-dispersive (EDXRF) or wavelength-dispersive (WDXRF) detectors (Enzweiler and Webb, 1999; Engelbrecht, 2011; Kable and 
Becker, 2016). The required concentration and precision define the time required to measure the sample (Kable and Becker, 2016). Major elements are typically reported as oxides.

The inductively coupled plasma optical emission spectrometry (ICP-OES) assesses the optical emissions from a stimulated sample to identify the presence of a particular element (Huggins, 2002). The sample becomes excited when it receives plasma energy which is generated when argon gas ionises due to electromagnetic field produced in the torch tube by the high frequency current. The accuracy of the technique is approximately $\pm 30 \%$ due to the obstruction of some elements with the detection of others (Swaine, 1990; Huggins, 2002). Sample preparation is more tedious than XRF as it involves sample digestion.

Atomic absorption spectrometry (AAS) quantifies elemental composition by measuring absorbed radiation from the chemical element. The atoms of a variety of elements absorb the wavelength of light. The technique quantifies energy in the form of light from the specific element and matches them to the wavelengths which originally passed through the sample (García and Báez, 2012). Sample preparation involves digesting the sample with a strong acid, peroxide fusion and it is not suitable for refractory elements (Kable and Becker, 2016).

\section{Mineral chemistry (EPMA)}

The electron probe micro analyser (EPMA) is used to determine spatially constrained mineral chemistry information. The method is similar to a scanning electron microscope whereby the sample is charged with an electron beam, producing characteristic X-rays that can be quantified accordingly to their wavelength or energy relative to a set of calibrated standards (Jansen and Slaughter, 1982; Pownceby et al., 2006). Samples are typically presented to the instrument as polished sections.

\section{Automated mineralogy with SEM-EDS}

A variety of customised platforms exist that combine scanning electron microscopy (SEM) with energy dispersive spectrometry (EDS) for the automated characterisation of minerals, for example Quantitative Evaluation of Minerals by Scanning Electron Microscopy (QEMSCAN), Mineral Liberation Analyser (MLA), Mineralogic or Tescan Integrated Mineral Analyser (TIMA). The technology is used to quantify bulk mineralogy, element deportment, grain size distribution, mineral association and liberation (FEI, 2014). Typically sized, polished sections are presented to the instrument for analysis. Mineral identification QEMSCAN is based on a combination of the characteristic of back scattered electrons (dependent on the particle density) and X-ray energies (quantified using EDS), as well as the user-defined mineral database, otherwise known as the species identification protocol (SIP). The data can then be sorted and quantified by mineral grade, size, shape, mineral associations or liberation degree 
(FEI, 2014). SEM-based automated mineralogy is often considered as the most dependable way of determining mineral grades but the method demands careful and tedious sample preparation and the method itself is expensive and time-consuming (Sutherland and Gottlieb, 1991; Petruk, 2000; Gu, 2003; Lamberg et al., 2013).

\section{Quantitative X-ray diffraction}

Quantitative X-ray diffraction (QXRD) is an inexpensive technique used for quantifying crystalline phases and amorphous content (Mandile and Hutton, 1995). It has minimal sample preparation, and has a detection limits of 1 wt.\% (Petruk, 2000; Lamberg et al., 2013; Parian, 2015). The technique relies on the crystal information for the minerals. The phases are acquired by using a refinement method that uses least square fitting method to obtain the best profile match for the mineral, more commonly known as Rietveld refinement (Hestnes and Sørensen, 2012).

\section{Element to mineral conversion (EMC)}

Mineral analytical techniques such as auto-SEM-EDS instruments (e.g. QEMSCAN, etc) tend to be the 'work horses' for providing quantitative mineralogical information on mineral grades, mineral grain size distribution, valuable mineral liberation and association characteristics (Wightman et al., 2016). Although the value of the information provided by these techniques is immense (Gu et al., 2014; Lotter et al., 2017), there are various practicalities associated with obtaining this information related to its high cost per sample. An alternate means of determining mineral grades is through the element to mineral conversion (EMC) methodology.

Element to mineral conversion (EMC) converts bulk elemental composition into mineral grades by simultaneously solving a set of linear square equations (Lamberg et al., 1997; Paktunc, 1998; Whiten, 2007). Least square, non-negative least square, weighted least square and weighted non-negative least square are mathematical methods normally considered in the calculations. The method can be mathematically written as follows:

$$
A \times x=b ;\left[\begin{array}{ccc}
a_{11} & \cdots & a_{1 n} \\
\vdots & \ddots & \vdots \\
a_{n 1} & \cdots & a_{n n}
\end{array}\right] \times\left[\begin{array}{c}
x_{1} \\
\vdots \\
x_{n}
\end{array}\right]=\left[\begin{array}{c}
b_{1} \\
\vdots \\
b_{n}
\end{array}\right]
$$

where $A$ is the matrix representing the weight of each element in the mineral (mineral chemistry), $x$ is the vector of the unknown weight fractions of the minerals (mineral grade) and $b$ is the vector of the analysed chemical composition of the elements in the sample (elemental grade). Mineral compositions are rarely stoichiometric and should ideally be determined for each ore (e.g. using EPMA). Matrix $A$ is a square matrix and $x$ can be calculated by multiplication on each side with the matrix inverse, $A^{-1}$ and be expressed as demonstrated on Equation 2.2 whilst $x$ is expressed as Equation 2.3 (Lamberg et al., 1997; Whiten, 2007). 
$A \times A^{-1}=1$

$x=A^{-1} \times b$

The solution for the mineral grade $(x)$ can be found with a mathematical technique that minimizes the residual vector, $R$ as demonstrated on Equation 2.4. This will give the best possible solution for the equation system.

$R=[b-A \cdot x]$

The best solution for $x$ can also be solved by using Gaussian Elimination, LU Decomposition and multiple regression techniques to minimise the sum of the square of the deviations (Lamberg et al.,1997; Lund et al., 2013). Such calculations are rarely done by hand and require a mathematical software. The least square, non-negative least square, weighted least square and weighted non-negative least square are also used to minimize the sum of squares of residuals in the element-to-mineral conversion calculations.

Lund et al. (2013) developed an EMC recipe for the Malmberget magnetite apatite iron ore in Sweden. The mineralogical data was simplified by restricting the number of minerals to eleven. The best solution was determined by dividing the calculations into three rounds to avoid negative solutions. The least square (LS) was used on the first round and non-negative least square (NNLS) on the last two rounds. The first round calculated minerals that contain one element, the silicates were estimated on the second round and the minerals that contain iron $(\mathrm{Fe})$ and titanium $(\mathrm{Ti})$ were determined on the third round using the residual of the elements. SATMAGAN was used to analyse hematite and magnetite as both are Feminerals. Minz (2016) also developed an EMC recipe for a polymetallic $\mathrm{Zn}-\mathrm{Cu}$ volcanic-hosted massive sulfide ore in Sweden. The recipe was divided into three rounds, the first two rounds were calculated using a non-negative least square method and the last round was determined using the least square method. In a further iteration of the EMC method, Parian (2015) developed a combined X-ray powder diffraction and element-to-mineral conversion (combined EMC-XRD) in order to prevail some of the limitations that the methods have when used individually. Such an approach ultimately increases the applicability of the method.

Once set up, element to mineral conversion is inexpensive, timeous and can be used routinely. The downfall of the technique is developing the recipe is time-consuming and expensive. This is because sophisticated techniques (e.g. QEMSCAN) have to be utilised to understand ore variability and different 
trials have to performed to come up with the ideal recipe for the specific ore (Lund et al., 2013; Parian, 2015).

Table 2.2: Methods for mineralogical characterisation (Adapted from Lamberg et al., 2013).

\begin{tabular}{|c|c|c|c|}
\hline Technique & Advantage & Disadvantage & Reference \\
\hline $\begin{array}{l}\text { Bulk chemistry } \\
\text { (XRF, AA, ICP- } \\
\text { OES) }\end{array}$ & $\begin{array}{l}\text { Quantitative data for total } \\
\text { metals and metalloids. }\end{array}$ & $\begin{array}{l}\text { Analyses are cost - effective } \\
\text { and can have short } \\
\text { turnaround times. }\end{array}$ & $\begin{array}{c}\text { Price, } 2009 \\
\text { Kable and Becker, } \\
2016\end{array}$ \\
\hline $\begin{array}{l}\text { Mineral chemistry } \\
\text { (EPMA) }\end{array}$ & $\begin{array}{l}\text { Non-destructive analytical } \\
\text { technique concentration } \\
\text { of almost any element in } \\
\text { almost any solid material. }\end{array}$ & $\begin{array}{l}\text { It is not optimal for } \\
\text { analysing hydrous minerals. }\end{array}$ & $\begin{array}{c}\text { Potts, } 2015 \\
\text { Pownceby et al., } \\
\text { 2006) }\end{array}$ \\
\hline $\begin{array}{l}\text { Automated } \\
\text { mineralogy SEM- } \\
\text { EDS (QEMSCAN, } \\
\text { MLA, TIMA, } \\
\text { Mineralogic) }\end{array}$ & $\begin{array}{l}\text { Reliable, all types of ore, } \\
\text { complete mineralogical } \\
\text { information. }\end{array}$ & $\begin{array}{c}\text { Time-consuming, sized } \\
\text { samples needed, expensive. }\end{array}$ & $\begin{array}{l}\text { Sutherland and } \\
\text { Gottlieb, 1991; } \\
\text { Moen, } \\
\text { 2006; Liipo et al., } \\
\text { 2012; Gu et al., } \\
2014\end{array}$ \\
\hline $\begin{array}{l}\text { Quantitative X-ray } \\
\text { diffraction }\end{array}$ & Fast, inexpensive. & $\begin{array}{l}\text { High detection limits, not } \\
\text { for non-crystalline phases. }\end{array}$ & $\begin{array}{c}\text { Rietveld, 1969, } \\
\text { Paine } \\
\text { et al. 2011, Hestnes } \\
\text { and } \\
\text { Sorensen, } 2012\end{array}$ \\
\hline $\begin{array}{l}\text { Element to mineral } \\
\text { conversion (EMC) }\end{array}$ & $\begin{array}{l}\text { Fast, inexpensive, large } \\
\text { amount of sample, low } \\
\text { detection limit. }\end{array}$ & $\begin{array}{l}\text { Requires extra analyses for } \\
\text { complex ores. }\end{array}$ & $\begin{array}{l}\text { Paktunc, 1998; } \\
\text { Whiten, 2007; } \\
\text { Lamberg et al., } \\
1997\end{array}$ \\
\hline
\end{tabular}

\subsection{Flotation and process units}

The focus area of this study is on the flotation circuit, therefore this will be the battery limit for discussion in this section. Similarly, the discussion focuses on flotation as relevant to the process of complex and polymetallic sulfide ores. Flotation is extensively used in the mining industry for separating valuable from gangue minerals by utilizing the difference in surface properties of the minerals (Wills and Napier-Munn, 2006). It is currently the only process that beneficiates complex sulfide ores and approximately 400 million tons are treated annually worldwide (Kohad, 1998; Fuerstenau, 2005). The ore is initially milled to a fine powder to physically liberate the valuable minerals from the gangue and to also obtain optimum particle size range for flotation. The ore is then fed into the flotation circuit to achieve maximum recovery. 
Flotation process takes place in a rectangular or cylindrical shaped tank as illustrated in Figure 2.5. The feed stream (the mixture of water, valuable and gangue minerals) is the feed to the flotation cell, whilst there are two outputs referred as a concentrate (valuable) and tailings (gangue) streams. Chemicals (collector, frother and auxiliary reagents) are added to make the valuable minerals hydrophobic (water repellent) and gangue minerals hydrophilic (easily wettable by water) to enable separation. Air is fed into a well-mixed slurry so hydrophobic particles can attach to the bubbles where they rise to the froth and are collected as a concentrate in direct flotation system. The non-valuable minerals are rendered as hydrophilic and exit the flotation cell as tailings. There are a variety of mechanisms by which particles can enter the concentrate: true flotation, entrainment and then entrapment (composite particles) (Wills and Napier-Munn, 2006; Lotter et al., 2008). True flotation is the mechanism where the mineral of interest is exploited by the reagent (collector) to adhere to the air bubble and report to the froth to be recovered in the concentrate. The separation efficiency is dependent on entrainment and entrapment as both of these mechanisms can recover both valuable and gangue minerals. Entrainment is when particles are suspended in the water between bubbles enter the froth phase and are transferred to the concentrate (Runge et al., 2015; Wang et al., 2015). Entrainment is effective in fine particles especially below 38 $\mu \mathrm{m}$ and it is correlative to the recovery of water to the concentrate (Johnson, 1972; Smith and Warren, 1989). Entrapment is due to composite particles found in the concentrate and the size range varies (Lotter et al., 2008).

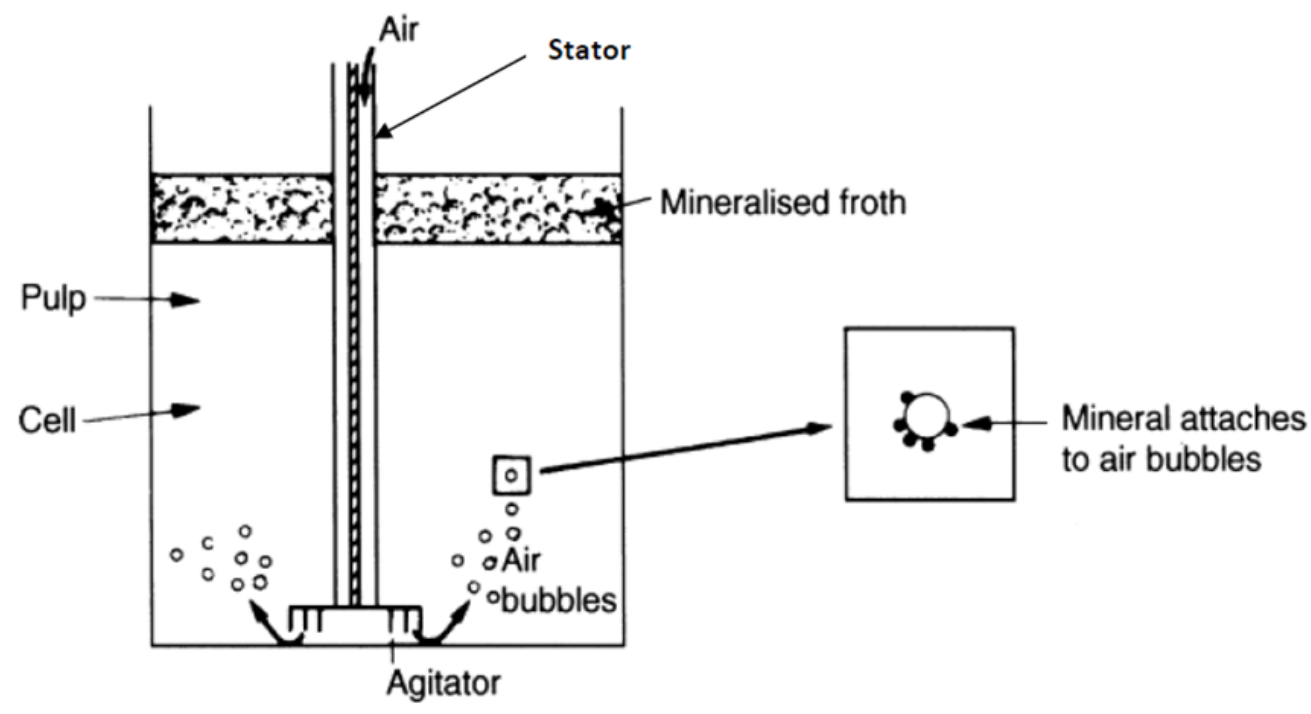

Figure 2.5: A diagram of the process of froth flotation (Wills and Napier-Munn, 2006).

\subsubsection{Factors affecting flotation}

Flotation is a very intricate process and the accomplishment of the performance depends on the number of variables (Rahman et al., 2012). It is conceded that many factors have an impact on the flotation process. Chemical condition and mineralogy will be discussed in this session. 


\section{Effects of chemical conditions on recovery}

Reagents are utilised to enhance the separation process by altering the surface properties. There are a variety of reagents used for specific purposes and they are summarised in Table 2.3. Sulfide minerals are naturally floating, therefore, it is important to prevent the recovery of the undesired concentrates and this is achieved by utilising the different reagents. Sodium ethyl xanthate (SEX) is used as a collector to recover valuable mineral(s) and a frother is used to stabilise the bubble. In the copper circuit sulfurous acid is added to depress lead and zinc. Sodium cyanide $(\mathrm{NaCN})$ and zinc sulfate $\left(\mathrm{ZnSO}_{4}\right)$ are used to depress zinc in the lead circuit and copper sulfate $\left(\mathrm{CuSO}_{4}\right)$ is added to activate zinc in the lead tails. Pulp pH also plays a significant role as it affects reagent stability, activity and the nature of the mineral and lime is usually added as the alkali pH regulator (Wills and Napier-Munn, 2006). The efficiency of the alkali depends on the balance between reagent concentration and $\mathrm{pH}$ value required to depress the sulfide mineral and this is known as critical $\mathrm{pH}$. In polymetallic sulfide ores, lime is added to depress pyrite.

Table 2.3: Summary of reagents and their purpose (Wills and Napier Munn, 2006).

\begin{tabular}{|l|l|}
\hline Reagent & Purpose \\
\hline Collector & $\begin{array}{l}\text { Collectors are utilised used to make the surface of minerals to be hydrophobic in } \\
\text { order to make the mineral floatable and attach to the bubble. Collector renders } \\
\text { the surface of the valuable to be non-polar, increasing the floatability by easing } \\
\text { the attachment of minerals to bubbles surface. }\end{array}$ \\
\hline Frother & $\begin{array}{l}\text { Frother is a surface-active reagents that enhances the stability of the air bubble } \\
\text { containing valuable mineral. The stability is achieved when the reagent interacts } \\
\text { with the quantity of water of the slurry, decreasing its surface tension. }\end{array}$ \\
\hline Depressant & $\begin{array}{l}\text { Depressants render particular minerals hydrophilic when adsorbed onto the } \\
\text { mineral surface. }\end{array}$ \\
\hline pH regulators & $\begin{array}{l}\text { pH regulators are added to alter the surface of minerals so that it becomes } \\
\text { hydrophobic by the action of collectors. It regulates the purpose of collectors } \\
\text { which adsorb on to the surfaces of minerals at particular pH values. Chemicals } \\
\text { are employed to control alkalinity are known as pH modifiers. }\end{array}$ \\
\hline
\end{tabular}

\section{Effects of mineralogy and particle size on recovery}

There are several different mechanisms that affect flotation recovery and grade. The theoretical graderecovery curve (or mineral potential curve) is a useful means of establishing the potential grade and recovery of a stream based on the mineralogical characteristics of the feed (Cropp et al. 2013; Evans \& Morrison, 2016). The construction of this curve is based on mineral liberation data for the mineral(s) of interest and defines the extent to which the grade or recovery (or both) can be improved (see Figure 2.6). Once this is known, the causes for losses and dilution can be evaluated. If the calculated grade and recovery are less than the theoretical curve, this could be a result of mineralogy or operational condition 
of the flotation circuit (e.g. reagent and $\mathrm{pH}$ dosage, etc.) (see (1) in Figure 2.6). If the desired grade and recovery are above theoretical potential (see (2) in Figure 2.6), then the feed characteristics need to be changed, for example improving the liberation by finer grinding. Prior to identifying opportunities for improvement, the mineralogical potential of the ore should be established.
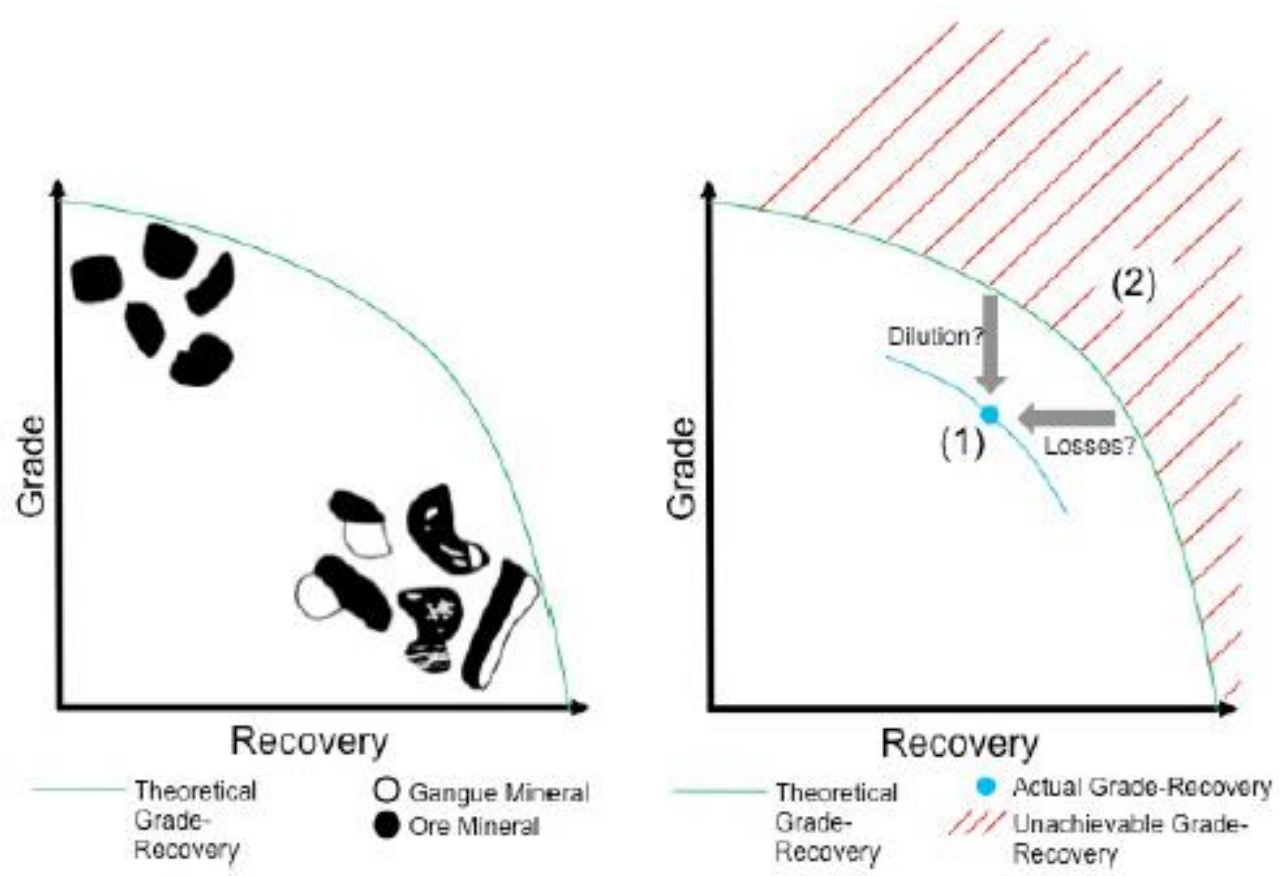

Figure 2.6: Theoretical grade-recovery curve. The picture on the left demonstrates that high recovery can be a combination of valuable and gangue minerals which that reduces the grade of the concentrate. The picture on the right shows that if the actual grade and recovery is lower than the theoretical, then it might be required to change operational conditions to improve this (1). If grade or recovery are above the theoretical curve, then the texture of the feed will be required to change (2) (Cropp et al., 2013).

Particle size is one of the mineralogical components that has a huge impact on flotation recovery (Feng and Aldrich, 1999; Pease, 2004; Runge et al., 2013; Cropp et al., 2013). A considerable investigation has been carried out on the subject (Gaudin et al., 1931; Collins and Jameson, 1976; Trahar, 1981) and the studies suggest that optimum recovery can be achieved at an intermediate size range. These particles are considered to be fully or partially liberated, and therefore be amenable to separation in a flotation circuit. Size range for optimum recovery varies with minerals, for example, $6-70 \mu \mathrm{m}$ for galena, $8-90 \mu \mathrm{m}$ for sphalerite, $15-60 \mu \mathrm{m}$ for chalcopyrite and $20-150 \mu \mathrm{m}$ for pyrite (Trahar et al., 1976). Coarse (composite) particles contain valuable minerals locked in gangue material. Recovering these particles will increase recovery but compromise the concentrate grade because locked gangue will also be recovered. Rejecting these minerals will not compromise the concentrate grade but the target grains may be lost in the tailings, therefore reducing overall recovery (Wills and Napier-Munn, 2006; Cropp et al., 2013). This depends how the operation is run, and how hard they pull mass recovery. Coarse particles are more likely not to be recovered due to the poor liberation of minerals and are too heavy to be lifted by the bubble so therefore bubble-particle attachment is disrupted. Fine particles $(<38 \mu \mathrm{m})$ are 
liberated and have a lower probability to be recovered due to the poor particle-bubble collision, but fine gangue material may be collected by entrainment and recovered to the final concentrate (Wills and Napier-Munn, 2006). The loss of recovery is significant at a particle size less than $38 \mu \mathrm{m}$ (Johnson, 1972; Smith and Warren, 1989). The inefficiency of recovering these particles leads to loss of revenue and unnecessary waste of the material (Deglon, 2005). Figure 2.7 demonstrates that flotation recovery is optimal at the intermediate size range, lower recoveries obtain for coarse particles and slower flotation kinetics exhibit for fine particles.

Particle size also has an impact on the chemical condition and the froth phase of the floatation cell. Fine and intermediate particles can be floated with a minor portion of collector dosage whilst coarse particles require a high degree of surface coverage by the collector (Shannon and Trahar 1986; Klimpel, 1997). A mineralogical analysis should be conducted for complex ores, to determine the liberation size of particles, in order to establish the required fineness of the grind (Wills and Napier-Munn, 2006). Information on the liberation and locking of the size by size sulfide minerals can assist in understanding the flotation behaviour (Johnson, 1987; Sutherland et al., 1988; Pease et al., 2006; Cropp et al., 2013).

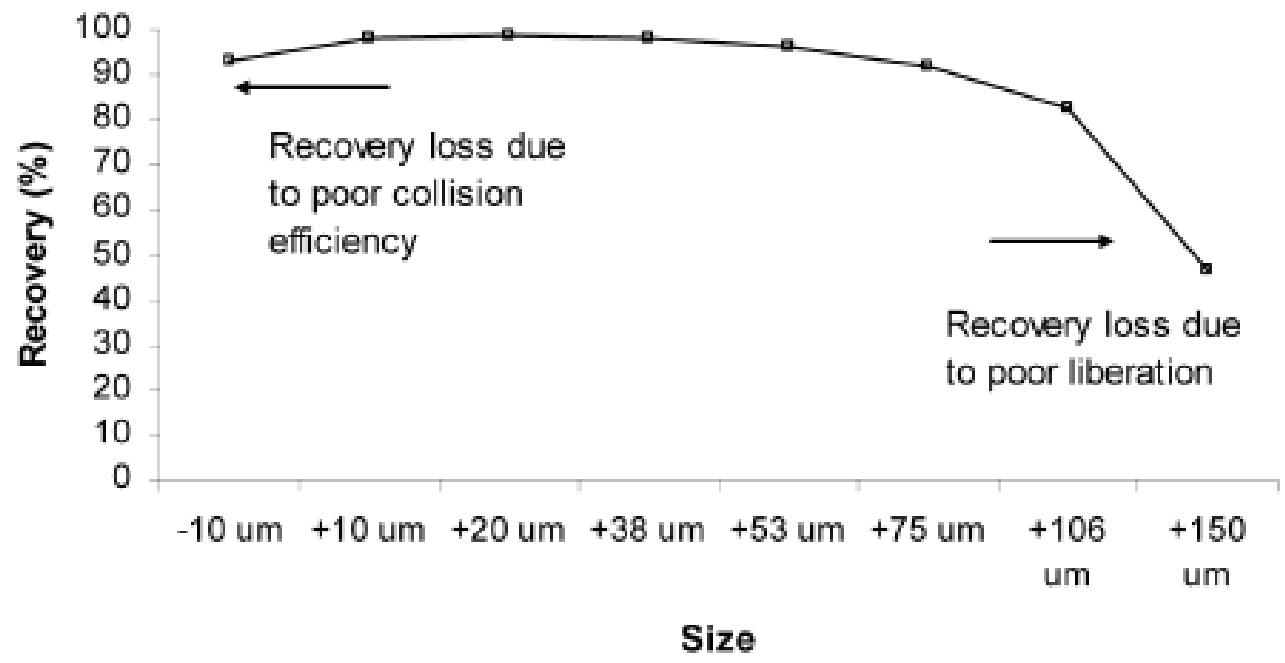

Figure 2.7: Conventional route of mineral recovery according to the particle size (Runge et al., 2013).

\subsection{Acid rock drainage}

Acid rock drainage (ARD) refers to when sulfur-rich rocks are oxidised (generally those containing pyrite and pyrrhotite). It results in low $\mathrm{pH}$ waters with high sulfate contents and high concentrations of dissolved often toxic elements such as $\mathrm{As}, \mathrm{Cd}, \mathrm{Cu}, \mathrm{Pb}$ and $\mathrm{Zn}$ (Becker et al., 2015; Parbhakar-Fox and Lottermoser, 2015). Sulfide minerals have different rates of reaction and the sequence of their reactivity is: pyrrhotite > galena - sphalerite > arsenopyrite > pyrite > chalcopyrite (Moncur et al., 2009). Acid rock drainage generation from sulfidic deposits is identified as one of the significant environmental 
problems in the mining industry (Bowell et al., 2006; Lindsay et al., 2009). This is because ARD can have a negative impact on communities, aquatic life and surroundings within the vicinity of the mine and the generation of ARD can continue into perpetuity.

\subsubsection{Factors affecting acid rock drainage formation}

Acid rock drainage (ARD) is influenced by the rate and extent of sulfide oxidation, oxygen availability, bacterial activity, mineralogy and texture (Blowes et al., 1998, Baker et al., 2003; Weber et al., 2004; Dold, 2010; Lottermoser, 2010). Both oxygen $\mathrm{O}^{2-}$ and ferric iron $\left(\mathrm{Fe}^{3+}\right)$ oxidise the sulfide minerals, and the reaction rate of ferric iron is up to 5 time faster than oxygen (Equation 2.5). Various microbial species also play an important role in contributing to the regeneration of ferric iron which in turn oxidises the sulfide minerals to further generate ferrous iron and acidity $\left(\mathrm{H}^{+}\right)$in a cyclic process (Equation 2.6) (Blowes et al., 2005). Mineralogy and textural characteristics such as degree of liberation, sulfide morphology, particle size and mineral association also contribute to the sulfide oxidation (Parbhakar-Fox et al., 2011). These attributes largely define the accessibility of the sulfide mineral to oxidation.

$\mathrm{FeS}_{2}+\left(\frac{7}{2}\right) \mathrm{O}_{2}+\mathrm{H}_{2} \mathrm{O} \rightarrow \mathrm{Fe}^{2+}+2 \mathrm{SO} 4{ }^{2-}+2 \mathrm{H}^{+}$

$\mathrm{Fe}^{2+}+\left(\frac{1}{4}\right) \mathrm{O}_{2}+\mathrm{H}^{+} \rightarrow \mathrm{Fe}^{3+}+\left(\frac{1}{2}\right) \mathrm{H}_{2} \mathrm{O}$

The reaction can be buffered by the presence of neutralising minerals contained in the surrounding rocks. Carbonate minerals comprised of calcium and magnesium such as calcite $\left(\mathrm{CaCO}_{3}\right)$, magnesite $\left(\mathrm{MgCO}_{3}\right)$, dolomite $\left(\mathrm{CaMg}\left(\mathrm{CO}_{3}\right)_{2}\right.$ are capable of neutralising acid formation due to their fast dissolution rates (Plumlee et al., 1999; Lapakko, 2002). Carbonates that contain $\mathrm{Fe}$ such as siderite $\left(\mathrm{FeCO}_{3}\right)$ and ankerite $\left(\mathrm{CaFe}\left(\mathrm{CO}_{3}\right)_{2}\right.$ as well as $\mathrm{Mn}$ (e.g Rhodochrosite- $\left.\mathrm{MnCO}_{3}\right)$ do not provide neutralising capacity because they hydrolyse to generate hydrogen ions (Skousen et al., 1997).

Silicate minerals also have capacity for long term acid neutralisation, but their dissolution rates are several orders of magnitude slower compared to carbonate minerals. The decreasing degree of reactivity can be linked with the increasing degree of complexity within the silicate mineral structure with minerals such as olivine considered as 'fast weathering' compared to the complex silicate structure of quartz which is 'inert'(Jambor et al., 2002). Table 2.4 summarises the dissolution rates of the neutralising minerals at $\mathrm{pH} 5$ relative to the carbonates. 
Table 2.4: Grouping of minerals according to their reactivity at $\mathrm{pH} 5$ adopted from (Lawrence and Scheske, 1997).

\begin{tabular}{|l|l|l|}
\hline $\begin{array}{l}\text { Mineral } \\
\text { group }\end{array}$ & $\begin{array}{l}\text { Relative } \\
\text { reactivity at pH 5 }\end{array}$ & Typical minerals \\
\hline Dissolving & 1.00 & $\begin{array}{l}\text { Carbonates (Calcite, aragonite, dolomite, magnesite, } \\
\text { brucite). }\end{array}$ \\
\hline $\begin{array}{l}\text { Fast } \\
\text { weathering }\end{array}$ & 0.40 & $\begin{array}{l}\text { Feldspar (anorthite), olivine (forsterite), pyroxenes (diopside, } \\
\text { hedenbergite, jadeite, spodumene, bronzite), wollastonite, } \\
\text { garnets, epidotes, nepheline, leucite. }\end{array}$ \\
\hline $\begin{array}{l}\text { Intermediate } \\
\text { weathering }\end{array}$ & 0.02 & $\begin{array}{l}\text { Pyroxene (enstatite, augite), amphiboles (tremolite, } \\
\text { serpentine, (chrysolite), mica (biotite), chlorite, talc, } \\
\text { hypersthene. }\end{array}$ \\
\hline $\begin{array}{l}\text { Slow } \\
\text { weathering }\end{array}$ & 0.01 & $\begin{array}{l}\text { Feldspar (albite, oligoclase, labradorite), clay (kaolinite, } \\
\text { vermiculite, montmorillonite). }\end{array}$ \\
\hline $\begin{array}{l}\text { Very slow } \\
\text { weathering }\end{array}$ & 0.01 & Feldspar (K-feldspar), mica (muscovite). \\
\hline Inert & 0.004 & Quartz, rutile, zircon. \\
\hline
\end{tabular}

Secondary aluminium hydroxides also provide buffering capacity in the waste material. Hydroxides can offset ARD formation due to the rise of $\mathrm{pH}$ and an increase of $\mathrm{Al}^{3+}$ and $\mathrm{Fe}^{3+}$ forming solid hydroxide minerals like ferrihydrite, schwertmannite, jarosite-alunite, and gibbsite (Blowes et al.,2005; Dold, 2016).

\subsubsection{ARD characterisation}

Characterising and predicting acid rock drainage is crucial as it permits for the advance planning of disposal practices and finding measures to mitigate the risk associated with acid formation. Long term negative effects on the on ecosystems and human health and financial consequences are the results of failing to accurately predict acid rock drainage (ARD) (Parbhakar-Fox and Lottermoser, 2015). Acid rock drainage characterisation is divided into static and kinetic tests. Static tests are rapid (hours or days), inexpensive and are traditionally used as screening tests to categorise wastes as non-acid forming (NAF), acid forming (AF), potentially acid forming (PAF) or uncertain (Dold, 2016). Static tests consist of the determination of acid-base accounting (ABA) and net acid generation (NAG). Kinetic tests provide information on the trajectory of acid generation, but these tests are difficult to set-up and operate and can be extremely time-consuming, sometimes meaningful results can be produced after couple of years (INAP, 2009). Kinetic tests involve column leach, humidity cell and biological shake flask tests are the commonly used laboratory scale (Stewart et al., 2006; Price, 2009; INAP, 2009; Hesketh et al., 2010). 


\section{Acid-base accounting (ABA)}

Acid-base accounting (ABA) estimates the theoretical net acid producing potential (NAPP) by calculating the balance between maximum potential acidity (MPA) and acid neutralizing capacity (ANC). The MPA is calculated from quantifying the sulfur in the sample whereas ANC is conventionally determined using laboratory chemical tests (Sobek et al.,1978; Lawrence and Scheske, 1997; Paktunc, 1999; Jurjovec et al. 2002, Kaartinen et al. 2009). If NAPP is negative, this indicates that the sample has the potential for acid neutralisation, whereas a positive stipulates that the waste has a potential to form acid. ANC and MPA are both either expressed as $\mathrm{kg} \mathrm{H}_{2} \mathrm{SO}_{4} /$ tonne of waste rock or equivalently as $\mathrm{kg} \mathrm{CaCO}_{3} /$ tonne of waste rock. An alternate approach for acid base accounting is based on mineralogical calculations alone (Lawrence and Scheske, 1997; Paktunc, 1999; Plante et al., 2012).

\section{Maximum potential acidity (MPA)}

Calculation of the maximum potential acidity (MPA) is derived from the sulfur grade in the sample (typically analysed by a Leco sulfur analyser). The calculation assumes that all the sulfur contained in the sample is pyritic (Plante et al., 2012). MPA can be overestimated by 1.5 if the sample being tested is comprised of pyrrhotite (Paktunc, 1999). The stoichiometric factor of 30.6 is multiplied by the sulfur grade to obtain MPA in $\mathrm{kg} \mathrm{H}_{2} \mathrm{SO}_{4} / \mathrm{t}$ (Paktunc, 1999; Smart et al. 2002, Stewart 2005) and 31.25 is used to express MPA in $\mathrm{kg} \mathrm{CaCO}_{3} / \mathrm{t}$ (White et al., 1999).

\section{Chemical acid neutralising capacity (ANC)}

Acid neutralisation capacity is assessed chemically by digesting the sample with acid. The sample is initially subjected to a process called 'fizz rating' which determines the amount of acid required to leach the samples, as well as the base for back-titration. Hydrochloric acid $(\mathrm{HCl})$ is added and the solution is heated for $1-2$ hours to allow the acid to react with neutralising minerals before back titrating it with sodium hydroxide $(\mathrm{NaOH})$ to $\mathrm{pH}$ 4.5. The amount of base added is used to determine neutralization capacity that results from the dissolution of carbonate and aluminosilicate minerals. The unreacted acid in the solution is estimated by back-titrating the sample to $\mathrm{pH}$ 7.0. The original method was developed by Sobek et al. (1978) and has since been refined by various researchers (Lawrence and Wang, 1996; Skousen et al., 1997; Stewart et al., 2009).

\section{Mineralogical calculation for acid potential (AP)}

Paktunc (1999) presented a method to determine the mineralogical acid potential (AP) by considering the grade of the sulfide minerals present in the sample. Table 2.6 shows the equations used to calculate $\mathrm{AP}$ and Table 2.5 demonstrates parameters used in the calculation. 
The AP calculation can be simplified to Equation 2.7 when estimating pyrite and Equation 2.8 to determine pyrrhotite.

$\mathrm{AP}=16.33 \mathrm{X}_{\mathrm{s}}$

$\mathrm{AP}=11.15 \mathrm{X}_{\mathrm{S}}$

\section{Mineralogical calculation for neutralising capacity (NP)}

A theoretical acid neutralising capacity can be determined based on the relative grade of the neutralising minerals (Lawrence and Scheske, 1997; Paktunc, 1999; Plante et al., 2012). Lawrence and Scheske (1997) developed a procedure that takes into account the proportion and relative reactivity of the neutralising minerals using the dissolution rates at $\mathrm{pH} 5$ as demonstrated in Table 2.4. NP is expressed as $\mathrm{kg} \mathrm{CaCO}_{3} / \mathrm{t}$, where $\mathrm{MCaCO}_{3}$ is the molecular weight for calcite, $\mathrm{R}_{\mathrm{i}}$ is the relative activity of the neutralising mineral and $\mathrm{M}_{\mathrm{Mi}}$ is the mineral content of the neutralising mineral. Several shortcomings of this approach were recognised by Paktunc (1999) who later developed a further iteration, which also specifically considered the presence of oxidisable cations such as iron $(\mathrm{Fe})$ and manganese $(\mathrm{Mn})$. Table 2.5 shows the parameters used to calculate NP by Paktunc (1999) and the equation is presented in Table 2.6 . 
Table 2.5: Parameters considered when calculating mineralogical acid rock drainage (Paktunc, 1999).

\begin{tabular}{|c|c|c|}
\hline $\begin{array}{l}\text { Measured } \\
\text { parameter }\end{array}$ & Meaning of the parameter & Unit of measurement \\
\hline AP & Mineralogical acid potential. & $\mathrm{kg} \mathrm{H}_{2} \mathrm{SO}_{4} /$ tonne \\
\hline S & Name of sulphide mineral. & \\
\hline $\mathrm{n}_{\mathrm{s}}$ & $\begin{array}{l}\text { Moles of sulfuric acid formed by oxidation of one } \\
\text { sulfide mineral. }\end{array}$ & mol \\
\hline $\mathrm{m}$ & Number of sulfide mineral in the sample. & \\
\hline $\mathrm{X}_{\mathrm{s}}$ & Amount of sulfide mineral in the sample. & wt. \% \\
\hline NP & Mineralogical neutralising potential. & $\mathrm{kg} \mathrm{H}_{2} \mathrm{SO}_{4}$ / tonne \\
\hline i & Name of the neutralising mineral. & \\
\hline $\mathrm{X}_{\mathrm{i}}$ & Amount of neutralizing mineral in the sample. & wt. \% \\
\hline$c_{i}$ & $\begin{array}{l}\text { Number of non-oxidisable cations in one } \\
\text { formula unit of neutralizing mineral. }\end{array}$ & - \\
\hline $\mathrm{n}_{i}$ & $\begin{array}{l}\text { Moles of neutralising mineral required to } \\
\text { consume moles of sulfuric acid produced by one } \\
\text { of sulfuric acid from oxidation. }\end{array}$ & mol \\
\hline$\omega_{i}$ & Molecular weight of the neutralising mineral. & $\mathrm{g} / \mathrm{mol}$ \\
\hline $\mathrm{k}$ & Number of neutralising minerals in the sample. & - \\
\hline 98 & Molecular weight of sulfuric acid. & $\mathrm{g} / \mathrm{mol}$ \\
\hline 10 & Conversion factor. & $\mathrm{kg} / \mathrm{t}$ \\
\hline
\end{tabular}

A later study by Plante et al. (2012) compared the Lawrence and Scheske (1997) and Paktunc (1999) methods to evaluate the neutralising potential of mine waste on five different rocks. A further modification of the method was proposed to improve the accuracy. A key conclusion of the study by Plante et al. (2012) was that a working knowledge of the sample mineralogy was needed to inform the choice of method for mineralogical NP calculation. 
Table 2.6: Mineralogical ANC methods (Plante et al., 2012).

\begin{tabular}{|c|c|c|}
\hline Method & Formulation & Characteristics \\
\hline $\begin{array}{l}\text { Lawrence } \\
\text { and Scheske } \\
(1997)\end{array}$ & $\begin{array}{l}\mathrm{AP}=31.25 \times \% \mathrm{~S}_{\text {sulfide }} \\
\mathrm{NP}=1000 \frac{\mathrm{kg}}{\mathrm{t}} \times \mathrm{MC}_{\mathrm{a}} \mathrm{CO}_{3} \sum_{\mathrm{t}=1}^{\mathrm{n}} \frac{\mathrm{C}_{\mathrm{Mi}} \mathrm{R}_{\mathrm{i}}}{\mathrm{M}_{\mathrm{Mi}}}\end{array}$ & $\begin{array}{l}\text { Takes into consideration } \\
\text { carbonates and neutralising } \\
\text { silicates. The calculation does } \\
\text { not account for Mn and Fe } \\
\text { carbonates. Acid potential (AP) } \\
\text { is calculated using chemistry. }\end{array}$ \\
\hline $\begin{array}{l}\text { Paktunc } \\
\text { (1999) }\end{array}$ & $\begin{array}{l}\mathrm{AP}=\sum_{\mathrm{s}=1}^{\mathrm{m}} \frac{\mathrm{n}_{\mathrm{s}} \times 98 \times \mathrm{X}_{\mathrm{s}} \times 10}{\omega_{\mathrm{s}}} \\
\mathrm{NP}=\sum_{\mathrm{i}=1}^{\mathrm{k}} \frac{98 \times 10 \times \mathrm{X}_{\mathrm{i}} \times c_{i} \times n_{s}}{\mathrm{n}_{i} \times \omega_{i}}\end{array}$ & $\begin{array}{l}\text { Takes only carbonates into } \\
\text { account. Accounts for Mn and } \\
\text { Fe carbonates. Acid and } \\
\text { neutralising potential is } \\
\text { calculated using mineralogy. }\end{array}$ \\
\hline $\begin{array}{l}\text { Plante et al. } \\
\text { (2012) }\end{array}$ & $\begin{array}{l}\mathrm{AP}=31.25 \times \% \mathrm{~S}_{\text {sulfide }} \\
\mathrm{NP}=1000 \frac{\mathrm{kg}}{\mathrm{t}} \times \mathrm{MC}_{\mathrm{a}} \mathrm{CO}_{3} \sum_{\mathrm{t}=1}^{\mathrm{n}} \frac{\mathrm{C}_{\mathrm{Mi}} \mathrm{R}_{\mathrm{i}} \times \mathrm{c}_{\mathrm{i}}}{\mathrm{M}_{\mathrm{Mi}}}\end{array}$ & $\begin{array}{l}\text { Considers } \mathrm{Mn} \text { and } \mathrm{Fe} \text { carbonate } \\
\text { and the approach includes } \\
\text { carbonates and silicates. Acid } \\
\text { potential (AP) is calculated } \\
\text { using chemistry. }\end{array}$ \\
\hline
\end{tabular}

\section{Net acid generation (NAG)}

The net acid generation (NAG) test is a common and widely practised chemical method utilised to detect the acid forming capacity of the sample. It is based on the interaction of the powdered samples with hydrogen peroxide, and simultaneous interaction between the acid forming and acid consuming minerals. The solution is back titrated with sodium hydroxide to evaluate the net acid forming capacity, reported in $\mathrm{kg} \mathrm{H}_{2} \mathrm{SO}_{4} / \mathrm{t}$. The $\mathrm{NAG} \mathrm{pH}$ is the parameter being measured, if is less than 4.5, the waste is classified as acid forming (Stewart et al., 2006). The method is however, subject to numerous limitations, e.g. decomposition of $\mathrm{H}_{2} \mathrm{O}_{2}$ prior to sulfide oxidation, incomplete sulfide oxidation, presence of carbonation and sulfate material interacting with $\mathrm{H}_{2} \mathrm{O}_{2}$. This has motivated the development of a variety of methods that addresses these limitations (e.g. sequential and kinetic NAG tests) (Miller et al., 1997; Smart et al., 2002).

\subsubsection{Interpretation of the static test results}

Static characterisation techniques are used to establish acid-generating potential of the mine waste material. More than one test is used to enhance the confidence in the results obtained. The waste material can be classified as non-acid forming (NAF), potentially acid forming (PAF) or uncertain (UC). Table 2.7 presents the guidelines used by the different methods to classify mine tailings. 
Table 2.7: Guidelines for ARD classification using different static chemical tests (Smart et al., 2002; Stewart et al., 2006).

\begin{tabular}{|l|l|l|}
\hline Test & Result $\left(\mathbf{k g ~ H}_{2} \mathrm{SO}_{4}\right.$ /ton) & Classification guidelines \\
\hline $\begin{array}{l}\text { Acid base accounting } \\
(\mathrm{ABA})\end{array}$ & $\begin{array}{l}\mathrm{NAPP}>0 \\
\mathrm{NAPP}<0\end{array}$ & $\begin{array}{l}\text { Potentially acid forming (PAF) } \\
\text { Non-acid forming (NAF) }\end{array}$ \\
\hline $\begin{array}{l}\text { Net acid generation } \\
\text { NAG) }\end{array}$ & $\begin{array}{l}\mathrm{NAG} \mathrm{pH}<4.5 \& \mathrm{NAG}_{\mathrm{pH} 7}>10 \\
\mathrm{NAG} \mathrm{pH}>4.5 \text { and } 5<\mathrm{NAG}_{\mathrm{pH} 7}<10\end{array}$ & $\begin{array}{l}\text { Acid forming } \\
\text { Non-acid forming (NAF) }\end{array}$ \\
\hline Kinetic NAG & $\begin{array}{l}\text { Temperature peak lag }>3 \text { hours } \\
\text { Temperature peak lag }<15 \text { minutes }\end{array}$ & $\begin{array}{l}\text { PAF with slow reaction kinetics } \\
\text { PAF with fast reaction kinetics }\end{array}$ \\
\hline $\begin{array}{l}\text { Combined NAG and } \\
\text { ABA }\end{array}$ & $\begin{array}{l}\text { NAG pH }<4.5 \& \text { NAPP }>0 \\
\text { NAG pH }>4.5 \& \text { NAPP }<0\end{array}$ & $\begin{array}{l}\text { Potentially acid forming (PAF) } \\
\text { Non-acid forming (NAF) }\end{array}$ \\
\hline $\begin{array}{l}\text { If either of these criteria fails, the results are considered uncertain and further testing is required } \\
\text { for classification }\end{array}$
\end{tabular}

\subsection{Modelling tools}

There are several commercially available mineral processing flowsheet modelling software. Key features of a good modelling flowsheet software is the ability to incorporate minerology during process flowsheet modelling. Most commercially available flowsheet modelling software have not accomplished the full potential of integrating ore minerology into process flowsheet modelling. This is partly due to a lack of mass balancing techniques and data reconciliation methods capable of handling mineralogical data by size fraction (Parian et al., 2016).

\section{HSC Chemistry}

HSC chemistry software was developed by Outotec and it is designed for chemical reaction and equilibria calculations (Outotec, 2015). The software contains calculation modules for mass balancing, element to mineral conversion (mineralogical calculations) (HSC Chemistry Geo module) and simulation of process units (HSC Chemistry Sim module). Mineral grades can be calculated by using element to mineral conversion which is located on the HSC GEO module. The module consists of a mineral database which can be used if electron probe micro analyser (EPMA) analysis is unavailable. A mineralogical mass balancing can be done on size by size basis. Mass balancing is performed on the HSC Mass Balance module. The data is validated by assigning standard deviations which minimises the error between balanced and experimental data and also indicates the adjustment error. It has different simulation functions that can be used to simulate any type of process (Outotec, 2015). Different types 
of process models in chemistry, metallurgy and mineralogy are available in HSC chemistry. The HSC Sim module is comprised of different modelling approaches which are particle, reaction and distribution based.

\section{JKSIMFloat}

JKSimFloat was developed at the Julius Kruttschnitt Mineral Research Centre (JKMRC). It forms part of their suite of processing software JKSimmet, JKMultiBal and JKSimblast. JKSimFloat simulates flotation Plants. JKSimFloat software permits the user to set up and run a mass balance once the flowsheet has been constructed all experimental data has been imported. The software permits the user to indicate the number and type of measurements for each stream. JKSimFloat contains an extensive library of unit models to use for unit modelling. The unit process simulation is performed by keeping constant unit model parameters determined from model fitting whilst various process scenarios can be investigated by changing model design variables. Model variables include parameters such as solid feed rates, water addition rates, ore breakage characteristics and equipment dimension and flowsheet arrangement.

\section{MODSIM}

MODSIM can calculate a detailed mass balance for any ore dressing circuit and it is known to be a steady-state flowsheet simulator (King, 2001). It is based on a modular structure which allows new models to be imported for simulating different unit operations (King, 2001). The software is based on the population balance model and can calculate particle size, mineral liberation, density, elemental composition and magnetic susceptibility (King, 2001).

\section{Aspen plus}

Aspen plus was developed by Massachusetts Institute of Technology (MIT) and it is a steady state chemical process simulator (Doherty et al., 2009). The software contains a collection of unit operations blocks (e.g. pumps, heat exchangers, reactors, splitters), which portray the actual operation in a chemical plant. Aspen plus contains routine mathematical equations that can be used to solve material and energy balances as well as equilibrium (Magnusson, 2005). A sequential modular approach to the flowsheet is used where mass and energy balances for individual unit operation blocks are evaluated sequentially. The process model in a flowsheet programme is constructed by defining the flowsheet (inlet and outlet streams, etc.), chemical components (e.g. reactants and intermediates, etc.) and operating conditions (e.g. temperature pressure, etc.). The software uses FORTRAN blocks and design specifications to simulate chemical process. Excel can be used to create user models or they can be written using Fortran code and be integrated into Aspen plus flowsheet (Doherty et al., 2009). The 
specifications of a particular design are utilised for feedback control and permits the user to define particular design values for any flow sheet variable or function of flow sheet variable. These specifications manipulate parameters such as flow sheet, feed stream or block input in order to achieve the design value. FORTRAN codes can also be used to compute design specification function values. Stream and block variables must be manipulated manually, to iterate towards the mass and energy balance, until it obtains a solution.

\subsection{Scenario analysis}

Operational targets for operating a mineral processing plant include achieving target grade and recovery whilst ensuring that the potential for acid rock drainage (ARD) formation is known prior to disposing of waste material into the tailings dam. Operational problems can occur on a daily basis that might comprise both metallurgical performance and maximise environmental impacts. It is important to develop tools that can monitor different possible scenarios to evaluate the relationship between operational performance and environmental risk. Scenario analysis is a process of examining uncertain possibilities and considering possible outcome to minimise the risk of making the wrong decision (Swart et al., 2004; Pallottino et al., 2005; Duinker and Greig, 2007). It has become an effective tool for decision-makers to develop long-term strategic plans (Senshaw, 2014). Scenario analysis is not a forecasting tool but it creates future development techniques for the system, obtained from describing and evaluating alternative possibilities (Swart et al., 2004; Postma and Liebl, 2005; Duinker and Greig, 2007). This is because scenarios stimulate thinking, highlights target inconsistencies and identifies knowledge gap as well as develop frameworks to transform planning into actions (Dortmans and Eiffe, 2004; Senshaw, 2014). The number of scenarios to be evaluated depends on the number of issues examined, so therefore two, three or four scenarios are sufficient to look at different possibilities (Weidenbach et al., 2016).

Mahmoud et al. 2009 proposed the following steps in developing scenario analysis:

- Conceptualise the whole system by defining the scenarios and choosing the best model. If a model is used to construct scenario analysis, it has to be built to identify assumption and decision factors and be transparent among the stakeholders (Liu et al., 2008). It is also important to identify input (e.g type of data) and output variables.

- Develop the model and it is important to consider if the selected model will be able to represent all the scenarios. Model input data is essential as this is linked to the scenarios and is used for decision making. The model has to be realistic to achieve the credible result and be at the appropriate level of complexity so that the stakeholders can comprehend the data. 
- Examine the outputs of the different scenarios. Inspect consistency of the data and identify the conditions of the system and trends.

- Identifying risk, mitigating opportunities, possible trade-offs, examine implications and derive plans to monitor the scenarios. This phase relies on extensive discussion amongst stakeholders and researchers.

- Implement strategies for reducing risks, derive resources to exploit opportunities and increasing resiliency to problematic conditions.

- Monitor decisions acquired from variables and indicators. Evaluate if the current scenarios or model parameters should be modified and if new scenarios are required.

\subsection{Summary of the literature review}

An integrated modelling framework is a very promising tool that can be utilised for incorporating sustainable development principles at the operational level. This is because, it is a mathematical model that is comprised of indicators that can measure the outcomes and uncertainties of a process. The steps required in developing this framework are; definition of the operational and sustainable development goals for the operation as well as the scope of the study, determination of sustainable development opportunities or issues by examining defined battery limits and formulation of a business case which describes how the issues will be addressed as well as their priorities, benefits and the cost of each option. A missing gap in the majority of frameworks, is that they do not consider the role of mineralogy which is a critical component as it defines the behaviour of the ore. Four case studies were presented to demonstrate how to incorporate integrated modelling frameworks at the operational level, that consider sustainable development principles as part of the decision-making process. Three of the case studies did not focus on all aspects of sustainable development, with Charikinya et al. (2017) being the only that attempted consider all aspects. Charikinya et al. (2017) also considered the role of mineralogy but the data was acquired using a technique that has long turn - around time and this limits the framework to be used on a daily basis for operational decisions.

Process mineralogy can be used to understand and solve problems encountered during mineral processing. Key mineralogical characteristics used in process mineralogy are element deportment, mineral grades, grain size distribution, texture, liberation and association. Process mineralogy can be used for the following applications; circuit design and optimisation as the characteristic of the ore defines flowsheet design (Lotter, 2011; Whiteman et al., 2016), benchmarking and optimisation where it contributes to processing in a sustainable manner by minimising energy consumption (Evans et al., 2011) and integrated design approach to mitigate acid rock drainage from waste material (Hesketh et al., 2010). Mineralogy can be quantified using a variety of techniques such as auto-SEM technology 
(e.g. QEMSCAN). These techniques are not necessarily applicable in the context of developing the framework as obtaining information is expensive and requires extensive sample preparation ( $\mathrm{Gu}$ et al., 2014; Lotter et al., 2017). Element to mineral conversion has the potential to produce timeous results, rapid and cost-effective. The downfall of using EMC is developing a recipe for the ore in question is expensive, time-consuming (and provides no information on mineral liberation) but as soon the recipe has been established, it can be used be for routine analysis of mineral grades.

Mineralogy can also be applied in characterising the potential of acid rock drainage (ARD) formation from waste material. Acid rock drainage is characterised by the contribution of various sulfides and neutralising minerals that have different reaction rates and have a varying contribution capacity to the net acid generation. The formation of ARD can cause land degradation, pollution of scarce water resources and demolition of marine life. Acid rock drainage can be managed by using simple, reliable and cost - effective prediction and characterising procedures to classify the waste material for ARD generation. These procedures can be divided into a static and kinetic tests: static tests are rapid and relatively inexpensive whereas the more costly and time consuming kinetic tests provide information on the trajectory of acid generation (Dold, 2016). Static tests are classified as acid-base accounting (ABA) and net acid generation (NAG) and can be determined by using either using either chemistry or mineralogy (Sobek et al.,1978; Lawrence and Scheske, 1997; Paktunc, 1999; Jurjovec et al. 2002, Kaartinen et al. 2009). Mineralogical studies are important in the selection and interpretation of ARD characterisation procedures (Lawrence and Scheske, 1997; Morin et al., 1998; Paktunc, 1999; Akabzaa et al., 2012; Plante et al., 2012).

Simulation models assist in defining process performance and design criteria without conducting different trials during the production process of a mine and this minimises operating cost (King, 2001; Wills and Napier-munn, 2006). Simulation software has not accomplished the full potential of including mineralogy due to lack of mass balancing techniques and data reconciliation methods capable of handling liberation data (Parian et al., 2016). Simulation models can be used for scenario analysis. The outcomes of scenario analysis can be used to minimise the risk of making the wrong decision (Swart et al., 2004; Pallottino et al., 2005; Duinker and Greig, 2007). The number of scenarios depends on the number of issues to be evaluated.

\subsection{Key questions}

Based on the critical review of the literature, the following key questions are proposed in this study:

a) Can an appropriate EMC recipe be developed for the polymetallic sulfide ore case study, and what are the key minerals that should be included in the recipe? 
b) Does the element to mineral conversion (EMC) methodology provide a suitable means of including the first level of mineralogical data in the development of the integrated framework which can be used to assess metallurgical performance (mineral grade and recovery) as well as an associated environmental indicator (acid rock drainage potential) for the polymetallic sulfide ore case study?

c) Can the developed integrated framework be used for different scenario analyses that take into account both techno-economic and environmental indicators? 


\section{Chapter 3}

\section{Material and methods}

This chapter presents a description of the methods and materials used in the study in the first phase of the development of an integrated modelling framework: i.e. identification of a suitable case study and associated sampling points around the mineral processing circuit, a sampling campaign to generate samples, sample preparation, chemical and ore characterisation analytical methods and HSC chemistry software. Figure 3.1 provides an overview of the sections covered in this chapter. This study is the first phase of a larger flagship project in the Minerals to Metals Initiative in the Department of Chemical Engineering.

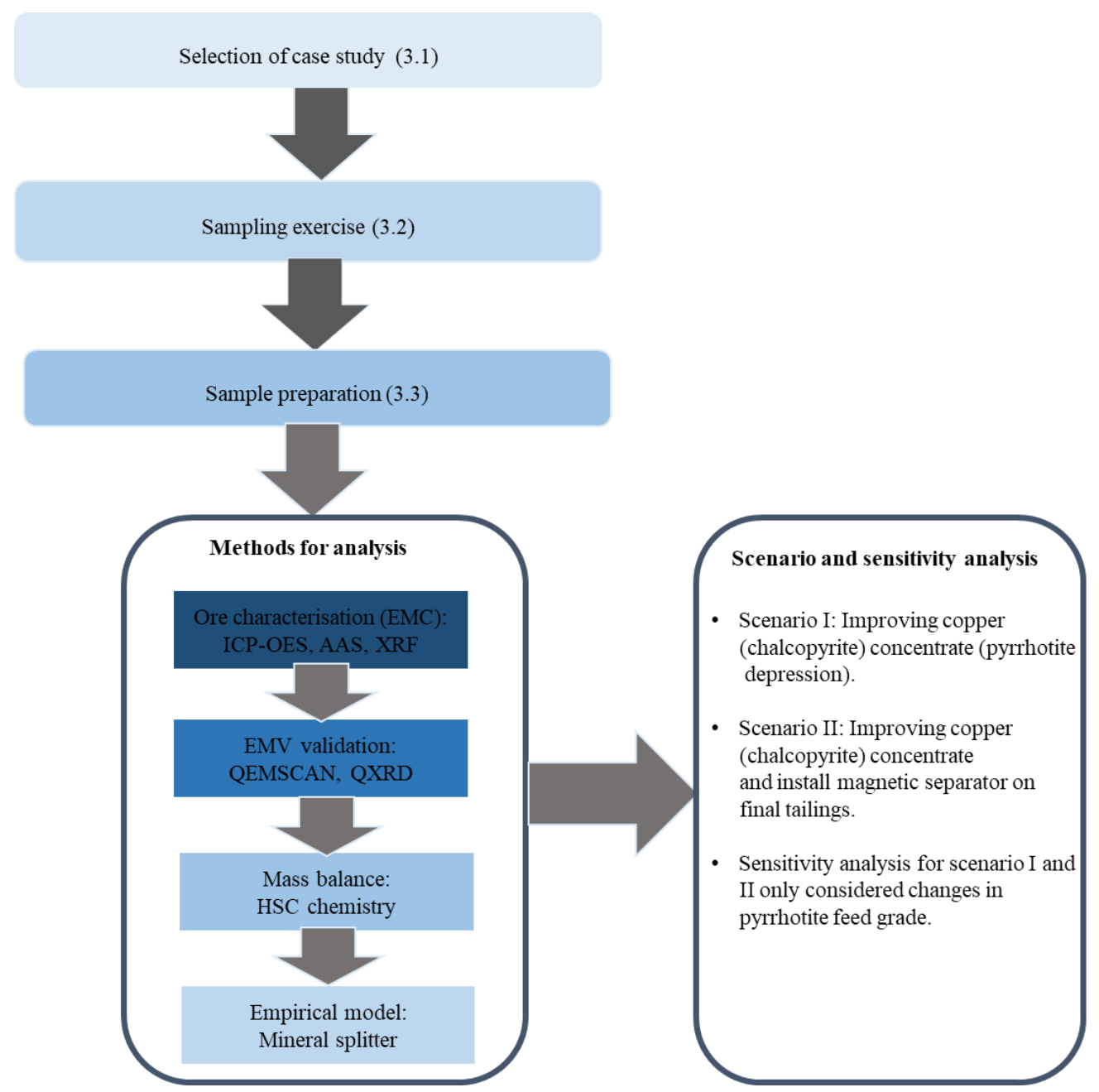

Figure 3.1: Flow diagram of the experimental procedure. 


\subsection{Selection of a case study}

A polymetallic $\mathrm{Cu}-\mathrm{Pb}-\mathrm{Zn}$ sulfide ore was chosen as an initial case study upon which to initiate the development of the integrated modelling framework. The 10 x $30 \mathrm{~km}$ regional ore district consists of four known ore bodies with varying degrees of economic mineralisation (Bailie et al., 2007). The ore deposits are sedimentary-exhalative, Broken-hill type occurring within an area which has experienced regional metamorphism. Mining currently takes place within two of the ores bodies which are then blended to a specific ratio to produce run of mine material which is fed to the concentrator. The ore is initially jaw crushed, and thereafter crushed by secondary and tertiary cone crushers. The crushed material is further reduced in size by a two-stage grinding circuit comprised of rod and ball milling. The slurry is pumped into the two stage cyclones for particle size classification. The cyclone overflow is fed to the aeration circuit and the underflow returned to the ball mill for further size reduction. The slurry is transferred to three sequential flotation stages to produce copper, lead and zinc concentrates respectively. The tailings produced from the flotation circuit are pumped either to the tailings dam or to backfill. The final flotation concentrates are thickened, dewatered, and dried ready for further offsite metallurgical processing. A general flow diagram of the mine is illustrated in Figure 3.2.

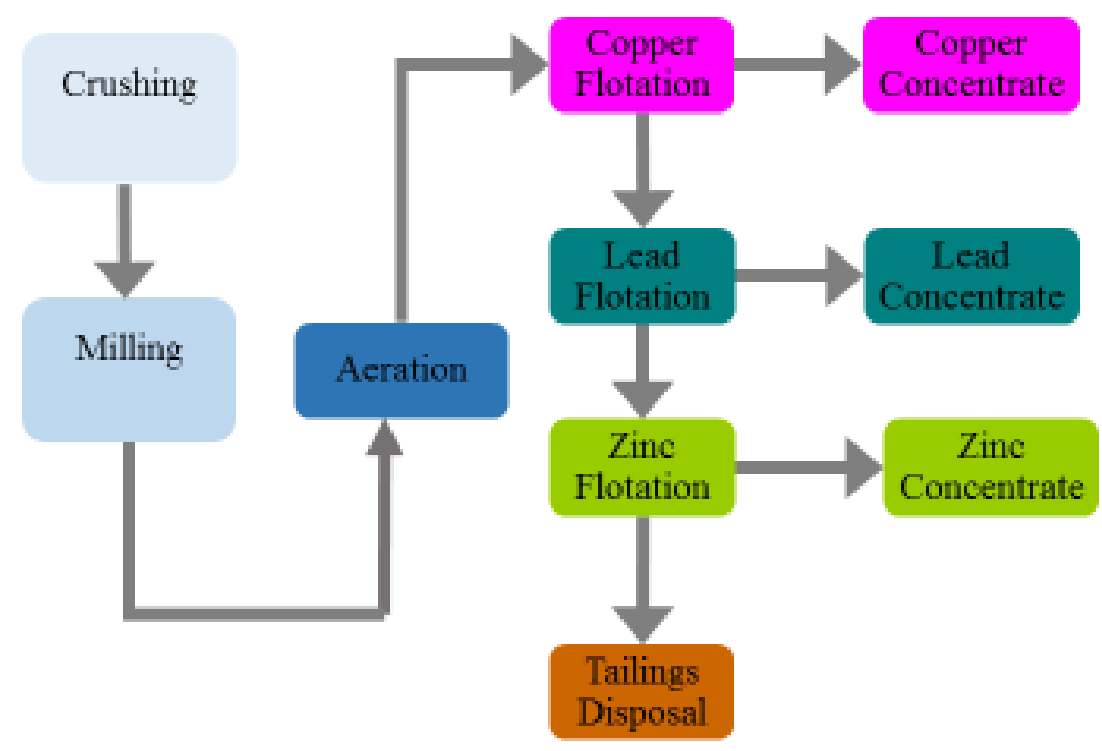

Figure 3.2: A general process flow diagram of the polymetallic mine. 


\section{2. Sampling exercise}

In line with the guiding principles of the integrated framework development, the sampling exercise on the flotation circuit focused on key intermediate and terminal streams. These are highlighted in Figure 3.3: copper feed, copper concentrate, lead feed (copper tails), lead concentrate, zinc feed (lead tails), zinc concentrate and final tails (i.e. seven sampling points in total). Two identical samples were collected from each stream, and the second sample kept as a back-up. All sampling equipment was cleaned and dried prior to sampling (see Fig 3.4). The control room was visited prior and after the sampling period to confirm the plant was running at a steady state. Approximately 5-15 kg samples were cumulated over a period of one hour, with one cut taken with a pelican cutter every 15 minutes. The sample had to be a substantial size to be regarded as a representative sample (Petersen et al., 2004). The final mass of the sample depends on the number of tests to be conducted and the number of people involved. Therefore, a lot of sample may be required to ensure there is enough to complete all the required tests. In the case for UCT, $300 \mathrm{~g}$ is required for sub-sieving which gives sufficient sample to screen and obtain reasonable masses on each screen. The final $300 \mathrm{~g}$ is obtained after splitting from an initial larger mass, with $1 \mathrm{~kg}$ being the preferable minimum amount of slurry required from the sampling exercise.

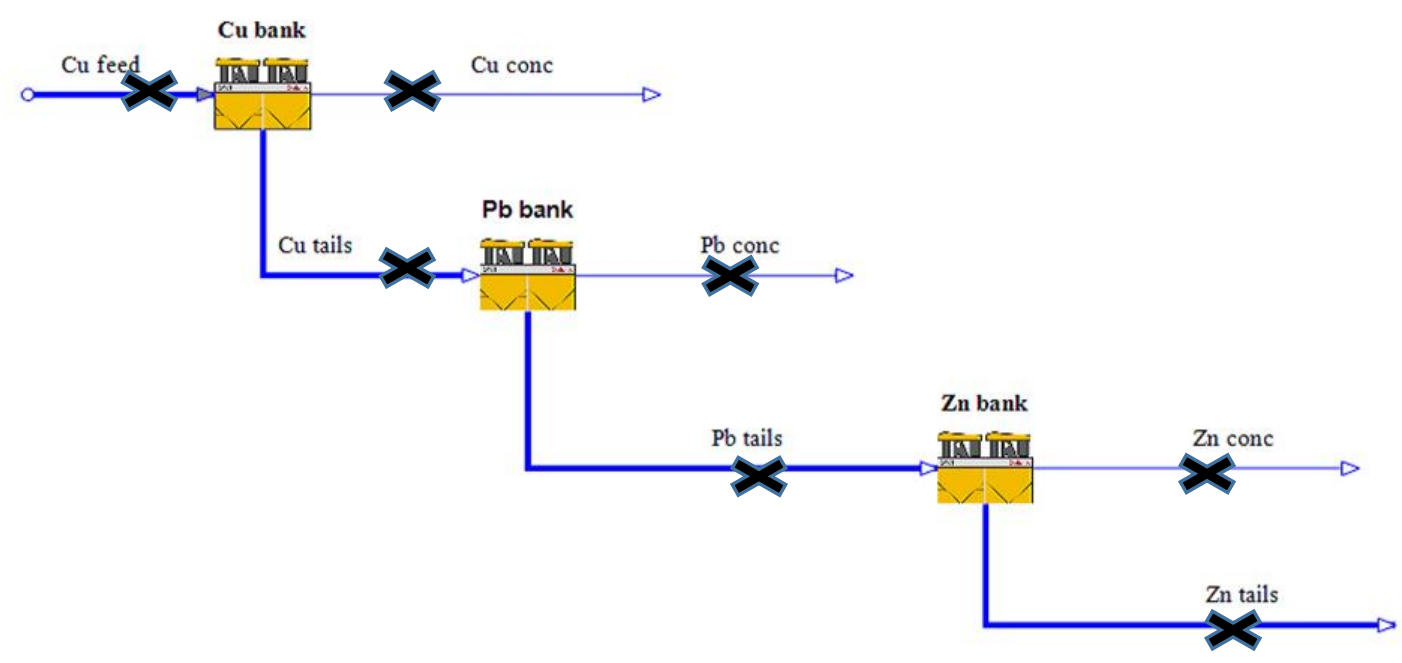

Figure 3.3: Flowsheet of the case study flotation circuit with key sampling points annotated.

\section{3. Sample preparation}

After sample collection, the slurry samples were filtered using a batch laboratory-scale pressure filter. Thereafter they were placed in the oven at $60{ }^{\circ} \mathrm{C}$ to remove all residual moisture. The samples were packaged for shipping and all subsequent sample preparation and characterisation was done at the Centre for Minerals Research, at the University of Cape Town (UCT). Figure 3.4 illustrates equipment that was used for the sampling exercise and sample preparation. The pelican sampler was used to cut 
the sample across the stream, a rotary splitter to split samples into smaller aliquots, an air filter was used filter water from slurry and an oven was to dry samples.

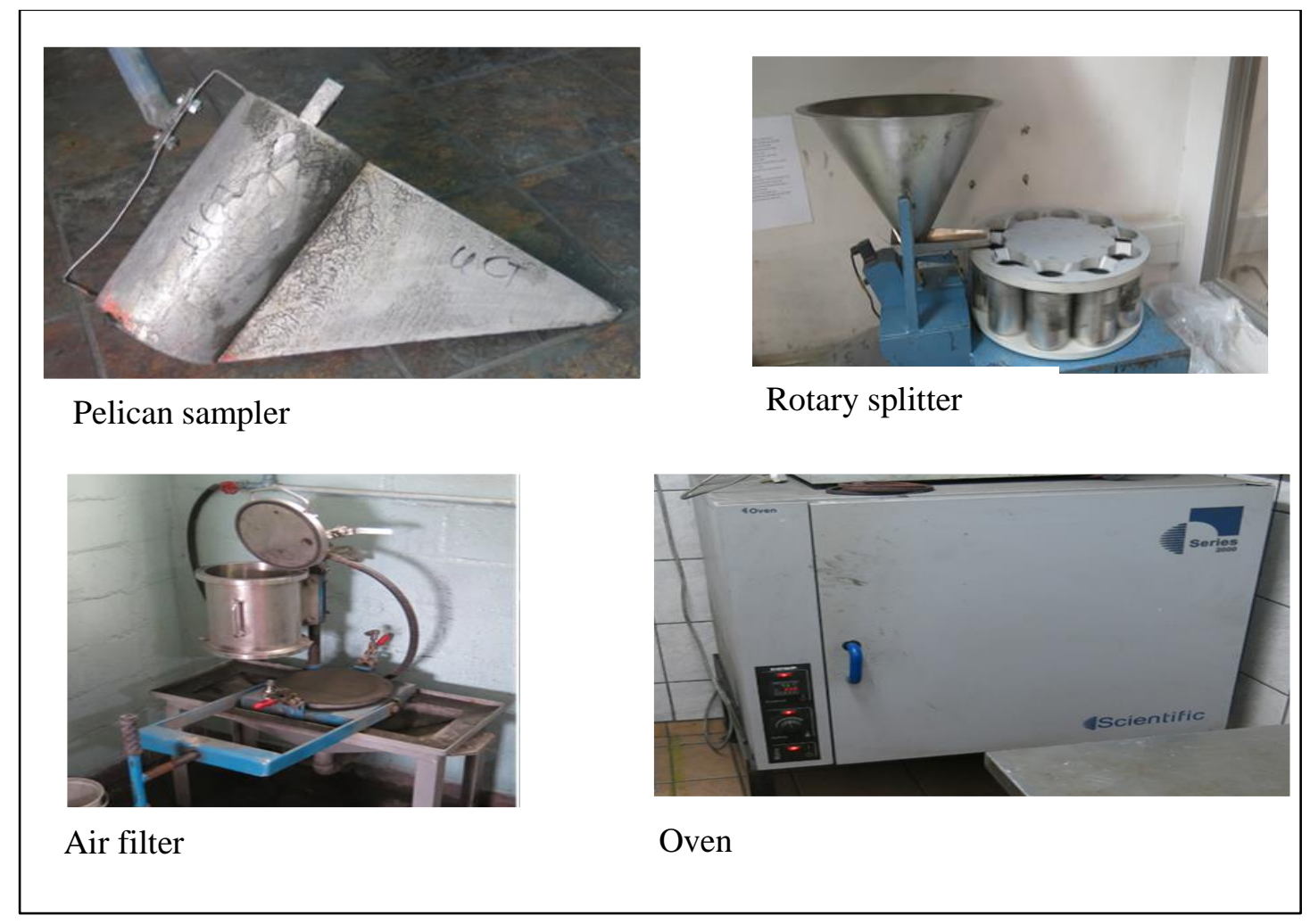

Figure 3.4: Photographs of equipment used in the sampling campaign and sample preparation.

Upon receipt at UCT, the dried samples were reweighed and subjected to splitting into smaller aliquots for chemical and mineralogical analysis. They were split into $250 \mathrm{~g}$ sub-samples using a 10-cup rotary splitter. This was done to achieve a representative of the bulk sample in order to acquire accurate information (e.g. elemental assay). This information was used for mass balancing to provide data on mineral grades, recovery and characterising waste material for acid rock drainage. Splitting was an important task, as sample homogeneity was essential to reduce bias before subjecting the samples to laboratory analysis. The samples were subjected to wet screening at screen aperture sizes of 75, 53, 38 and $25 \mu \mathrm{m}$. The screens were firmly positioned on a vibrating sieve shaker and an empty 20 litre bucket was placed underneath the screen. The sample was placed on the vibrating screen and water was added continuously until only clear water was discharged from the screen. The undersize of $25 \mu \mathrm{m}$ was further screened to less than $10 \mu \mathrm{m}$ using a screening cloth and ultrasonic bath. The sub-samples in the bucket for each screen were filter pressed and dried in an oven at $60{ }^{\circ} \mathrm{C}$. The dried samples were weighed and recorded and kept in sample containers. The material larger than $75 \mu \mathrm{m}$ was dried and thereafter dry screening was performed on a stack of screens from 850, 600, 425, 300, 212, 150, 106, 75, 53, 38 and $25 \mu \mathrm{m}$. The complete size distribution was achieved by combining data from the wet and dry screening processes. Screening was performed to get high quality chemistry and mineralogical data. The particle 
size distribution (PSD) of the seven samples across the flotation circuit, is demonstrated in Figure 3.5. As expected, concentrate samples are significantly finer than the tailings. The lead (galena) concentrate was the finest $(98.1 \%$ passing $75 \mu \mathrm{m})$ of the three flotation concentrates, followed by copper (chalcopyrite) concentrate $(92.7 \%)$ and zinc (sphalerite) concentrate $(92.6 \%)$ passing $75 \mu \mathrm{m}$ The copper feed as well as the tailings samples showed a similar particle size distribution ( $66.9 \%$ for the $\mathrm{Cu}$ feed and the tailings have an average of $62.0 \%$ passing $75 \mu \mathrm{m})$. The very fine PSD of the $\mathrm{Pb}$ concentrate suggests possible overgrinding taking place within the circuit (Muketekelwa, 2017).

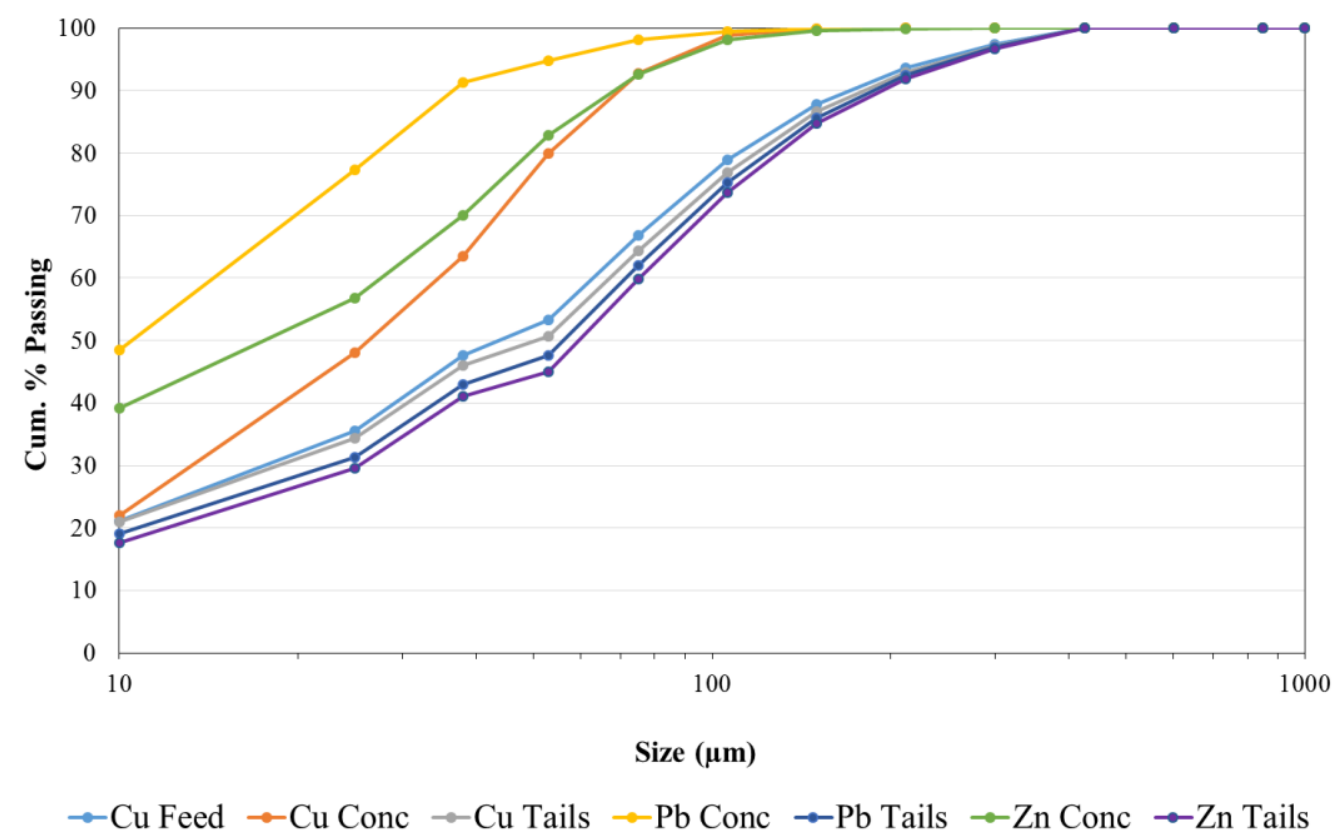

Figure 3.5: Particle Size Distribution of the samples collected across the flotation circuit. Conc refers to concentrate.

\subsection{Chemical characterisation}

Chemical / elemental assays of $\mathrm{Si}, \mathrm{Al}, \mathrm{Mn}, \mathrm{Fe}, \mathrm{Cu}, \mathrm{Pb}, \mathrm{Zn}, \mathrm{S}$ and $\mathrm{Ba}$ were conducted using a combination of inductively coupled plasma optical emission spectrometry (ICP-OES), X-ray fluorescence spectrometry (XRF) and atomic absorption spectroscopy (AAS). Several sets of chemical assays were performed (on both sized and unsized samples). All samples were pulverised using a laboratory mill prior to chemical analysis to minimise particle size effects and to ensure a fully homogenous sample. Different techniques were used to develop a clearer picture of the ore characteristics, as elements analysed for, are not common in rock forming minerals and there was a wide range of element concentration occurring in the samples. These chemical analyses provided the input elemental data for setting up the element to mineral conversion (EMC) recipe. The scope of the of this work, only considered bulk mineralogy. Table 3.1 shows the detection limit of the different chemical techniques. 
Table 3.1: Detection limit of the chemical techniques and it is applicable for both sized and bulk samples.

\begin{tabular}{|l|l|l|}
\hline Method & Sized / bulk & Classification guidelines \\
\hline XRF & Sized / bulk & $2-10 \mathrm{ppm}$ \\
\hline ICP-OES & Sized / bulk & $0.1 \mathrm{ppm}$ \\
\hline AAS & Sized / bulk & $1 \mathrm{ppm}$ \\
\hline
\end{tabular}

\subsubsection{X-ray fluorescence spectrometry (XRF)}

The samples were analysed using Bruker AXS-S4 Explorer wavelength dispersive X-ray fluorescence spectrometry at a company known as Sciba. The samples were analysed for both major and minor element oxides: $\mathrm{SiO}_{2}, \mathrm{Al}_{2} \mathrm{O}_{3}, \mathrm{MnO}, \mathrm{Fe}_{2} \mathrm{O}_{3}, \mathrm{CuO}, \mathrm{PbO}, \mathrm{ZnO}$ and $\mathrm{BaO}$. Samples were prepared into fusion discs for major element oxide analysis. The data for elemental oxides is presented in Appendix B.

\subsubsection{Inductively coupled plasma optical emission spectrometry (ICP-OES)}

Major and minor elemental assays of each sample was analysed a using Varian 730 inductively coupled plasma optical emission spectrometry (ICP-OES) at the University of Cape Town. The samples were digested with a mixture of hydrochloric, hydrofluoric and nitric acids. Boric acid $\left(\mathrm{H}_{3} \mathrm{BO}_{3}\right)$ was added to neutralize the mixture prior to the analysis. The instrument was calibrated with synthetic solutions containing the elements that were analysed.

The lead concentrate sample was analysed at the polymetallic sulfide mine using ICP-OES, for quality check purposes. This is because different results were obtained from a variety of chemical techniques used at the University of Cape Town and Sciba. The sample was mixed with hydrochloric acid and allowed to boil for 5 minutes and thereafter the solution was cooled at room temperature. A combination of hydrochloric acid, nitric acid and bromine/acetic acid were added to the mixture and subjected to boiling until $1 \mathrm{ml}$ solution remained in the beaker. The mixture was permitted to cool, nitric acid was added and the solution was allowed to boil to dissolve soluble salts. The mixture was cooled and diluted with deionised water and the element was analysed using ICP-OES.

\subsubsection{Atomic absorption spectroscopy (AAS)}

Atomic absorption spectroscopy (AAS) was used to analyse chemical elements present in the sample, by measuring absorbed optical radiation (or light) from the element of interest. A generation (calibration) curve was used to measure a specific element and can be generated by introducing known concentrations of standards. The measured absorption at each concentration was plotted to generate a 
straight line that was drawn between resulting points. From this line, the content of the elemental assay was extrapolated from the substance absorbance.

\subsubsection{Leco}

A Leco S632 sulfur analyser housed at the University of Cape Town was used to detect the sulfur content. A sample with a mass of $0.2 \mathrm{~g}$ was heated to $1350{ }^{\circ} \mathrm{C}$ in an induction furnace while passing a stream of oxygen through the sample. The sulfur content is quantified by using an infrared spectrophotometer to measure sulfur dioxide released in the process of high temperature combustion.

\section{5. Mineralogical characterisation}

Mineralogical characterisation was completed using both Quantitative Evaluation of Minerals by Scanning Electron Microscopy (QEMSCAN) and Quantitative X-ray diffraction (QXRD). All mineralogical characterisation was conducted at the University of Cape Town.

\subsubsection{QEMSCAN}

All samples were prepared as vertical (transverse) sections (on a size by size basis) to minimise settling of the heavier minerals present in the ore. A total of two blocks of vertical sections were prepared for each sample by splitting them into $4 \mathrm{~g}$ aliquots using a rotary micro riffler. Two grams of milled graphite was added to each sample at a ratio of 1:1. The purpose of graphite was to reduce the effect of touching particles and enhance electron conductivity during analysis. The mixture was positioned in labelled and lubricated moulds mixed with resin and hardener, then placed in vacuum chamber for 10 minutes to remove any air bubbles. The moulds were placed in a pressure pot to cure overnight and then they were polished through a series of grinding and polishing steps to a $1 \mu \mathrm{m}$ diamond finish, washed in an ultrasonic bath and dried at $30{ }^{\circ} \mathrm{C}$ for an hour. The blocks were carbon coated using a Quorum Q150T E coater to diffuse electrons off the surface of the sample when they are in the QEMSCAN. The QEMSCAN analyses were run on an FEI QEMSCAN $650 \mathrm{~F}$ at $25 \mathrm{kV}$ and $10 \mathrm{nA}$ using the bulk mineralogical analysis (BMA) and particle mineralogical analysis (PMA) measurements. The measurements were run at a pixel spacing between 2 and $5 \mu \mathrm{m}$. The raw data obtained through QEMSCAN was processed using the QEMSCAN iExplorer software. QEMSCAN has mineral library system called species identification protocol (SIP) which is used for mineral identification. The SIP file and accompanying primary mineral list was tailored for the ore in question by importing known mineral chemistry data into the QEMSCAN mineral list. Although the data was analysed on a size by size basis as part of a larger aligned study, only the bulk / recombined mineralogy of the seven samples is presented here. 


\subsubsection{Quantitative X-ray diffraction (QXRD)}

Quantitative X-ray diffraction (QXRD) was used to cross check the mineral identity and their relative abundance at the University of Cape Town, since there was already a working knowledge of the mineralogy of the ore (Ryan et al., 1982; McClung and Viljoen, 2011) . The Rietveld method was used to quantify the abundance of mineral phases present in the samples. The sample preparation involved splitting the samples into $3.5 \mathrm{~g}$ using a rotary micro riffler. The samples were milled for 10 minutes in a McCrone micronizer using $7 \mathrm{ml}$ of ethanol as a grinding agent to a particle size of less than $10 \mu \mathrm{m}$ which this is the particle size required for quantitative X-ray diffraction (Rietveld refinements) in order to produce intensities which accurately reflect the structure and composition of the phases analysed. Ethanol was also utilised for cleaning any remaining sample from the mill and the samples were left to dry overnight under an organic fume hood. The micronized sample were analysed by a Bruker D8 Advance powder diffractometer with Vantec detector and fixed divergence and receiving slits with Co$\mathrm{K} \alpha$ radiation. The operating parameters of the instrument were step size of 0.01 degree $2 \Theta$. The Bruker Topas 4.1 software was used to quantify the mineral phases (Coelho, 2007). Two parameters were used to assess whether the refinements were successful; the weighted-profile R-value (Rwp) and goodness of fit (GOF) test (Young, 1993). Weighted-profile R-value (Rwp) indicates the correlation between the identified phases to the complete scanned profile. Topas calculates the ideal Rwp depending on the quality of the data. The GOF was used to evaluate how the calculated Rwp correlates with the calculated value. Theoretically Rwp for a perfect fit is 0 and the GOF is 1 (Young, 1993). The detection limits depend on the sample type and sample preparation, $1 \mathrm{wt}$. \% is the detection limit in most cases. The results for QXRD are presented in Appendix C.

\subsection{HSC chemistry}

The HSC chemistry software produced by Outotec is an extensive package including chemical reactions, equilibriums and calculation modules for mass balancing, mineralogical calculations and process simulations (Outotec, 2015). The HSC GEO module was used to develop the element to mineral conversion (EMC) recipe, and the SIM flowsheet module used for mass balancing.

\subsubsection{Mass balancing procedure}

Lamberg and Vianna (2007) developed a technique for mineralogical mass balancing known as 'particle tracking' for flotation circuits. This method converts elemental assays to mineral grades and then to the liberation level, but in this study only the mineralogical bulk mass balancing was performed. HSC chemistry by Outotec was used for mass balancing and mineralogical calculations. The HSC Geo calculation module was used to perform the element to mineral conversion (EMC). Mineral chemistry and elemental assays were the main input for the calculations. The mass balance was conducted on the 
HSC Sim 8 Mass Balancing tool. In order to conduct a mass balance for the flotation circuit of the intermediate and terminal streams, data of various parameters were collected. This data included the percent solids and the slurry mass flowrate of particular streams, as well as the assay analysis of all the valuable and non-valuable minerals. The feed, concentrates and tailing streams were initially mass balanced on a solids basis and then on elemental basis using HSC Chemistry 8 software (Outotec, 2015). Mass balanced and experimental data are expected to be similar, however this is not always the case due to propagation of error as a result of fluctuations in the system, sampling error, bias associated with analytical methods, etc. (Pitard, 1993; Holmes, 2004). The standard deviation was used to determine how close the measurement is to another measurement. The weighted sum of squared errors (WSSQ) was used to minimise the error between the measured and balanced data. 


\section{Chapter 4}

\section{Developing a case study for an integrated modelling framework}

The guiding principle in developing the larger integrated modelling framework is to keep the approach simple, cost effective and applicable, so its strength lies in the ability to simultaneously evaluate several processes, rather than the detailed optimisation of any single specific unit operation. This principle also applies to the acquisition of mineralogical data inputs to the framework, since the model is underpinned by minerology. Thus, the manner in which mineralogical information is acquired should also be simple, cost effective, and applicable to the ore being processed. In this chapter the steps taken to develop the base case for the flotation flowsheet operation will be presented. This will include a presentation of the chemical characterisation results of the flotation circuit streams, as well as results from developing a simple and cost-effective element to mineral conversion recipe for obtaining mineralogical data (mineralogical characterisation). This chapter also presents the application of models to calculate acid rock drainage (ARD) and $\mathrm{ARD}$ characterisation results of final product streams from the base case analysis as well an assessment of the circuit performance during the time the circuit streams were sampled.

\subsection{Ore characterisation}

\subsubsection{Chemical characterisation}

The element to mineral conversion (EMC) calculation requires both chemical assays and known mineral compositions (mineral chemistry) for the ore in question as these are the main inputs for setting up the EMC recipe. Unbalanced major and minor element chemical assays of the different streams sampled are given in Table 4.1. This data was obtained from the analytical techniques (inductively coupled plasma optical emission spectrometry (ICP-OES), X-ray fluorescence spectrometry (XRF) and atomic absorption spectroscopy (AAS). $\mathrm{Cu}, \mathrm{Pb}$ and $\mathrm{Zn}$ grades of the respective flotation concentrates were consistent with the sequential upgrading of chalcopyrite, galena and sphalerite by flotation. $\mathrm{Fe}$ is dominant in most streams except for lead and zinc concentrate. Si occurs is significant amount in the tailings streams, whilst the $\mathrm{S}$ is dominant in the concentrate streams. $\mathrm{Al}, \mathrm{Ba}$ and $\mathrm{Mn}$ occur in minor amounts in all streams. 
Table 4.1: Chemical composition of the different streams samples analysed by the different analytical techniques, given in wt. \%. (Unbalanced data).

\begin{tabular}{|l|c|c|c|c|c|c|c|c|c|}
\hline \multirow{2}{*}{ Stream name } & \multicolumn{8}{|c|}{ Chemical assays (wt. \%) } \\
\cline { 2 - 11 } & $\mathbf{A l}$ & $\mathbf{B a}$ & $\mathbf{C u}$ & $\mathbf{F e}$ & $\mathbf{M n}$ & $\mathbf{P b}$ & $\mathbf{S}$ & $\mathbf{S i}$ & $\mathbf{Z n}$ \\
\hline Copper feed & 1.5 & 0.5 & 0.6 & 39.9 & 1.9 & 2.0 & 4.7 & 13.8 & 2.6 \\
\hline Copper concentrate & 0.4 & 0.0 & 20.7 & 36.8 & 0.2 & 2.4 & 30.4 & 1.9 & 1.3 \\
\hline Copper tails & 1.4 & 0.6 & 0.2 & 39.4 & 2.0 & 1.3 & 4.1 & 14.7 & 2.6 \\
\hline Lead concentrate & 0.2 & 0.0 & 1.3 & 3.3 & 0.4 & 75.5 & 11.9 & 5.4 & 1.2 \\
\hline Lead tails & 1.5 & 0.6 & 0.2 & 40.9 & 2.6 & 0.5 & 3.4 & 13.5 & 1.9 \\
\hline Zinc concentrate & 0.1 & 0.1 & 0.6 & 8.0 & 0.6 & 2.6 & 28.4 & 0.7 & 50.3 \\
\hline Zinc tails & 1.4 & 0.6 & 0.1 & 40.4 & 2.8 & 0.4 & 2.3 & 14.0 & 0.9 \\
\hline
\end{tabular}

\subsection{Mass balance}

Elemental assays were imported into HSC SIM flowsheet module 8 for mass balancing to minimise the error between measured and balanced data (Figure 4.1). The data in Figure 4.1 show that the elements have an $\mathrm{R}^{2}$ value above 0.95 , so therefore the results are comparable. The balanced chemical assays are presented in the Appendix B. Solid, water and flowrates of the chemical assays were acquired from mass balancing and the data is presented in Table 4.2. A flowsheet of the flotation circuit with solid flowrates for each stream is presented in Appendix A.

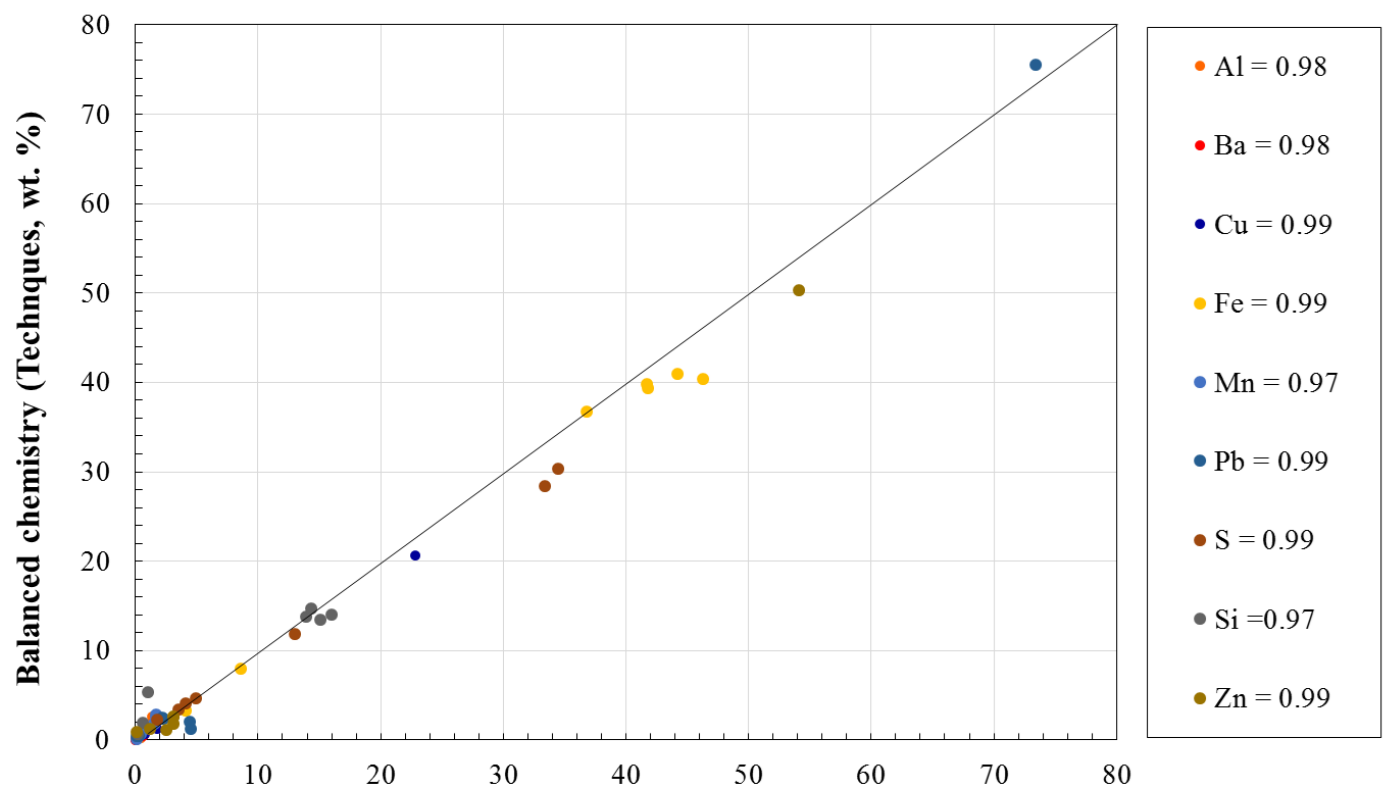

Unbalanced measured chemistry (Technques, wt. \%)

Figure 4.1: Comparison of the unbalanced chemical assays analysed by techniques with balanced chemical assay analysed by techniques for all samples. The associated $R^{2}$ value is included for each element. 
Table 4.2: Overall mass balance across the flotation circuit. The mass balance data was obtained from HSC SIM flowsheet module.

\begin{tabular}{|l|c|c|c|c|c|c|c|}
\hline $\begin{array}{l}\text { Stream } \\
\text { name (t/h) }\end{array}$ & $\begin{array}{c}\text { Copper } \\
\text { feed }\end{array}$ & $\begin{array}{c}\text { Copper } \\
\text { concentrate }\end{array}$ & $\begin{array}{c}\text { Copper } \\
\text { tails }\end{array}$ & $\begin{array}{c}\text { Lead } \\
\text { concentrate }\end{array}$ & $\begin{array}{c}\text { Lead } \\
\text { tails }\end{array}$ & $\begin{array}{c}\text { Zinc } \\
\text { concentrate }\end{array}$ & $\begin{array}{c}\text { Zinc } \\
\text { tails }\end{array}$ \\
\hline $\begin{array}{l}\text { Solid } \\
\text { flowrate }\end{array}$ & 188.0 & 5.0 & 183.0 & 10.5 & 172.5 & 9.6 & 162.8 \\
\hline $\begin{array}{l}\text { Water } \\
\text { flowrate }\end{array}$ & 333.5 & 42.3 & 192.8 & 151.1 & 169.8 & 65.6 & 171.5 \\
\hline $\mathrm{Al}$ & 4.3 & $<0.1$ & 4.3 & $<0.1$ & 4.3 & $<0.1$ & 4.3 \\
\hline $\mathrm{Ba}$ & 1.1 & $<0.1$ & 1.1 & $<0.1$ & 1.1 & $<0.1$ & 1.1 \\
\hline $\mathrm{Cu}$ & 1.5 & 1.1 & 0.3 & 0.2 & 0.1 & $<0.1$ & 0.1 \\
\hline $\mathrm{Fe}$ & 78.4 & 1.8 & 76.6 & 0.4 & 76.1 & 0.8 & 75.3 \\
\hline $\mathrm{Mn}$ & 2.9 & $<0.1$ & 2.9 & $<0.1$ & 2.9 & $<0.1$ & 2.8 \\
\hline $\mathrm{Pb}$ & 8.3 & 0.1 & 8.2 & 7.7 & 0.4 & 0.2 & 0.2 \\
\hline $\mathrm{S}$ & 9.2 & 1.7 & 7.5 & 1.4 & 6.1 & 3.2 & 2.9 \\
\hline $\mathrm{Si}$ & 26.2 & $<0.1$ & 26.1 & 0.1 & 26.0 & 0.0 & 26.0 \\
\hline $\mathrm{Zn}$ & 5.7 & 0.1 & 5.7 & 0.3 & 5.4 & 5.2 & 0.2 \\
\hline
\end{tabular}

The sum of weighted square (Sum WSQQ) was used to minimise the error between measured and balanced data. Lower values indicate that there were minor adjustments between measured and balanced values. The copper feed had the highest adjustment followed by the zinc tails. The zinc concentrate had the lowest adjustment. All the streams have RSMD (root mean square deviation) values lower than $5 \%$ which indicate that the measured and balanced data are close to another. Table 4.3 shows the data reconciliation of the mass balance.

Table 4.3: Data reconciliation of the flotation circuit during the survey.

\begin{tabular}{|l|c|c|c|}
\hline Stream name & Sum WSQQ (\%) & RSMD (\%) & Relative RMSD (\%) \\
\hline Copper feed & 32.2 & 1.1 & 10.3 \\
\hline Copper concentrate & 14.8 & 3.6 & 33.0 \\
\hline Copper tails & 26.2 & 4.0 & 36.3 \\
\hline Lead concentrate & 4.5 & 0.2 & 2.0 \\
\hline Lead tails & 28.5 & 4.2 & 38.0 \\
\hline Zinc concentrate & 2.7 & 0.3 & 2.7 \\
\hline Zinc tails & 30.0 & 4.6 & 42.2 \\
\hline
\end{tabular}

\subsubsection{Element to mineral conversion and mineralogical balance}

Prior to setting the EMC recipe, chemistry results were validated by comparing the actual chemistry results with the calculated chemistry from QEMSCAN. The accuracy of the data was determined by evaluating the $\mathrm{R}^{2}$ value. Figure 4.2 illustrates the relationship between the unbalanced chemistry data from QEMSCAN and from the different chemical techniques. The results show that the data is comparable, as all the elements have an $\mathrm{R}^{2}$ value above 0.95 with Ba being the only exception. 


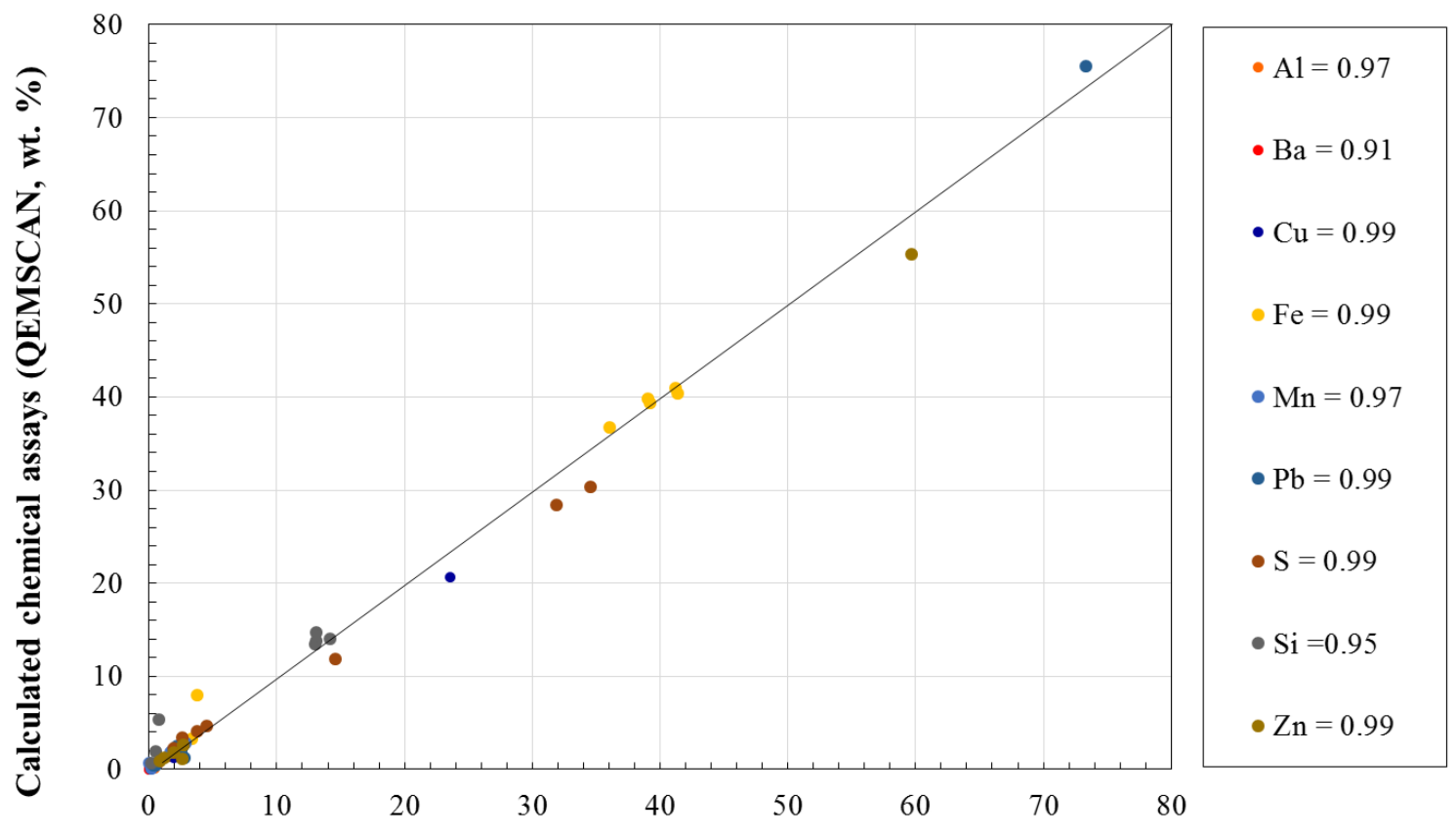

Unbalanced chemical assay (Techniqes, wt. \%)

Figure 4.2: Comparison of the unbalanced chemical assays with the QEMSCAN calculated chemical assay for all samples. The associated $R^{2}$ value is included for each element.

The element to mineral conversion (EMC) routine was developed after obtaining the bulk mineralogy from QEMSCAN, because knowledge of the ore variability was required to successfully develop the recipe for the ore in question. The QEMSCAN analysis indicated that 16 minerals were present in significant quantities (see Table 4.4). In line with keeping the analysis as simple as possible, minerals from QEMSCAN had to be further grouped. The grouping exercise focused on establishing which minerals were the most important on the basis of economic value, and in contributing to generating or neutralising acid rock drainage (ARD), and therefore needed to be reported in the framework. Similarly, the grouping exercise focused on which were the likely key elements which could be used to track specific minerals avoiding a case of the EMC recipe being either over or under determined. On this basis, the EMC method was designed to calculate 9 minerals, namely: sphalerite, chalcopyrite, galena, pyrrhotite, quartz, magnetite, garnet, biotite and barite. Given the dominance of pyrrhotite in the ore, pyrite was considered in the 'pyrrhotite' subgrouping since both minerals are Fe and $\mathrm{S}$ bearing. Garnet and pyroxmangite were grouped together as they are both manganese silicates. The number of elements had to be equal to the number of minerals calculated, because if there more chemical assays than minerals the solution will be over-determined and there can be more than one solution and if the number of minerals is higher than elements, the case is under-determined and there is no unique solution (Paktunc, 1998; Whiten, 2007) 
Table 4.4: QEMSCAN bulk mineralogy of the different samples. Note results shown are unbalanced and the data is expressed as wt. \%.

\begin{tabular}{|l|c|c|c|c|c|c|c|}
\hline Minerals & $\begin{array}{c}\text { Copper } \\
\text { feed }\end{array}$ & $\begin{array}{c}\text { Copper } \\
\text { concentrate }\end{array}$ & $\begin{array}{c}\text { Copper } \\
\text { tails }\end{array}$ & $\begin{array}{c}\text { Lead } \\
\text { concentrate }\end{array}$ & $\begin{array}{c}\text { Lead } \\
\text { tails }\end{array}$ & $\begin{array}{c}\text { Zinc } \\
\text { concentrate }\end{array}$ & $\begin{array}{c}\text { Zinc } \\
\text { tails }\end{array}$ \\
\hline Chalcopyrite & 2.0 & 67.6 & 0.7 & 5.4 & 0.5 & 1.5 & 0.5 \\
\hline Galena & 2.9 & 2.6 & 3.2 & 84.7 & 0.6 & 2.5 & 0.4 \\
\hline Sphalerite & 4.5 & 1.8 & 4.5 & 4.1 & 3.3 & 93.2 & 1.7 \\
\hline Pyrite & 1.0 & 1.7 & 0.9 & 0.1 & 0.8 & 0.1 & 0.7 \\
\hline Pyrrhotite & 4.0 & 23.3 & 3.2 & 0.4 & 2.3 & 0.5 & 2.4 \\
\hline Garnet & 3.4 & 0.1 & 3.7 & 0.2 & 3.7 & 0.1 & 4.2 \\
\hline Pyroxmangite & 3.9 & 0.6 & 4.1 & 0.7 & 6.6 & 0.1 & 6.9 \\
\hline Augite & 0.9 & 0.4 & 1.1 & 0.2 & 1.3 & 0.1 & 1.6 \\
\hline Chlorite & 0.1 & $<0.1$ & 0.1 & $<0.1$ & 0.2 & $<0.1$ & 0.1 \\
\hline Biotite & 3.0 & 0.3 & 3.2 & 0.4 & 2.9 & 0.2 & 2.7 \\
\hline Barite & 0.9 & $<0.1$ & 1.1 & $<0.1$ & 0.9 & $<0.1$ & 0.8 \\
\hline Feldspar & 0.4 & 0.1 & 0.4 & 0.1 & 0.4 & $<0.1$ & 0.4 \\
\hline Quartz & 22.5 & 0.5 & 22.1 & 1.0 & 20.7 & 0.3 & 23.1 \\
\hline Apatite & 0.6 & $<0.1$ & 0.6 & 0.1 & 0.7 & $<0.1$ & 0.6 \\
\hline Magnetite & 49.3 & 0.9 & 50.4 & 1.8 & 54.4 & 0.5 & 53.5 \\
\hline Other & 0.5 & 0.2 & 0.5 & 0.8 & 0.6 & 1.0 & 0.4 \\
\hline
\end{tabular}

The EMC method development focused on calculating minerals with unique elements in the early rounds, and thereafter using the residual elements to calculate minerals with common elements in the final rounds (e.g. Fe in magnetite and pyrrhotite). The mineral grades were calculated sequentially, and subsequent rounds continue until all the minerals in the list had been allocated. This gave a better control in cases where the least squares method does not give a solution and a non-negative equation has to be used. The sum of the calculated mineral grades cannot exceed $100 \%$ or be negative. After several revisions comparing which minerals were calculated in which rounds, trialling different refinement methods, a suitable recipe was obtained as given in Table 4.8. Table 4.5, 4.6, and 4.7 provides the accompanying mineral chemistry data upon which the recipe was developed. 
Table 4.5: Mineral chemistry of the sulfide minerals where the standard deviation is given in brackets. The number of analyses is also reported. (From Rudnick, 2018, Pers. Comm).

\begin{tabular}{|l|c|c|c|c|}
\hline \multicolumn{1}{|c|}{ Element (wt. \%) } & $\begin{array}{c}\text { Chalcopyrite } \\
\left(\mathbf{C u F e S}_{\mathbf{2}}\right)\end{array}$ & $\begin{array}{c}\text { Galena } \\
(\mathbf{P b S})\end{array}$ & $\begin{array}{c}\text { Sphalerite } \\
\left(\mathbf{Z n}_{\mathbf{0} . \mathbf{F}} \mathbf{F e}_{\mathbf{0} . \mathbf{S}} \mathbf{S}\right)\end{array}$ & $\begin{array}{c}\text { Pyrrhotite } \\
\left(\mathbf{F e}_{\mathbf{7}} \mathbf{S}_{\mathbf{8}}\right)\end{array}$ \\
\hline $\mathrm{Fe}$ & $30.6(0.3)$ & - & $6.3(2.8)$ & $60.3(2.0)$ \\
\hline $\mathrm{Mn}$ & - & - & - & - \\
\hline $\mathrm{Cu}$ & $34.2(0.4)$ & - & - & - \\
\hline $\mathrm{Ni}$ & - & - & - & - \\
\hline $\mathrm{Co}$ & - & - & - & - \\
\hline $\mathrm{Zn}$ & - & - & $59.8(3.4)$ & - \\
\hline $\mathrm{Pb}$ & - & $88.6(4.0)$ & - & - \\
\hline $\mathrm{S}$ & $35.2(0.4)$ & $11.4(2.8)$ & $33.9(0.4)$ & $39.7(2.3)$ \\
\hline $\mathrm{As}$ & - & - & - & - \\
\hline $\mathrm{Cd}$ & - & - & - & - \\
\hline $\mathrm{Number}$ of analyses & 11 & 21 & 17 & 11 \\
\hline
\end{tabular}

Table 4.6: Mineral chemistry for silicate minerals where the standard deviation is given in brackets. The number of analyses is also reported. (From Rudnick, 2018, Pers. Comm).

\begin{tabular}{|l|c|c|}
\hline Element (wt. \%) & $\begin{array}{l}\text { Garnet } \\
\left.\mathbf{M n}_{\mathbf{3}} \mathbf{F e A l}_{\mathbf{2}} \mathbf{( S i O 4}\right)_{\mathbf{3}}\end{array}$ & $\begin{array}{l}\text { Biotite } \\
\left(\mathbf{K F e}_{\mathbf{3}} \mathbf{A I S i}_{\mathbf{3}} \mathbf{O}_{\mathbf{1 0}} \mathbf{( O H}\right)_{\mathbf{2}}\end{array}$ \\
\hline $\mathrm{Si}$ & $36.5(0.6)$ & $33.6(2.1)$ \\
\hline $\mathrm{Ti}$ & - & - \\
\hline $\mathrm{Al}$ & $20.5(0.6)$ & $18.0(1.1)$ \\
\hline $\mathrm{Fe}$ & $22.5(9.0)$ & $19.5(2.8)$ \\
\hline $\mathrm{Mn}$ & - & - \\
\hline $\mathrm{Mg}$ & - & - \\
\hline $\mathrm{Ca}$ & - & - \\
\hline $\mathrm{Ba}$ & - & - \\
\hline $\mathrm{Na}$ & - & $9.0(1.6)$ \\
\hline $\mathrm{K}$ & 3.0 & 19.5 \\
\hline $\mathrm{O}$ & - & 0.4 \\
\hline $\mathrm{H}$ & 19 & 19 \\
\hline $\mathrm{Number}$ of analyses & & \\
\hline
\end{tabular}


Table 4.7: Mineral chemistry based on the stoichiometric composition of the minerals (Data taken from HSC database).

\begin{tabular}{|l|c|c|c|}
\hline Elements (wt. \%) & $\begin{array}{l}\text { Barite } \\
\left(\mathbf{B a S O}_{4}\right)\end{array}$ & $\begin{array}{l}\text { Magnetite } \\
\left(\mathbf{F e}_{3} \mathbf{O}_{\mathbf{4}}\right.\end{array}$ & $\begin{array}{l}\text { Quartz } \\
\left(\mathbf{S i O}_{2}\right)\end{array}$ \\
\hline $\mathrm{Si}$ & - & - & 46.7 \\
\hline $\mathrm{Fe}$ & - & 72.6 & - \\
\hline $\mathrm{Ba}$ & 58.9 & - & - \\
\hline $\mathrm{S}$ & 13.7 & - & - \\
\hline $\mathrm{O}$ & 27.4 & 27.4 & 53.3 \\
\hline
\end{tabular}

Table 4.8: Element to mineral conversion recipe used for the study. LS indicates least squares, NNLS indicates non-negative least squares.

\begin{tabular}{|c|c|c|c|c|}
\hline Mineral & Component & Round & Method & Element \\
\hline Chalcopyrite & $\mathrm{CuFeS}_{2}$ & \multirow[t]{3}{*}{1} & \multirow[t]{3}{*}{ LS } & $\mathrm{Cu}$ \\
\hline Galena & $\mathrm{PbS}$ & & & $\mathrm{Pb}$ \\
\hline Sphalerite & $\mathrm{Zn}_{0.9} \mathrm{Fe}_{0.1} \mathrm{~S}$ & & & $\mathrm{Zn}$ \\
\hline Barite & $\mathrm{BaSO}_{4}$ & 2 & $\overline{L S}$ & $\mathrm{Ba}$ \\
\hline Garnet & $\mathrm{Mn}_{3} \mathrm{FeAl}_{2}(\mathrm{SiO} 4)_{3}$ & \multirow[t]{3}{*}{3} & \multirow[t]{3}{*}{ NNLS } & $\mathrm{Mn}$ \\
\hline Biotite & $\mathrm{KFe}_{3} \mathrm{AlSi}_{3} \mathrm{O}_{10}(\mathrm{OH})_{2}$ & & & $\mathrm{Al}$ \\
\hline Quartz & $\mathrm{SiO}_{2}$ & & & $\mathrm{Si}$ \\
\hline Pyrrhotite & $\mathrm{Fe}_{7} \mathrm{~S}_{8}$ & \multirow[t]{2}{*}{4} & \multirow[t]{2}{*}{ NNLS } & $S$ \\
\hline Magnetite & $\mathrm{Fe}_{3} \mathrm{O}_{4}$ & & & $\mathrm{Fe}$ \\
\hline
\end{tabular}

The element to mineral conversion (EMC) data was mass balanced to minimise the error between measured and balanced data and this is demonstrated in Figure 4.4. The unbalanced data is presented in the Appendix C. The mass balanced EMC bulk mineralogy across the circuit is presented in the base case study analysis section and was used to evaluate the distribution and performance of the different streams. The unbalanced EMC is compared to the unbalanced QEMSCAN data to confirm that the EMC method is reliable (Figure 4.3). The QEMSCAN data was normalised as similar minerals were sub-grouped from the original list and those that occur in trace amounts were not included. The correlation between QEMSCAN and EMC was comparable as all the minerals had an $\mathrm{R}^{2}$ value greater than 0.95. This validates that the EMC method is effective and the recipe works very well for the samples which have been assessed in this study. 


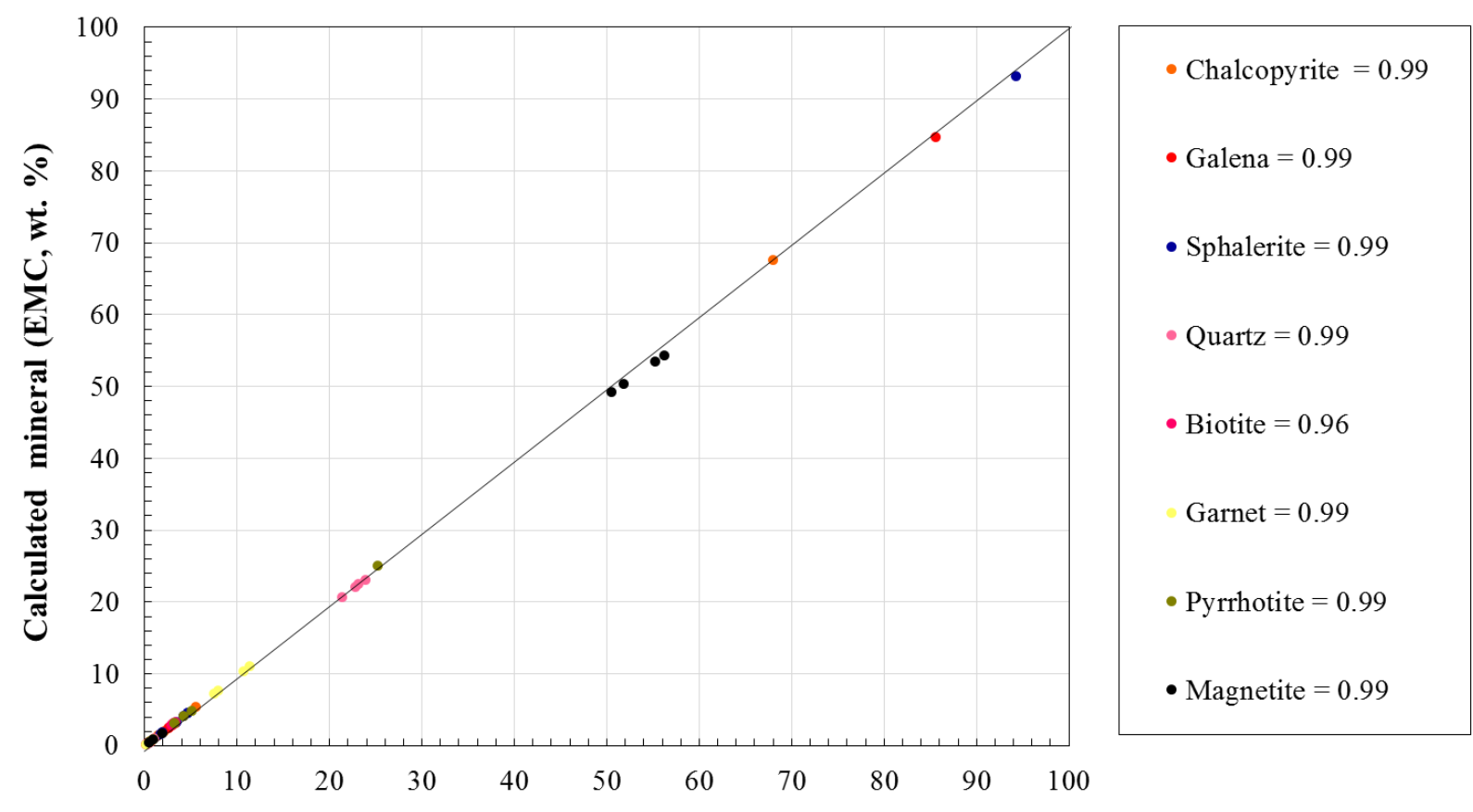

Measured mineral (QEMSCAN, wt. \%)

Figure 4.3: Comparison of the unbalanced EMC calculated mineralogy with the unbalanced QEMSCAN measured mineral grades for all samples.

Figure 4.4 compares mass balanced EMC mineral grades to the unbalanced EMC mineral grades. The results highlight to what extent differences exists between balanced and unbalanced data. There is minor adjustment between balanced and unbalanced data as the $\mathrm{R}^{2}$ value was above 0.95 . This confirms that the method was suitable for the polymetallic ore in question. 


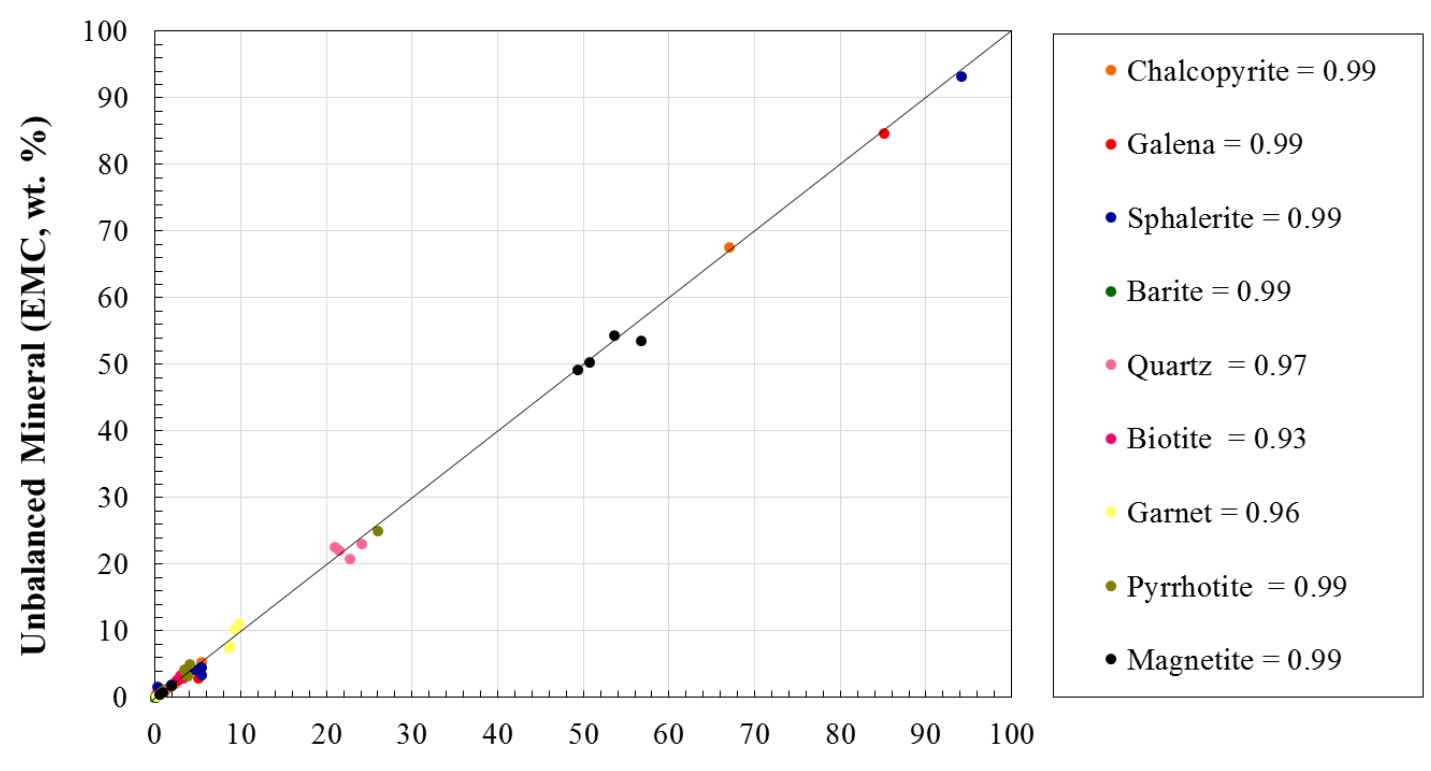

Balanced Mineral (EMC, wt. \%)

Figure 4.4: Comparison of the unbalanced EMC calculated mineralogy with the balanced EMC measured mineral grades for all samples.

\subsection{Characterisation of acid rock drainage potential}

The mass balanced mineralogy results determined from the EMC were used to calculate the acid rock drainage (ARD) potential of the tailings using a combination of the Paktunc (1999) and Lawrence and Scheske (1997) approaches. This is supported by various studies that have tracked the actual contribution of different minerals in standard laboratory chemical ARD tests (Jambor et al., 2002; Plante et al., 2012; Becker et al., 2015). The AP calculation was based on the pyrrhotite mineral grade (including pyrite by virtue of its subgrouping with pyrrhotite), chalcopyrite, Fe bearing sphalerite and galena mineral grades from the EMC calculation. The AP calculations were based by the stoichiometric reaction of the sulfide minerals as demonstrated on the equations below. These equations give an indication of the number of moles of the acid generated which is used in the AP calculation. The number of moles of chalcopyrite were calculated using Equation (4.1), whilst the number of moles for sphalerite and galena were calculated using Equation (4.2) and (4.3) respectively.

$$
\begin{aligned}
& 2 \mathrm{CuFeS}_{2}+\frac{17}{2} \mathrm{O}_{2}+5 \mathrm{H}_{2} \mathrm{O} \rightarrow 2 \mathrm{Cu}^{2+}+2 \mathrm{Fe}(\mathrm{OH})_{3}+4 \mathrm{SO}_{4}{ }^{2-}+4 \mathrm{H}^{+} \\
& \mathrm{Zn}_{0.9} \mathrm{Fe}_{0.1} \mathrm{~S}^{+} 2 \mathrm{O}_{2} \rightarrow 0.9 \mathrm{Zn}^{2+}+0.1 \mathrm{Fe}+\mathrm{SO}_{4}{ }^{2-}
\end{aligned}
$$


$\mathrm{PbS}+2 \mathrm{O}_{2} \rightarrow \mathrm{Pb}^{2+}+\mathrm{SO}_{4}^{2-}$

The neutralising potential was assessed considering the mineral grade of potentially neutralising minerals containing non-oxidisable cations. In deciding which minerals to include in the neutralisation calculation, one also needs to consider their relative weathering rates (Lawrence and Scheske, 1997). The dissolving carbonate minerals (e.g. calcite, dolomite) can be readily included in the calculation, and similarly 'fast weathering' silicate minerals (e.g. anorthite, forsterite), 'intermediate' weathering silicate minerals may also provide some contribution to the neutralising capacity. Calculation of the neutralising potential considered an initial list comprising all minerals which have a theoretical potential for neutralisation; namely garnet, chlorite, biotite, amphibole, feldspar and quartz (Lawrence and Scheske, 1997). From this list, further consideration was given to which minerals contained nonoxidisable cations. Based on the strong Fe-Mn tenor of the ore body, the majority of the aforementioned silicate minerals were subsequently excluded due to the presence of Fe-Mn garnet (almandine spessartine), Fe-rich chlorite (chamosite), Fe-rich biotite (annite), Fe-rich amphibole (grunerite) in the ore (see Table 4.4). Fe occurs in significant amount $(40.4$ wt. \%) in the final tails (zinc) followed by Mn (2.8 wt. \%) (see table 4.1). Magnetite was excluded from the calculation since it also contains a single oxidisable cation $\left(\mathrm{Fe}^{2+} \mathrm{Fe}^{3+}{ }_{2} \mathrm{O}^{2-}{ }_{4}\right)$, even though it may provide some intermediate buffering capacity (Moncur et al., 2009). Quartz is inert and was excluded from the calculation. On this basis, the calculation of NP is redundant for this particular sample.

Table 4.9: Summary of the relative potential contribution of the various minerals in terms of their acid forming or neutralising capacity.

\begin{tabular}{|l|l|l|}
\hline Mineral & Mineral chemistry & Classification \\
\hline Chalcopyrite & $\mathrm{CuFeS} 2$ & Acid forming \\
\hline Galena & $\mathrm{PbS}$ & Acid forming \\
\hline Sphalerite & $\mathrm{Zn}_{0.9} \mathrm{Fe}_{0.1} \mathrm{~S}$ & Acid forming \\
\hline Garnet & $\mathrm{Mn}_{3} \mathrm{FeAl}_{2}(\mathrm{SiO} 4)_{3}$ & Contains oxidisable cations, excluded from calculations. \\
\hline Biotite & $\mathrm{KFe}_{3} \mathrm{AlSi}_{3} \mathrm{O}_{10}(\mathrm{OH})_{2}$ & Contains oxidisable cations, excluded from calculations. \\
\hline Pyrrhotite & $\mathrm{Fe}_{7} \mathrm{~S}_{8}$ & Acid forming \\
\hline Magnetite & $\mathrm{Fe}_{3} \mathrm{O}_{4}$ & Contains an oxidisable cation, excluded from calculation. \\
\hline Quartz & $\mathrm{SiO}_{2}$ & Inert \\
\hline
\end{tabular}

\subsection{Base case analysis}

\subsubsection{Flotation performance}

The overall performance of the flotation circuit in terms of mineral grade and recovery is summarised in Table 4.10. The mineral grades were obtained from EMC and the recoveries were calculated from the mass balance on SIM mass balance module. Balanced mineral grades of the different streams from are illustrated in Figure 4.5. The recovery of chalcopyrite was $77 \%$ with a mineral grade of 67 wt. $\%$. 
The copper (chalcopyrite) concentrate showed moderate dilution with pyrrhotite (26 wt. \%), and minor dilution of sphalerite ( $2 \mathrm{wt}$. \%) and galena (3 wt. \%). Zinc (sphalerite) and lead (galena) achieved higher recoveries over $90 \%$. The lead concentrate had a high grade ( $85 \mathrm{wt}$. \% galena) with minor dilution by chalcopyrite $(5$ wt. \%), sphalerite (4 wt. \%), garnet (1 wt. \%) and quartz (1 wt. \%). The sphalerite concentrate had the highest grade (94 wt. \%) of the three circuits with minor dilution by chalcopyrite ( 2 wt. \%) and galena (3 wt. \%). The final tailings dominantly consisted of magnetite (57 wt. \%), quartz (24 wt. \%) and garnet (10 wt. \%) with lesser pyrrhotite (4 wt. \%) and the three minerals of value $(0.2$ wt. \%).

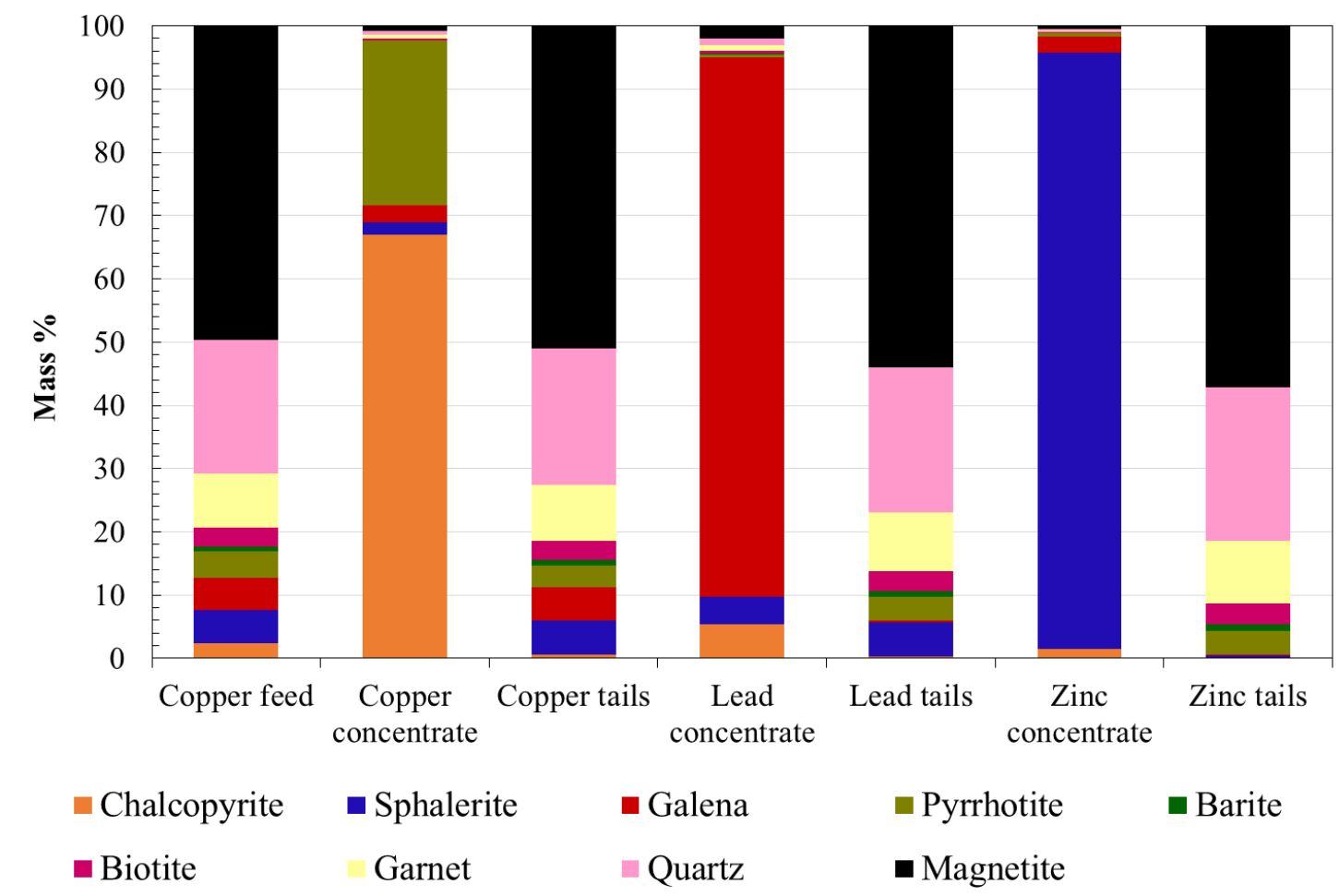

Figure 4.5: Balanced mineral grades across the flotation circuit, calculated using the EMC method.

Table 4.10: Balanced valuable mineral grade and recovery. Mineral grades were obtained from EMC and the recovery was calculated from SIM mass balance module.

\begin{tabular}{|l|l|c|c|}
\hline Circuit & Mineral & Grade (\%) & Recovery (\%) \\
\hline Copper & Chalcopyrite & 67.0 & 77.1 \\
\hline Lead & Galena & 85.1 & 94.6 \\
\hline Zinc & Sphalerite & 94.1 & 96.1 \\
\hline
\end{tabular}

Evaluating the recovery of different mineral species on a recovery by size basis provides a useful approach to understanding the causes for losses and dilution as summarised in Table 4.11, which can be later confirmed with actual quantitative mineral liberation data. Fine liberated valuable minerals (see 1 in Table 4.11) can be lost to the tailings due to insufficient reagent dosage as they have higher surface 
area per unit mass. They therefore have a lower probability of particle-bubble interaction thus making them slower to float into the concentrate, thus reducing grade and recovery (Feng and Aldrich, 1999; Wills and Napier-Munn, 2006; Cropp et al., 2013). Coarse valuable mineral composites locked with gangue may also be lost to the tailings if are too heavy to be floated or if they do not have sufficient surface area to be exploited by reagent (see 2 in Table 4.11). Loss of valuable minerals in the ideal flotation particle size range (see 3 in Table 4.11) suggests possible surface coating or non-ideal collector and dosage.

Dilution of the concentrate through the recovery of gangue minerals in the coarse particle sizes suggests possible locking with valuable minerals (see 4 in Table 4.11). Recovering these minerals will increase recovery but compromise the grade of the concentrate. Rejecting these will reduce recovery and produce good concentrate grade but with the possibility of losing valuable minerals locked in gangue. Recovery of fine gangue minerals is generally attributed to entrainment (see 5 in Table 4.11), which is the unselective recovery of both value and gangue minerals as a function of water recovery to the concentrate and it is effective in particle sizes less than $38 \mu \mathrm{m}$ (Johnson, 1972; Smith and Warren, 1989). Recovery of gangue minerals in the intermediate particle size ranges suggests inadvertent gangue activation or naturally floating gangue (see 6 in Table 4.11).

Table 4.11: Common causes for low grade and recovery in the flotation circuit. They are demonstrated relative to particle size (Cropp et al., 2013).

\begin{tabular}{|l|l|}
\hline Losses to Tailings & \\
\hline 1) Fine, liberated Minerals &
\end{tabular}

For this case study, the low chalcopyrite recovery and contamination by pyrrhotite in the copper concentrate could suggest the recovery of coarse composites of chalcopyrite and pyrrhotite. Liberation measurements would be needed to establish if this is the case. Activated pyrrhotite gangue could be another reason for the dilution caused by the imbalance between reagent concentration and $\mathrm{pH}$. In this case, ensuring sufficient lime addition to maintain an alkali $\mathrm{pH}$. The loss of sphalerite to the copper and zinc concentrates suggests inadequate depression of sphalerite in these earlier stages of flotation. It 
would be important to understand in which particle sizes these sphalerite losses occur: losses due to fine locked sphalerite in chalcopyrite and galena would motivate for more liberation, whereas loss of liberated sphalerite would indicate an operational or reagent problem. More detailed recovery by size, and recovery by size by liberation analysis of the results would provide more insight into the mechanisms resulting in the concentrate dilution and losses (Sutherland et al., 1988; Pease et al., 2006; Cropp et al., 2013).

To further demonstrate the usefulness of the framework, a simple mineral splitter function model was developed. The mineral splitter function is limited as it assumes that the splitting ratio is the same even when the amount of minerals has changed in the feed. The mineral splitter function was considered to be adequate as the first pass in the development of such a framework, because the purpose of this study was to demonstrate the conceptual approach and potential application of the sustainability modelling framework. The unit model parameters were percent mineral recoveries of the feed material to the flotation banks as demonstrated in Equation 4.4 and 4.5. Where $i$ represent mineral, $T$ denotes tailings stream, $C$ is the concentrate steam, $k$ is the elemental assay $(\mathrm{Cu}$ or $\mathrm{Pb}$, or $\mathrm{Zn})$ and $R$ represents recovery. These percent recoveries were back-calculated from the mineral mass balance of the flotation circuit. In reality mineral recoveries in the flotation bank vary with changes in equipment settings, operation parameters, and slurry characteristics. The model used in this study does not take this into account and in future, additional parameters considered to calculate mineral recovery will need to be integrated. Table 4.12 gives the mineral distribution across the circuit for each mineral in the feed stream. There was a significant recovery of pyrrhotite $(18 \%)$ in the copper bank flowed by minor recoveries of the minerals of interest galena (1.4\%) and sphalerite (1.0\%). This further supports that the low grade and recovery for copper (chalcopyrite) concentrate was due to significant presence of pyrrhotite. The lead bank was diluted by the recovery of chalcopyrite $(13.0 \%)$ followed by minor recovery of sphalerite $(4.6 \%)$. This could have contributed to diluting the lead concentrate to $85 \mathrm{wt}$. \%. There was minor dilution in the zinc bank by recovery of chalcopyrite (3.4 wt. \%) and galena (2.6 wt. \%) which this demonstrates that the lead (sphalerite) concentrate was the least diluted compared to copper (chalcopyrite) and lead (galena) concentrates. A size by size liberation data will be required to understand if the recoveries are due to the nature of the ore or operational performance of the circuit. This information forms the basis for the application of the framework presented in Chapter 5.

Mineral flow to concentate streami $=R C, \times$ Total solids flowrate to concentrator $\times k$

Mineral flow to tailings streami $=(1-R C$,$) \times Total solids flowrate to concentrator \times k$ 
Table 4.12: Mineral recoveries across the different streams within the flotation circuit. Mineral recovery is expressed in \%.

\begin{tabular}{|l|c|c|c|}
\hline Mineral & Copper bank & Lead bank & Zinc bank \\
\hline Chalcopyrite & 77.1 & 13.0 & 3.4 \\
\hline Galena & 1.4 & 94.6 & 2.6 \\
\hline Sphalerite & 1.0 & 4.6 & 96.1 \\
\hline Barite & $<0.1$ & 0.3 & 0.1 \\
\hline Garnet & 0.2 & 0.6 & 0.1 \\
\hline Biotite & 0.3 & 1.0 & 0.3 \\
\hline Quartz & 0.1 & 0.3 & 0.1 \\
\hline Pyrrhotite & 18.0 & 0.7 & 0.8 \\
\hline Magnetite & $<0.1$ & 0.2 & 0.1 \\
\hline
\end{tabular}

\subsubsection{Acid rock drainage characterisation}

The mass balanced mineralogy results determined from the EMC were used to calculate the ARD potential of the tailings using the Paktunc (1999) method. Table 4.13 summarises the ARD potential of the final tailings. The NP was estimated as $0 \mathrm{~kg} \mathrm{H}_{2} \mathrm{SO}_{4} / \mathrm{t}$ as the tailings did not contain any minerals capable of providing neutralising capacity. The calculated AP was $46.4 \mathrm{~kg} \mathrm{H}_{2} \mathrm{SO}_{4} /$ ton indicating the tailings have a theoretical potential to generate acid rock drainage. The assumption of combining pyrite and pyrrhotite in the EMC slightly underestimates the ARD estimation (48.9 $\mathrm{kg} \mathrm{H}_{2} \mathrm{SO}_{4} / \mathrm{t}$ if calculated using QEMSCAN mineral grades of pyrrhotite and pyrite (see Table 4.14), however, in both cases the waste is potentially acid forming. Note that this calculation does not provide information on the relative kinetics of acid generation or specifics on the characteristics of the ARD (e.g. metal deportment). More detailed static and kinetic tests would be required to obtain this information (e.g. Parbhakar-Fox et al., 2011). 
Table 4.13: Acid rock drainage potential of the final tailings calculated using balanced, EMC results. Pyrite AP contribution is grouped under pyrrhotite.

\begin{tabular}{|l|l|}
\hline Parameter & Value \\
\hline Neutralising minerals & None \\
\hline Neutralising potential $\left(\mathrm{kg} \mathrm{H}_{2} \mathrm{SO}_{4} / \mathrm{t}\right)$ & 0 \\
\hline Acid producing minerals & pyrrhotite, chalcopyrite, galena and sphalerite \\
\hline Acid producing potential value $\left(\mathrm{kg} \mathrm{H}_{2} \mathrm{SO}_{4} / \mathrm{t}\right)$ & 46.4 \\
\hline Net acid producing potential & 46.4 \\
\hline Classification & Potentially acid forming \\
\hline
\end{tabular}

Table 4.14: Acid rock drainage potential of the final tailings calculated using unbalanced QEMSCAN data. Pyrite AP contribution is calculated separately.

\begin{tabular}{|l|l|}
\hline Parameter & Value \\
\hline Neutralising minerals & None \\
\hline Neutralising potential $\left(\mathrm{kg} \mathrm{H}_{2} \mathrm{SO}_{4} / \mathrm{t}\right)$ & 0 \\
\hline Acid producing minerals & pyrrhotite, chalcopyrite, galena and sphalerite \\
\hline Acid producing potential value $\left(\mathrm{kg} \mathrm{H}_{2} \mathrm{SO}_{4} / \mathrm{t}\right)$ & 48.9 \\
\hline Net acid producing potential & 48.9 \\
\hline Classification & Potentially acid forming \\
\hline
\end{tabular}




\section{Chapter 5}

\section{Application of the integrated modelling framework}

This chapter demonstrates the application of the developed framework as a tool to evaluate scenario analysis in process operation. In demonstrating the application of the integrated modelling framework, different hypothetical scenarios are proposed including sensitivity analysis. In this chapter, the downstream effects of concentrate quality and payable grade during smelting is discussed. The section is followed by evaluating operational scenarios that can have an impact on the quality of the product and the potential of acid rock drainage (ARD) formation in the final tailings.

\subsection{The effects of final copper grade on net smelter return}

The purpose of the concentrator is to produce high grade concentrate as the quality of the concentrate determines the financial return per tonne of ore. Many polymetallic mines do not own downstream refining processes (smelter operation) so they regularly have to transport their concentrate for further refinement (Wills and Napier-Munn, 2006) ). Net smelter return (NSR) is the net revenue that the mine concentrator receives from the sale of concentrator metal products less transportation and refining cost (Equation 5:1; Figure 5.1) (Goldie, 1991; Wills, 2006). NSR is used as a criterion for optimizing extraction and beneficiation of ore according to the quality of the concentrates (Malewski and Krzeminska, 2012). A high NSR is desirable and is obtained at the optimum concentrate grade whereas smelting of low grade concentrate will incur penalties relative to the smelter contractual agreements for harmful impurities, resulting in a low NSR. 


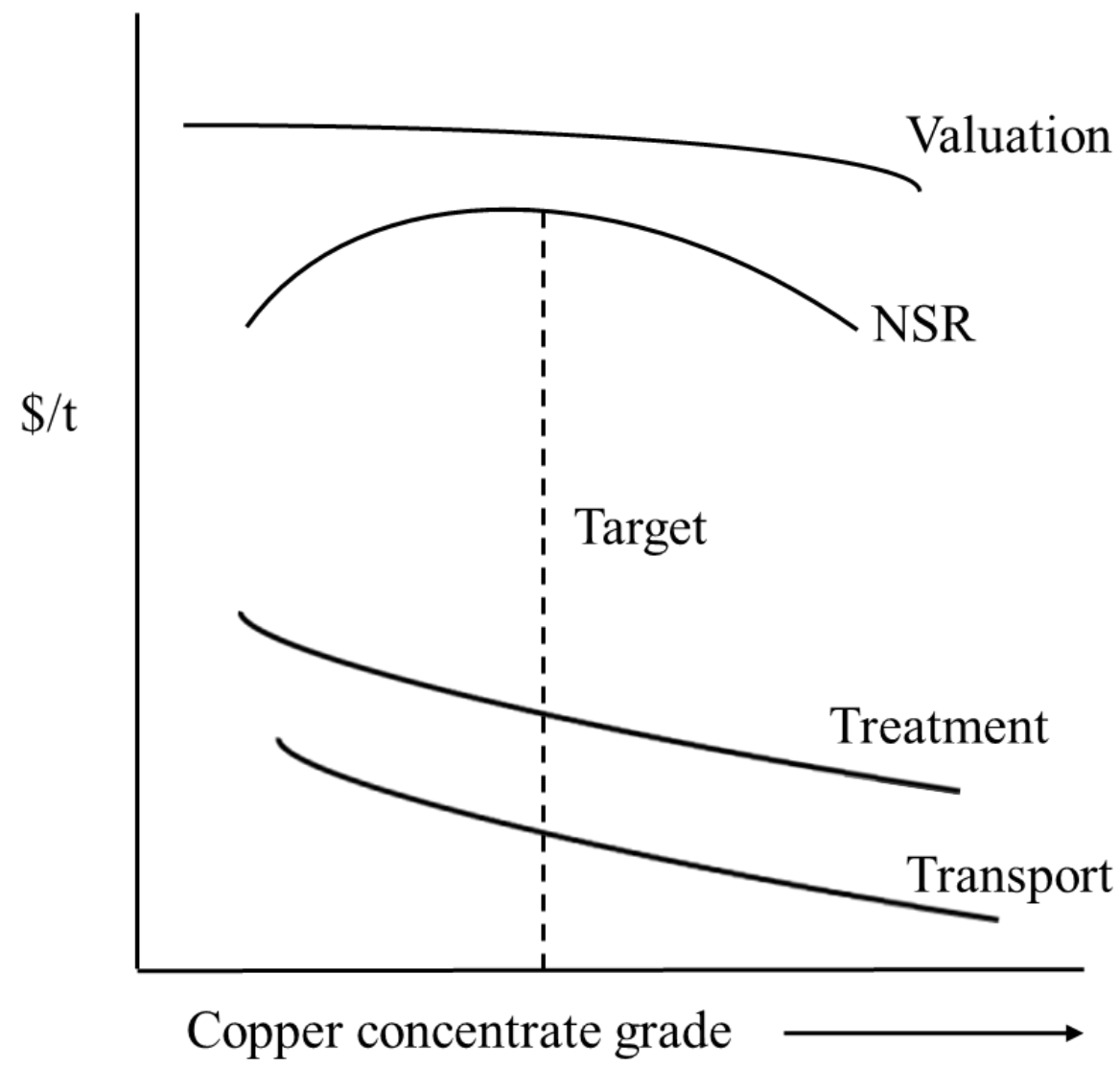

Figure 5.1:Payments and charges with concentrate grade (Wills and Napier-Munn, 2006).

$N S R=\left[\sum_{i}\left(\beta_{i} \cdot \delta_{i} \cdot p_{i}\right)-(M C+D C)-P+B\right] \cdot \gamma_{1}$ (equation taken from Malewski and Krzeminska, 2012).

where NSR - net smelter return measured in \$ per $1 \mathrm{Mg}$ of ore,

$\beta \mathrm{i}$ - share of $\mathrm{i}$-component (metal) in the main product (concentrate) (grade)

$\delta_{i}$ - payable part of metal in concentrate

$p_{i}$ - price of the i-component in the open market

$\mathrm{MC}=\mathrm{TC}+\mathrm{RC}-$ metallurgical charge

$\mathrm{TC}$ - treatment (smelting) charge dependent on quality of concentrate.

$\mathrm{RC}$ - refining charge, \$/unit of metal

DC- cost of delivery ex-recipient

$\mathrm{P}$ - penalties for the presence of harmful components (according to contract terms)

B - bonuses for the presence of desirable components (according to contract terms)

$\gamma 1=1-\gamma 2$ - yield of the concentrate from the feed (ore) 


\section{Payment for metal contained}

Payable metal is described as the quality of the metal contained in the concentrate (e.g. $\mathrm{Cu}$ ) that is paid to the miner by the smelter. Payable copper $(\mathrm{Cu})$ concentrate is usually between 1.0 to 1.4 units less than the copper contained in the concentrate (Goldie et al., 1991). Precious metals such silver (Ag) and gold $(\mathrm{Au})$ have a positive impact on the revenue of the mine. Copper (chalcopyrite) and lead (galena) concentrates get payments if silver and gold are present in their concentrates, whereas zinc (sphalerite) concentrates do not get any additional payments (Wills and Napier-Munn, 2006).

\section{Transportation Cost}

This is the cost of transporting the concentrate from the mine to the smelter. A lower grade concentrate will incur high smelter and transportation cost. The grade of the $\mathrm{Cu}$ concentrate in this case study was 23 wt. \% which classifies as a low grade concentrate (Goldie, 1991; Wills and Napier-Munn, 2006) due to significant dilution of $\mathrm{Fe}(37 \mathrm{wt}$ \%) and S (34 wt. \%) as demonstrated in Figure 5.2. These elements are the constituent elements of the mineral pyrrhotite (see Table 4.5). The payable copper content is therefore calculated as $96 \%$ as illustrated in Figure 5.3.

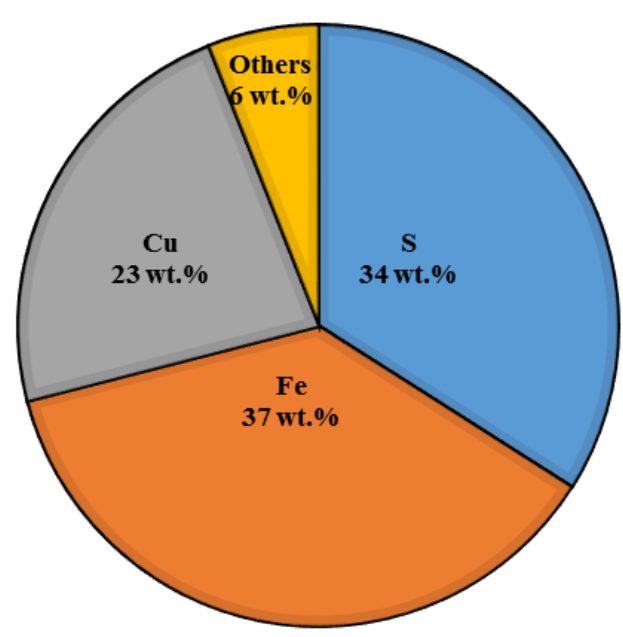

Figure 5.2: The elemental composition of a concentrate produced from the base case. 


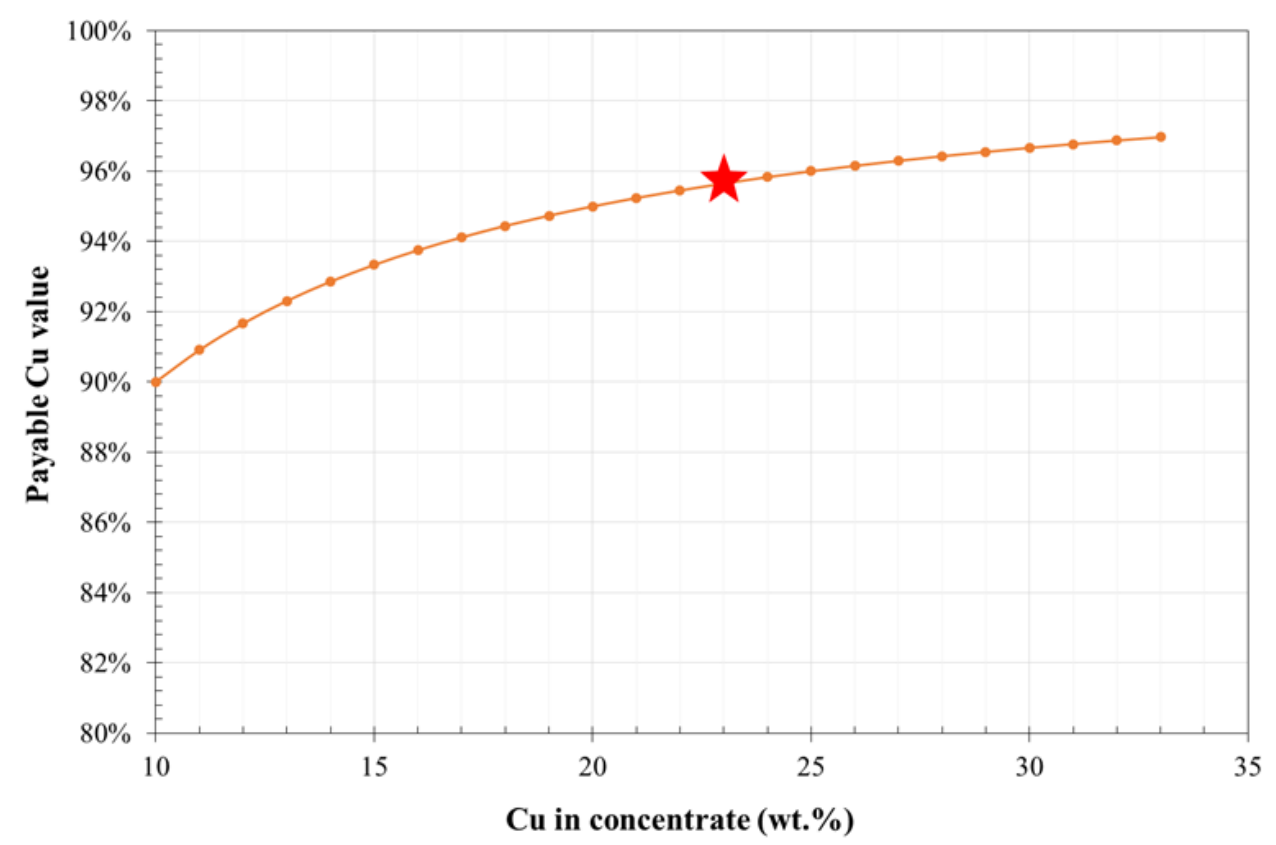

Figure 5.3: The relationship between final copper concentrate grade and percentage payable $\mathrm{Cu}$ concentrate of the base case. The asterisk indicates the copper content of the base case.

\section{Smelting charges}

Concentrates are transported to smelters where valuable metals are extracted and purified. A smelter does not pay for all the metals in the concentrate which it processes, as penalties are imposed on the miner if their concentrate is diluted with other metals and impurities. There are penalty costs for the presence of sphalerite and galena in chalcopyrite concentrate ( $\mathrm{Cu}$ concentrate), as well as sphalerite (zinc) present in the galena (lead) concentrate (Goldie, 1991;Wills and Napier-Munn, 2006). In general polymetallic mines produce poor grades and recoveries (Wills and Napier-Munn, 2006). Penalty costs are also imposed on the mine if their concentrates contains impurities such as $\mathrm{Fe}, \mathrm{Mn}$ and Si because they increase energy consumption (Evans et al., 2011). Other elements that impose penalty cost are antimony, bismuth, arsenic, fluorine, cadmium, mercury, selenium, tellurium and thallium. Table 5.1 shows impurity levels and the magnitude of the penalty. 
Table 5.1: Copper concentrate maximum impurity levels and approximate penalties (Salomon-defriedberg et al., n.d.).

\begin{tabular}{|l|c|c|}
\hline Element & Penalty limit (\%) & Penalty, \$/t per extra 0.1 \% \\
\hline Arsenic & 0.2 & 2 \\
\hline High arsenic & $>1$ & $>5$ \\
\hline Antimony & 0.05 & 15 \\
\hline Bismuth & 0.02 & 25 \\
\hline Cadmium & 0.03 & 30 \\
\hline Fluorine & 0.03 & 15 \\
\hline Lead & 1 & 0.3 \\
\hline Mercury & 0.0005 & 3000 \\
\hline Nickel and cobalt & 0.5 & 1 \\
\hline Selenium & 0.03 & 15 \\
\hline Zinc & 3 & 0.3 \\
\hline
\end{tabular}

\subsection{Scenario analysis}

Two scenarios were formulated based on the observations from the base case study: scenario I was improving copper (chalcopyrite) concentrate by addition of an appropriate flotation reagent to depress pyrrhotite so it can be recovered in tailings, scenario II considered installation of a magnetic separator on to the final tailings of the existing circuit to mitigate ARD in the waste stream. A sensitivity analysis was also conducted on both scenarios to assess the effect of pyrrhotite grade in the feed ore variability. In future when the framework has been fully developed, balance of increasing $\mathrm{Pb}, \mathrm{Zn}$ and $\mathrm{Cu}$ net smelter revenue will also be considered to minimise environmental impacts. Figure 5.4 demonstrates the matrix of the different scenarios considered for the study.

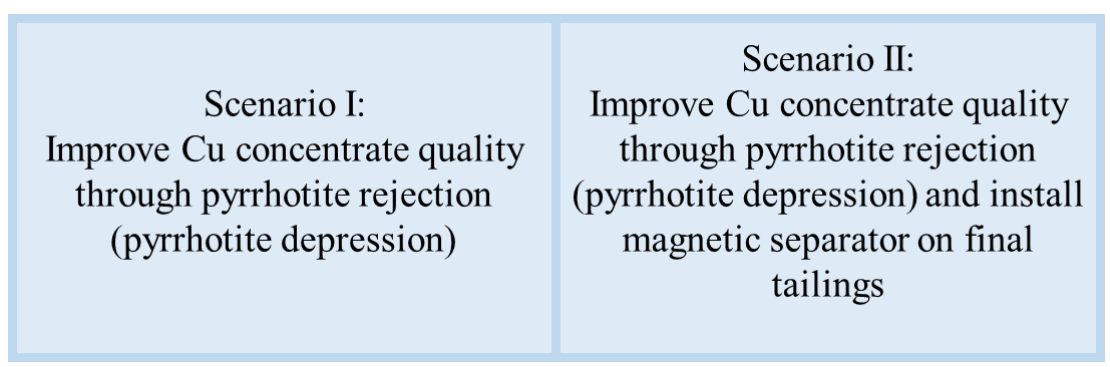

Sensitivity analysis

Variability in pyrrhotite feed grade

Figure 5.4: Matrix of the different scenario analysis considered for the study. 


\subsubsection{Scenario I: Improving copper (chalcopyrite) concentrate}

Scenario I considered means to improve the payable copper content the grade of the final copper (chalcopyrite) concentrate by rejecting pyrrhotite. This is because the results from the plant survey showed poor recovery of chalcopyrite $(77 \%)$ and a low $\mathrm{Cu}$ grade $(23 \mathrm{wt}$. \%) and payable copper content of $96 \%$. This in turn has a negative impact on the net smelter return and attracts penalty costs due to significant dilution of the concentrate. Without conducting liberation analysis, it is difficult to determine if the dilution was due to poor liberation or operational condition of the flotation circuit. In the absence of the liberation data and to demonstrate the use of the framework, it was assumed that the cause of pyrrhotite contamination was not a liberation problem but an operational one (e.g. reagent dosage). Therefore, conducting an analysing on liberation or size by size on the recovered concentrate grade could reveal more information on the behaviour of the minerals.

In considering this scenario (I), a Monte Carlo simulation was carried out varying the pyrrhotite recovery to concentrate from a minimum of $2 \%$ to a maximum of $18 \%$ and this was main input parameter to the simulation. The simulation parameters are presented in appendix $\mathrm{D}$. The recoveries of the other minerals were assumed to be constant and 25 runs were performed on the simulation. The variation of the pyrrhotite recovery was derived from base case which calculated the recovery of pyrrhotite to be $18 \%$ in the copper (chalcopyrite) concentrate. The simulation predicted the grade of pyrrhotite in the zinc (sphalerite) tails based on the predicted recovery. Subsequently, the predicted mineral grades were used to calculate the ARD potential by considering the difference between AP and NP. A consequence of this pyrrhotite rejection was the increased pyrrhotite grade in the final zinc tailings, and the associated increase in the mineralogically calculated ARD potential up to $53.9 \mathrm{~kg} \mathrm{H}_{2} \mathrm{SO}_{4} / \mathrm{t}$ for tailings with maximum pyrrhotite rejection (see Figure 5.5). Upgrading the copper (chalcopyrite) concentrate by removing $18 \%$ of pyrrhotite resulted in improved $\mathrm{Cu}$ grade (31 wt. \%) (see Figure 5.6) and a slightly higher payable copper content of $97 \%$ (see Figure 5.7). Elemental grades considered as impurities; Fe (34 wt. \%) and S (31 wt. \%) were also lower when compared to the base study (see Figure 5.6). 


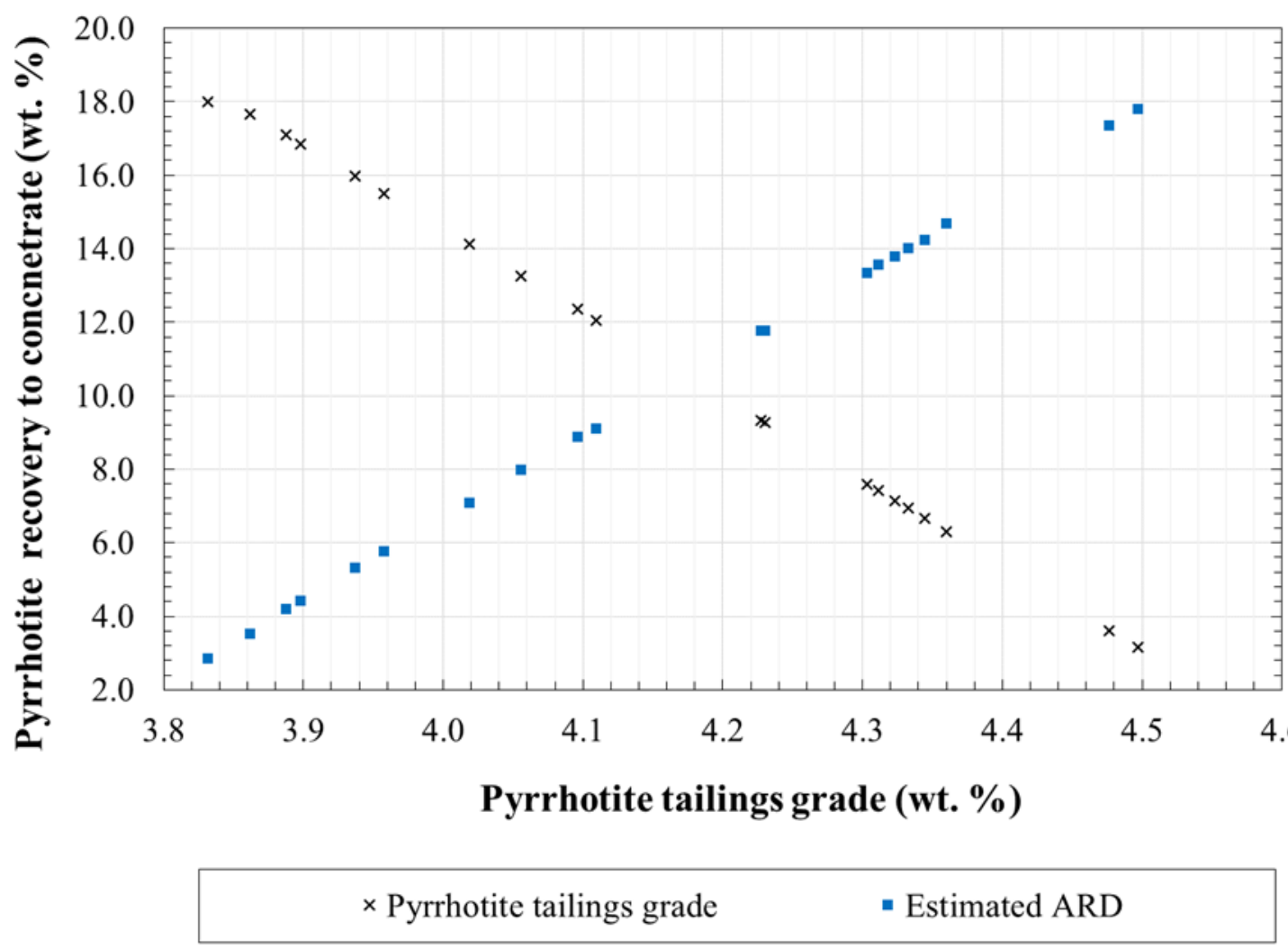

Figure 5.5: Correlation between predicted ARD potential and increased pyrrhotite grade in the final zinc tails for scenario $I$.

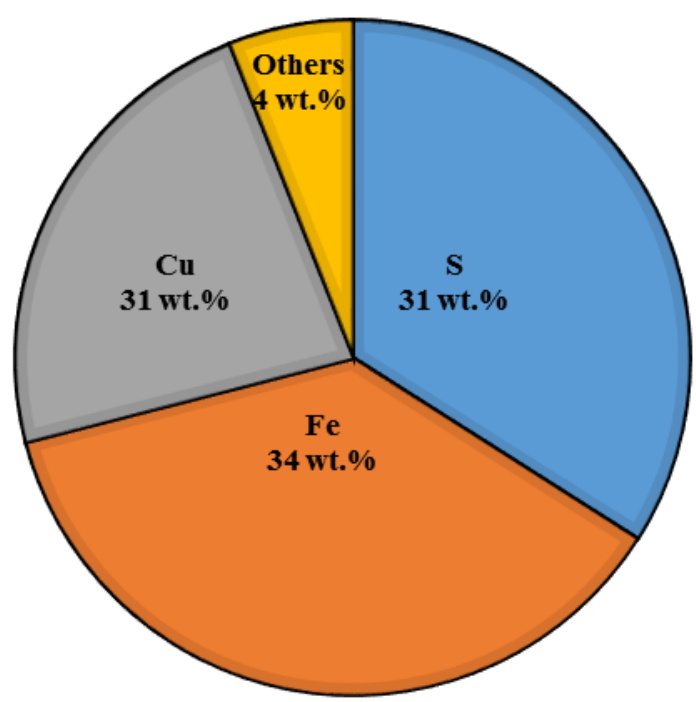

Figure 5.6: The elemental composition of a concentrate produced from the simulated $\mathrm{Cu}$ concentrate for scenario $I$. 


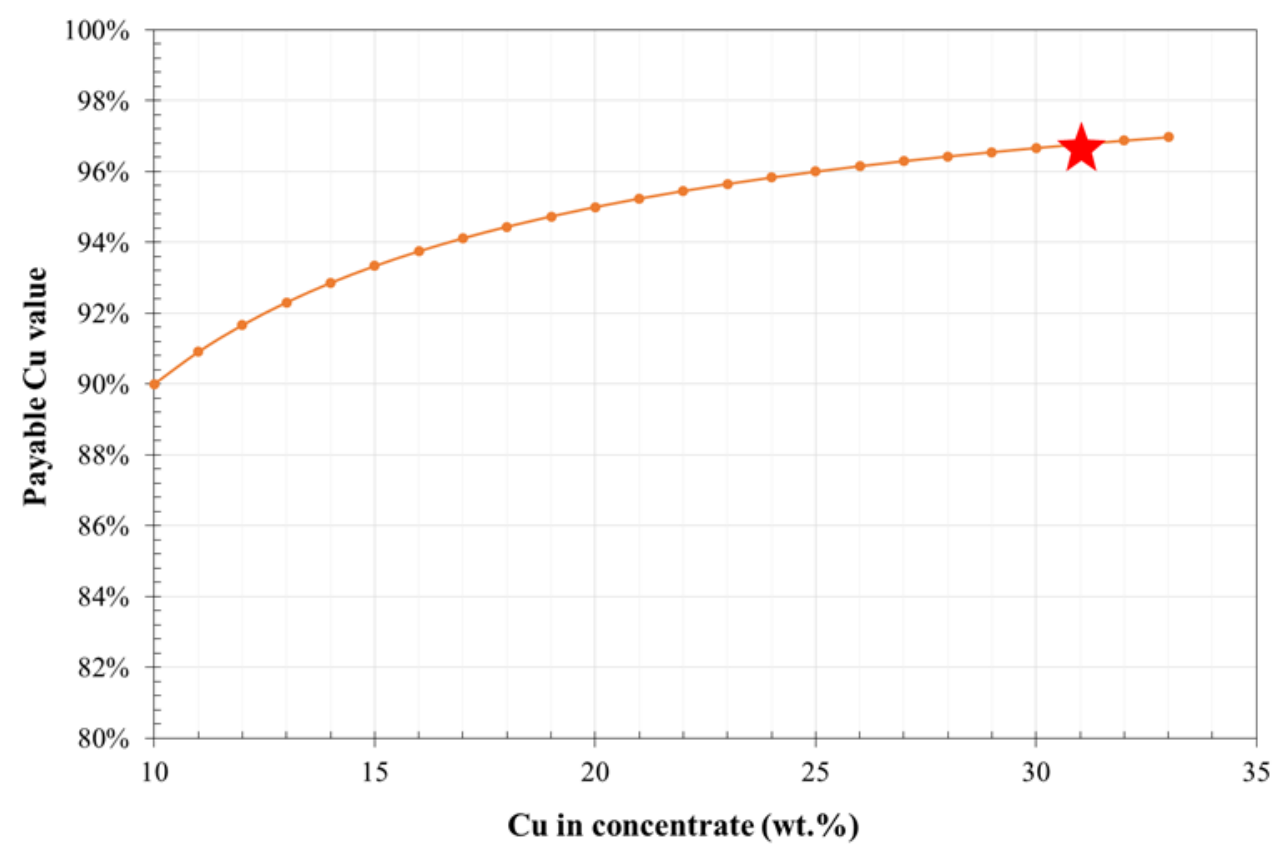

Figure 5.7: The relationship between final copper concentrate grade and percentage payable $\mathrm{Cu}$ concentrate for scenario I. The asterisk indicates the copper content of the simulated $\mathrm{Cu}$ concentrate for scenario $I$.

This suggest that improving copper concentrate grade can have positive impact on the net smelter return but has a potential effect on the acid formation in the final tails. The mine must therefore balance the trade-off, of improving the concentrate grade and finding measures to mitigate the potential of ARD formation.

5.2.2. Scenario II: Improving $\mathrm{Cu}$ (chalcopyrite) concentrate quality and installing a magnetic separator to remove pyrrhotite

The second scenario evaluates the impact of improving $\mathrm{Cu}$ (chalcopyrite) concentrate grade and installing a magnetic separator to remove pyrrhotite from the final tailings prior to disposal. Conventional magnetic separation devices are commonly used for the removal of tramp iron from different feed materials and for mineral processing of ferrous ores (Oberteuffer, 1974). The device separates material that is strongly magnetic, such as tramp iron, magnetite or pyrrhotite. Scenario I (see Figure 5.5) demonstrated that a significant amount of pyrrhotite was disposed into the tailings by further upgrading the copper concentrate and this had a downstream impact in increasing the ARD potential of the tailings. This scenario aims to evaluate if installing a magnetic separator prior to disposing the waste material will minimise the potential for ARD formation due to the removal of pyrrhotite from this waste stream. 
The pyrrhotite mineral family consists of a series of superstructures of varying composition $\left(\mathrm{Fe}_{1-\mathrm{x}} \mathrm{S}\right)$ and characteristics (Becker et al., 2010). Monoclinic pyrrhotite $\mathrm{Fe}_{7} \mathrm{~S}_{8}$ is ferrimagnetic and is amenable to magnetic separation. Magnetic separation has previously been applied across different commodities for the upfront rejection of pyrrhotite (Multani and Waters, 2017), and in nickel ores for the separation into magnetic and non-magnetic streams (Lawson et al., 2005; Schonewille et al., 2012). Historically, the case study site had a wet low intensity magnetic separator (WLIMS) in operation that recovered $90-95 \%$ of the magnetite ahead of the flotation circuit, and which is currently not being utilised.

In this scenario, it was assumed that all the pyrrhotite is magnetic and a flowsheet such as that given in Figure 5.8 is in operation. Similar to scenario I, pyrrhotite recovery to concentrate was varied between 2 and $18 \%$. It was assumed that the wet low intensity magnetic separator recovered $90 \%$ of both pyrrhotite and magnetite. This means that the remaining $10 \%$ of magnetite and pyrrhotite reported to the magnetic tails (final tails). The results show a decreased ARD potential for the final tails, due to the removal of pyrrhotite. The maximum calculated ARD was $15.4 \mathrm{~kg} \mathrm{H}_{2} \mathrm{SO}_{4} / \mathrm{t}$ (see Figure 5.9) which this was less than the estimated the ARD in Scenario I (53.9 $\mathrm{kg} \mathrm{H}_{2} \mathrm{SO}_{4} / \mathrm{t}$ ). An added advantage of such a scenario would be possible opportunities for further upgrading this magnetic stream to produce a saleable magnetite product and small volume pyrrhotite stream that can be disposed of accordingly (Hesketh et al., 2010; Harrison et al. 2015). The Cu grade (31 wt. \%) (see Figure 5.10) and the payable copper content $(97 \%)$ (see Figure 5.11) are similar to scenario I

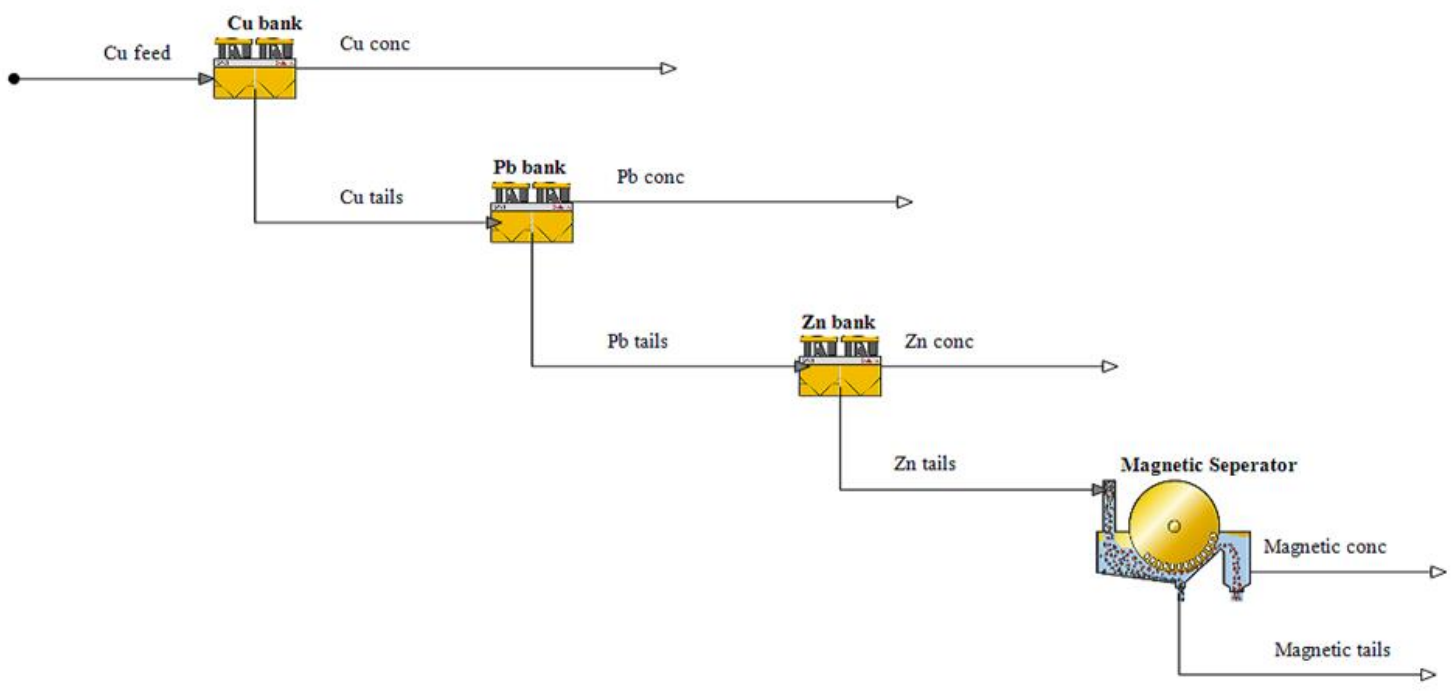

Figure 5.8: Flowsheet of the case study flotation circuit with a magnetic separator for scenario II. 


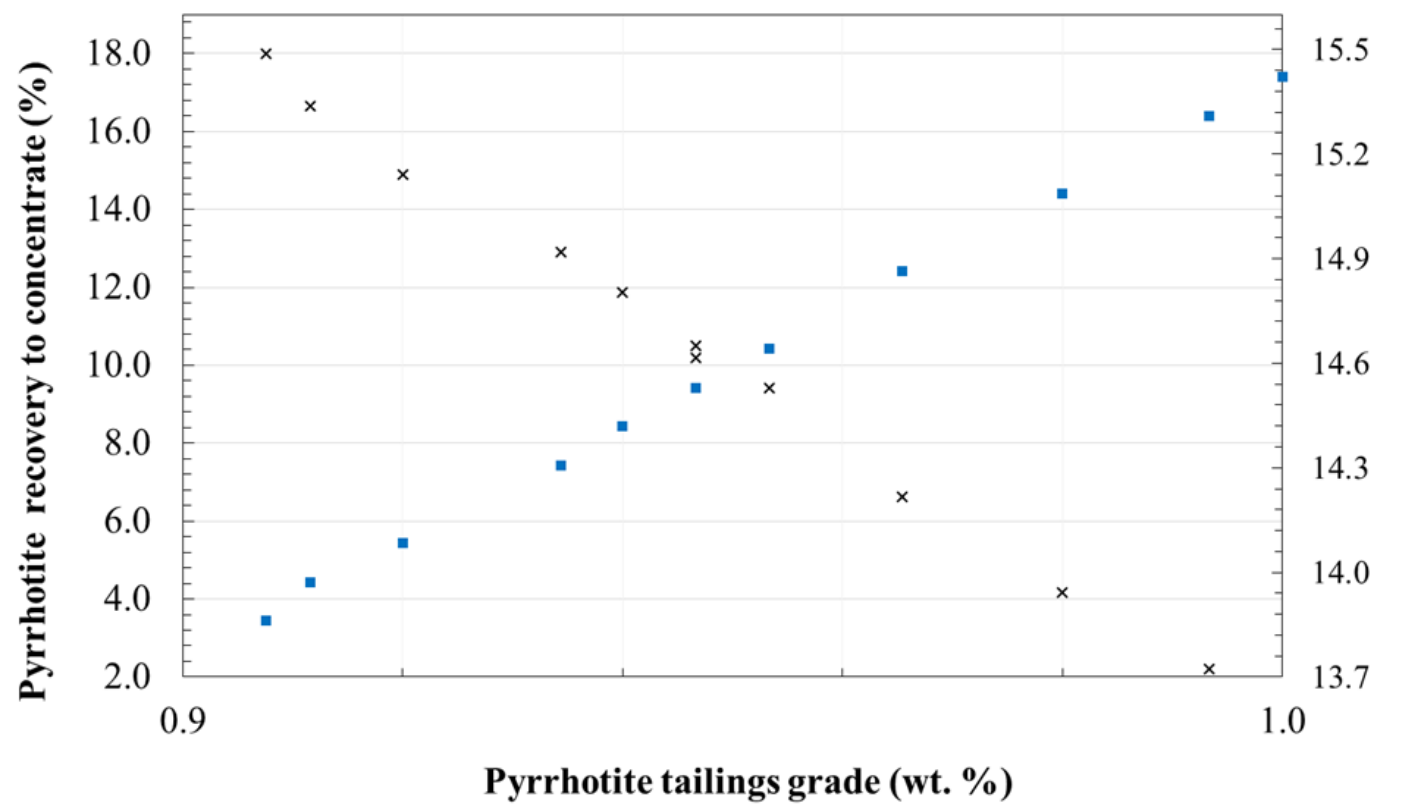

$\times$ Pyrrhotite tailings grade - Estimated ARD

Figure 5.9: Correlation between predicted ARD potential and increased pyrrhotite grade in the final magnetic tails for scenario II.

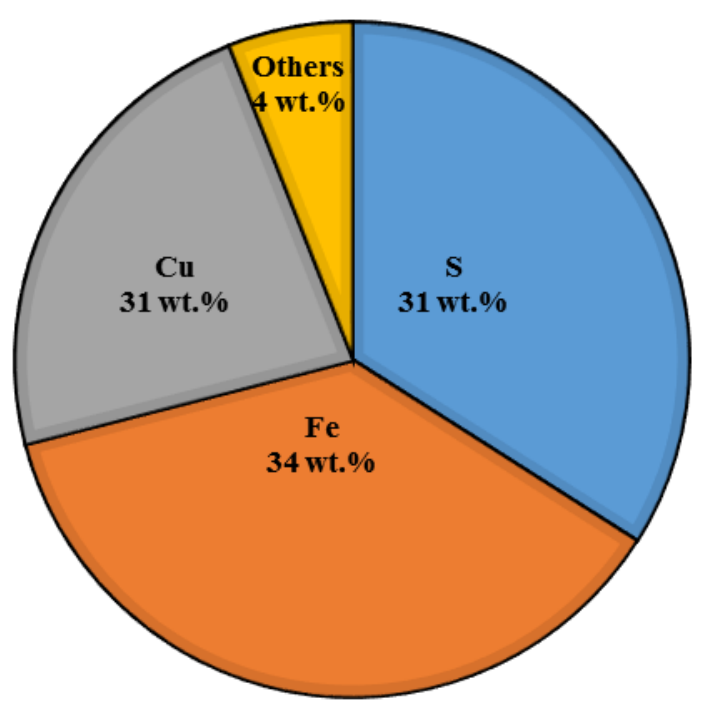

Figure 5.10: The elemental composition of a concentrate produced from the simulated Cu concentrate with a magnetic separator for scenario II. 


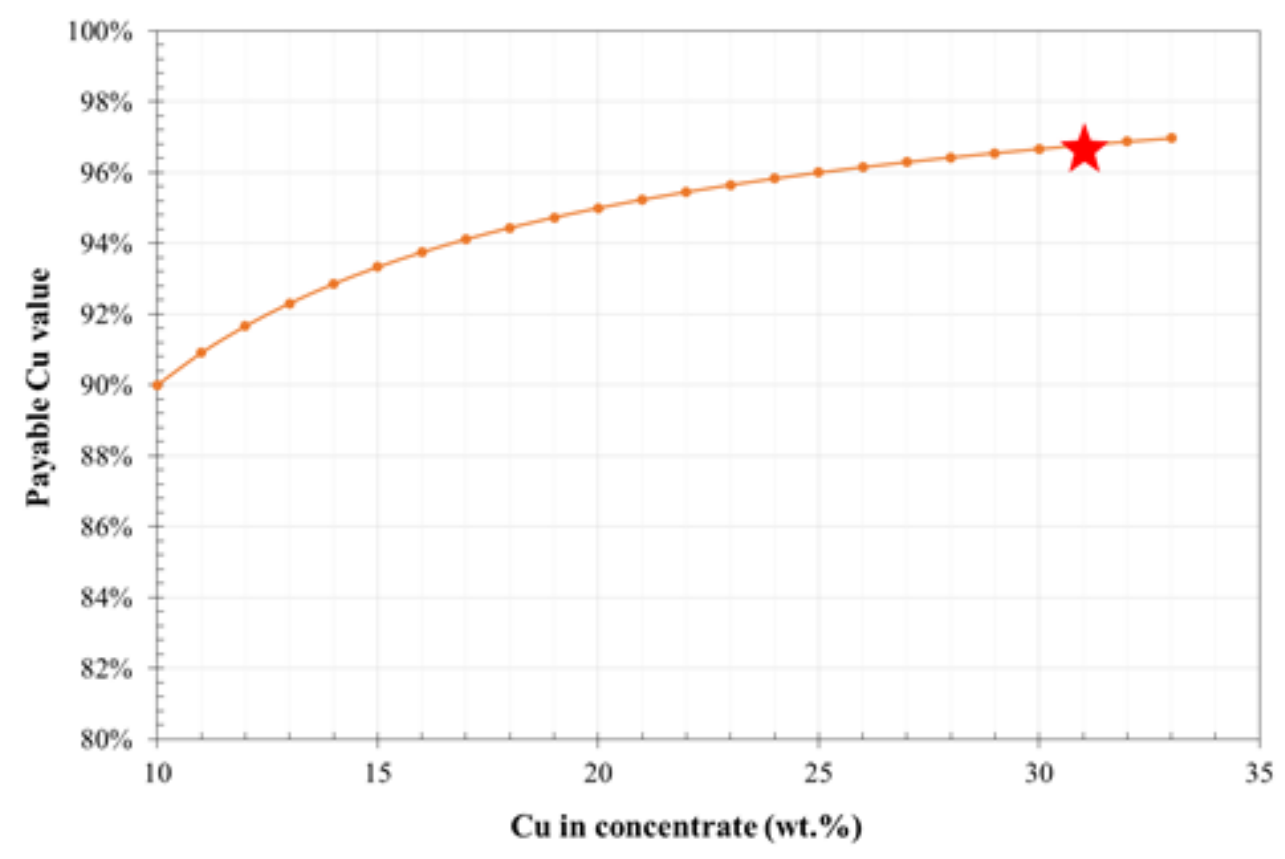

Figure 5.11: The relationship between final copper concentrate grade and percentage payable $\mathrm{Cu}$ concentrate for scenario II. The asterisk indicates the copper content of the improved Cu concentrate with a magnetic separator for scenario II.

\subsubsection{Sensitivity analysis of scenario I: Changes in feed ore variability}

The sensitivity analysis of scenario I of varying pyrrhotite feed grade to the flotation circuit was investigated. The pyrhotite feed grade was hypothetically varied between $10 \mathrm{wt} \%$ and $100 \mathrm{wt} . \%$ of the base case (4 wt. \%) and this was the main input to the simulation. All mineral recovery values were kept at base case value and the simulation calculated the final grade of pyrrhotite in the tailings based on this assumption. The results of the Monte Carlo simulation show a direct correlation between increased pyrrhotite feed grade with mineralogically calculated ARD potential, as illustrated in Figure 5.12. For a hypothetical pyrrhotite feed grade of approximately $8 \mathrm{wt}$. \%, the mineralogically calculated ARD potential is close to $89.6 \mathrm{~kg} \mathrm{H}_{2} \mathrm{SO}_{4} / \mathrm{t}$ of tailings (see Figure 5.12). The $\mathrm{Cu}$ grade (20 wt. \%) and payable copper content (95\%) were lower than the base case (see Figure 5.13 and 5.14 respectively). Comparison between these scenarios I and the sensitivity analysis demonstrate that managing the effects of ore variability is likely to be a more significant operational challenge than improving copper concentrate quality. This is because mineralogically calculated ARD potential and the dilution of the $\mathrm{Cu}$ concentrate were greater for scenario II compared to scenario I. 


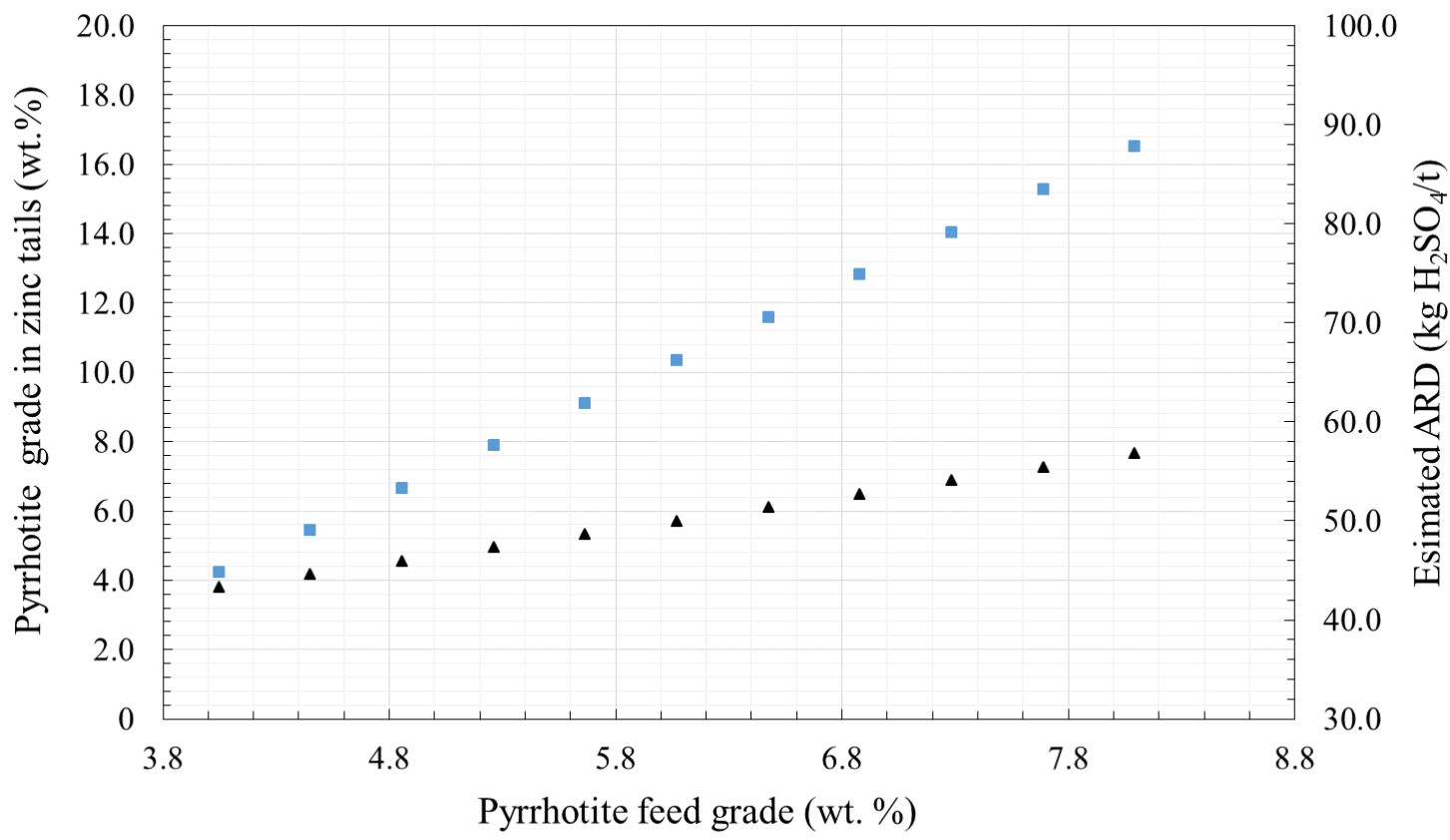

\ Pyrrhotite feed grade $\quad$ Estimated ARD

Figure 5.12: Correlation of modelled ARD potential and increased pyrrhotite grade in the feed for sensitivity analysis of scenario $I$.

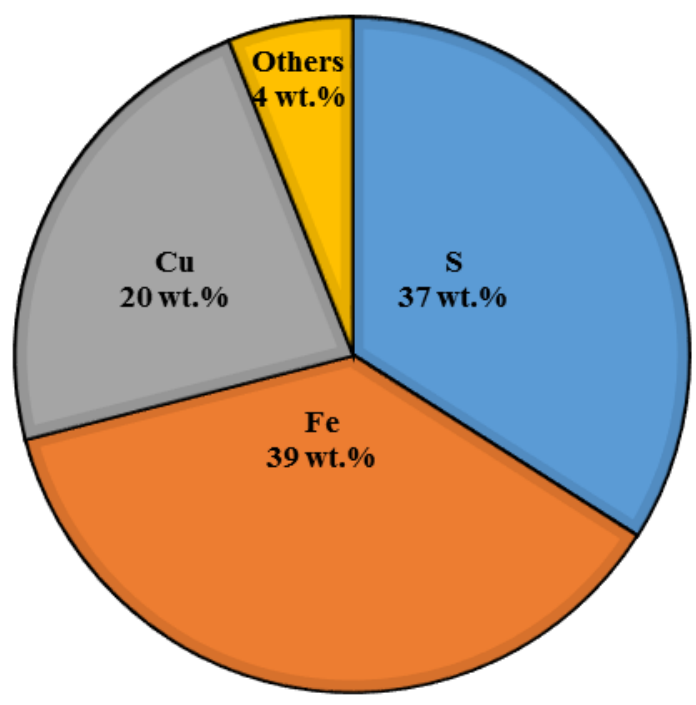

Figure 5.13: The elemental composition of a concentrate produced from the changes in ore variability for sensitivity analysis of scenario I. 


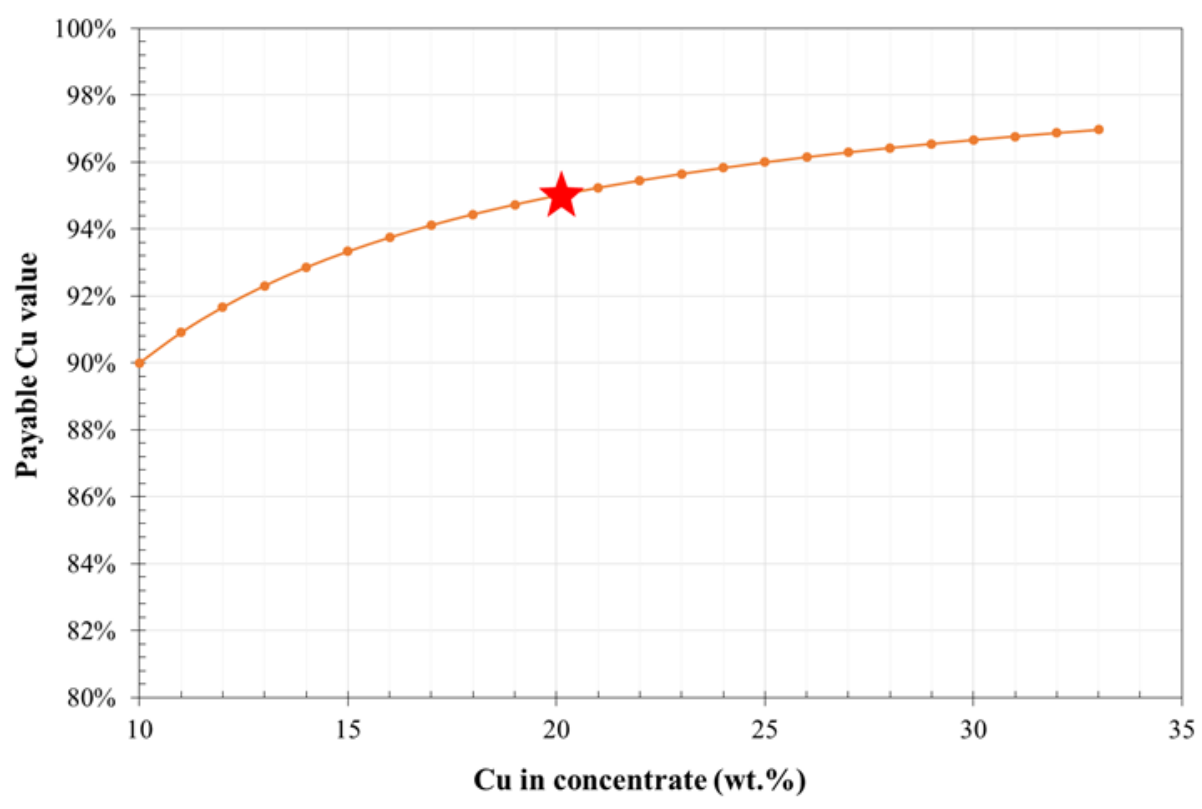

Figure 5.14: The relationship between final copper concentrate grade and percentage payable $\mathrm{Cu}$ concentrate for sensitivity analysis of scenario I. The asterisk indicates the copper content of the $\mathrm{Cu}$ concentrate when considering changes in ore variability for sensitivity analysis of scenario $I$.

\subsubsection{Sensitivity analysis for scenario II- Changes in feed ore variability}

Sensitivity analysis for scenario II evaluates the impacts of installing a magnetic separator on the final tailings stream when considering the role of feed ore variability. The inputs were similar to sensitivity analysis of scenarios I and the results are given in Figure 5.15. The maximum feed grade of 8 wt. \% was $28.6 \mathrm{~kg} \mathrm{H}_{2} \mathrm{SO}_{4} / \mathrm{t}$ and this is lower than the calculated ARD in scenario II (89.6 $\mathrm{kg} \mathrm{H}_{2} \mathrm{SO}_{4} / \mathrm{t}$ ). This scenario further indicates that installing a magnetic separator will minimise the formation of ARD in the waste stream. The payable copper content (95\%) (see Figure 5.17) and $\mathrm{Cu}$ grade (20 wt. \%) (see Figure 5.16) are similar to scenario II. 


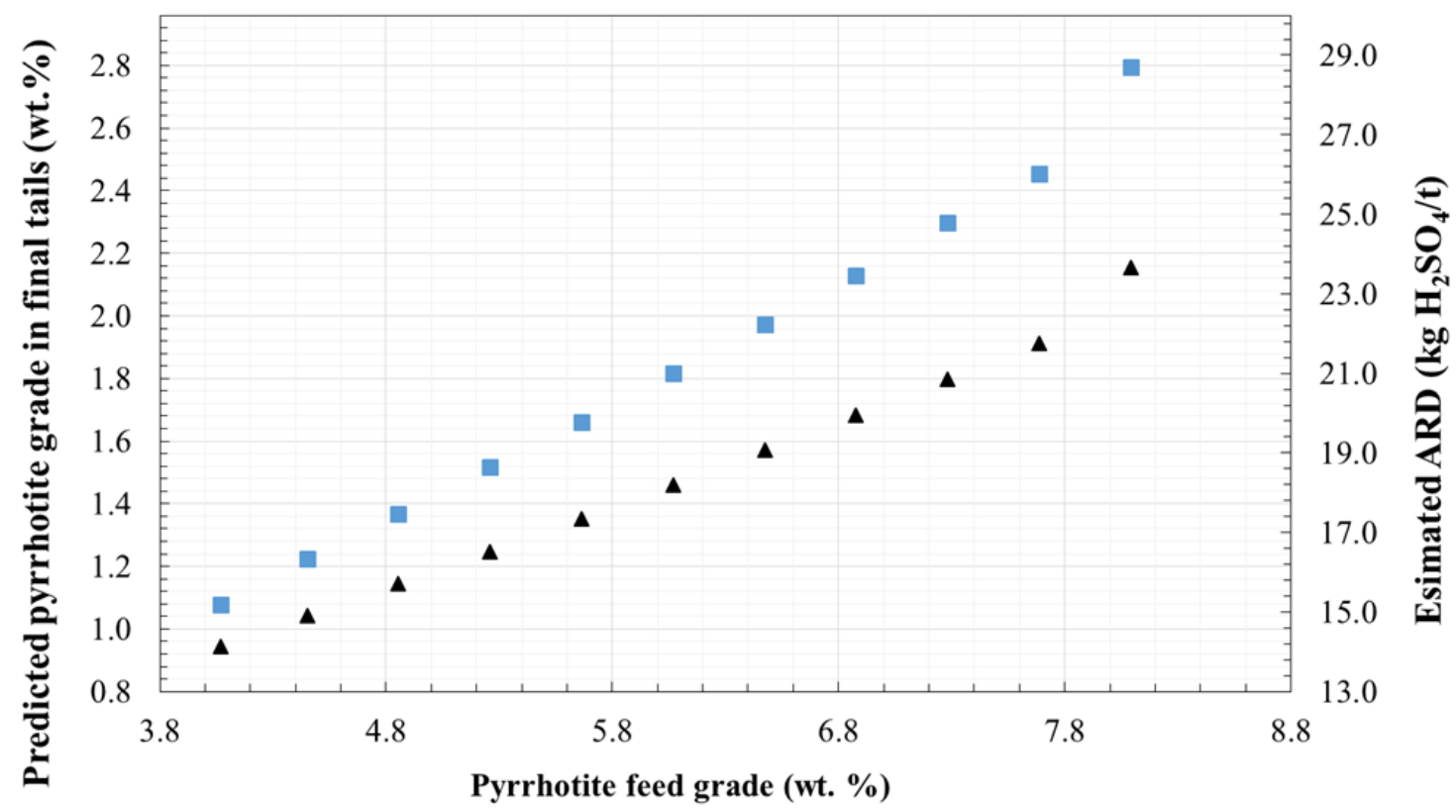

$\Delta$ Pyrrhotite feed grade $\quad$ Estimated ARD

Figure 5.15: Correlation of modelled ARD potential and increased pyrrhotite grade in the feed with the installation of a magnetic separator for sensitivity analysis of scenario II.

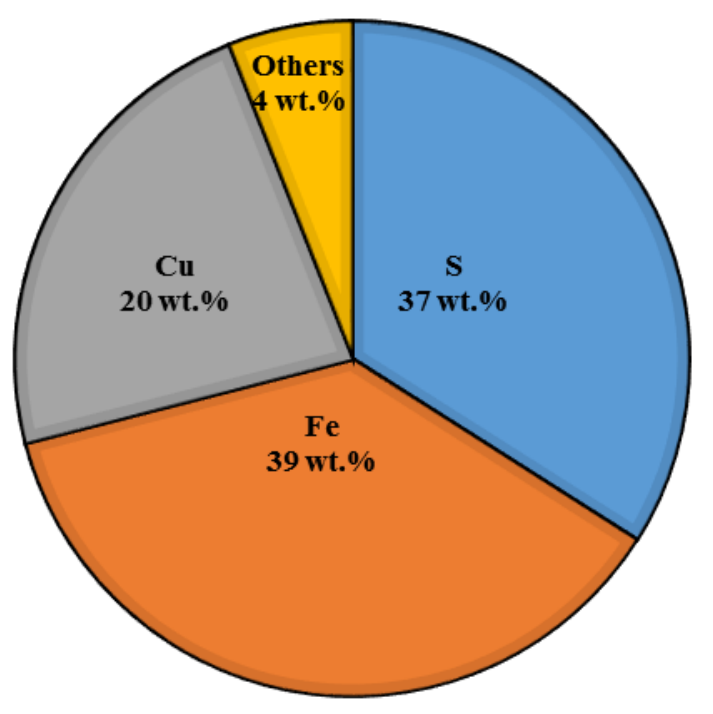

Figure 5.16: The elemental composition of a concentrate produced from the changes in ore variability magnetic separator for sensitivity analysis of scenario II. 


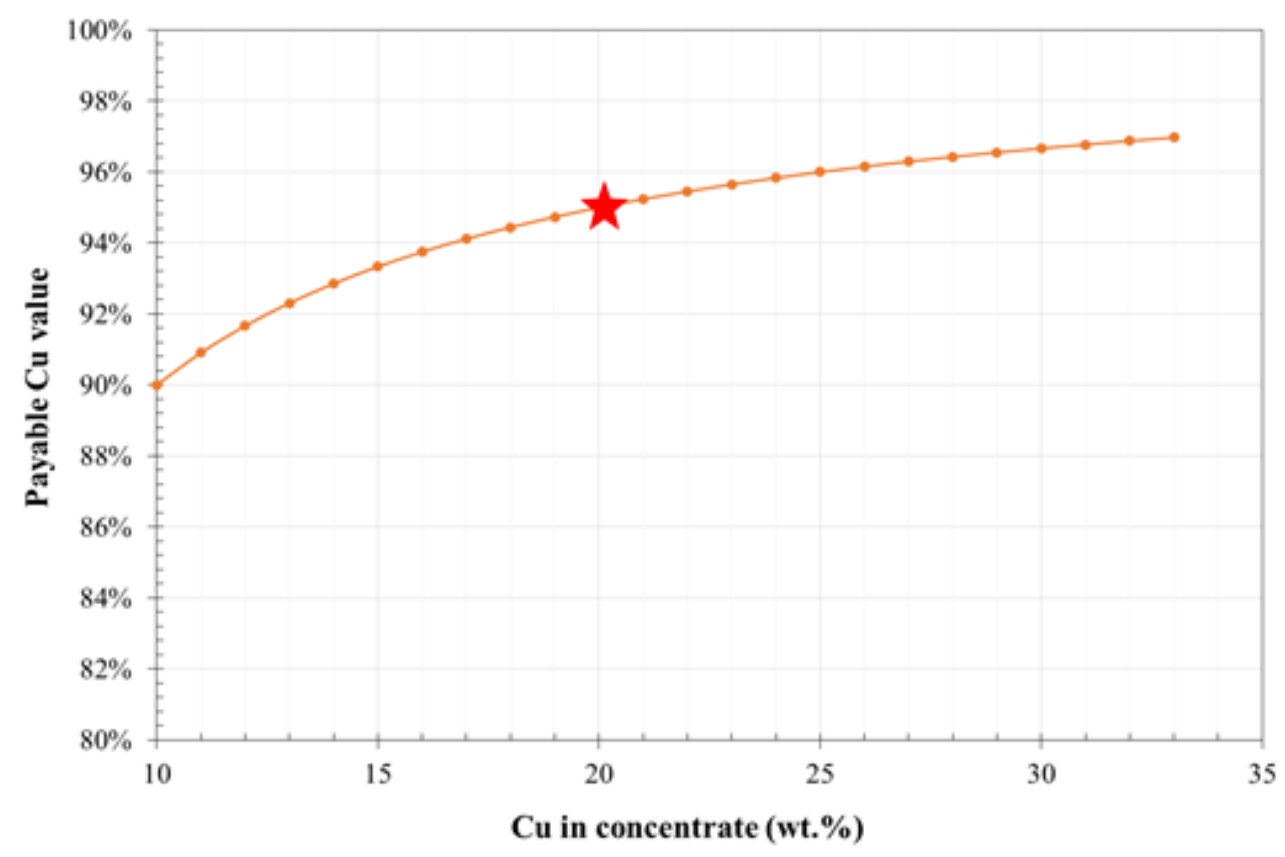

Figure 5.17: The relationship between final copper concentrate grade and percentage payable Cu concentrate for sensitivity analysis of scenario II. The asterisk indicates the copper content of the $\mathrm{Cu}$ concentrate when considering the changes in ore variability with the magnetic separator for sensitivity analysis of scenario II.

\subsection{Summary of the discussion}

Two hypothetical scenarios were considered to demonstrate the application of the integrated modelling framework. The scenarios were relative to the current operating conditions of the floatation circuit. Scenario I considered improving $\mathrm{Cu}$ (chalcopyrite) concentrate and scenario II evaluated the effect of installing a magnetic separator under the same conditions as scenario I. Sensitivity analysis was also conducted to assess the effect of feed ore variability on the two scenarios. Table 5.2. summarises the results obtained from different scenarios conducted for this case study.

Table 5.2: Summary of the scenario analysis.

\begin{tabular}{|l|c|c|c|c|}
\hline \multirow{2}{*}{ Scenario } & $\begin{array}{c}\text { Cu grade (wt. } \\
\text { \%) }\end{array}$ & $\begin{array}{c}\text { Payable Cu } \\
(\%)\end{array}$ & \multicolumn{2}{|c|}{ Estimated ARD (kg H2SO4/t) } \\
\cline { 2 - 5 } & Lowest: 10 & Lowest:90 & Lowest & Highest \\
\hline Base case & 23 & 96 & - & 46.4 \\
\hline Scenario I & 31 & 97 & 46.4 & 53.9 \\
\hline Scenario II & 31 & 97 & 13.8 & 15.4 \\
\hline $\begin{array}{l}\text { Sensitivity analysis } \\
\text { for scenario I }\end{array}$ & 20 & 95 & 46.1 & 89.6 \\
\hline $\begin{array}{l}\text { Sensitivity analysis } \\
\text { for scenario II }\end{array}$ & 20 & 95 & 15.2 & 28.6 \\
\hline
\end{tabular}


In scenario I, it can be observed that the consequence of rejecting $18 \%$ recovery of pyrrhotite resulted in an increased mineralogical calculated ARD of $53.9 \mathrm{~kg} \mathrm{H}_{2} \mathrm{SO}_{4} / \mathrm{t}$ compared $46.4 \mathrm{~kg} \mathrm{H}_{2} \mathrm{SO}_{4} / \mathrm{t}$ obtained from base case study (chapter 4). The upgrade had a positive impact on $\mathrm{Cu}$ grade which improved to $31 \%$ and this in turn increased the payable $\mathrm{Cu}$ from $96 \%$ (chapter 4) to $97 \%$. An improved $\mathrm{Cu}$ grade and high payable copper has a positive impact on the net smelter revenue and minimises penalty cost. Improving the grade had negative impacts on increasing formation of ARD and this motivated the idea to evaluate the impact of installing a magnetic separator. Scenario II demonstrated that installing a magnetic separator reduces ARD formation and this highlights the possibility of simultaneously improving metallurgical performance and mitigating the risk of ARD formation. The sensitivity analysis for both scenarios resulted in an increase of ARD formation. This further demonstrates that ore variability introduces more operational challenges, as it does not only have an impact on ARD formation but can cause dilution of concentrate grade if not appropriately managed. 


\section{Chapter 6}

\section{Conclusion and recommendations}

\subsection{Conclusion}

The conclusion is discussed by reviewing research questions to highlight the aim of the study. The aim was to develop an integrated modelling framework of the entire minerals value chain using mineralogy. The framework should be able to assess sustainability indicators at the operational level and the initial focus was on the techno-economic and environmental aspects. The framework should be underpinned by mineralogy and the data should be acquired in a cost-effective manner, and the technique should be reliable and have short turnaround times. The aim is discussed by reviewing key questions of the study.

\section{Key questions}

a) Can an appropriate EMC recipe be developed for the polymetallic sulfide ore case study, and what are the key minerals that should be included in the recipe? A suitable recipe was developed, calculated in four different rounds using least square and non-negative least square method. The recipe was successfully developed by firstly understanding the ore variability, which was achieved by using a time consuming and expensive technique known as QEMSCAN. This technique indicated that 16 minerals were present in significant quantities. In developing the EMC recipe, this data had to be further grouped in line with keeping the analysis as simple as possible. The grouping focused on which minerals were the most important on the basis of economic value, and in contributing to generating or neutralising acid rock drainage (ARD), and therefore needed to be reported in the framework. The recipe was achieved after trialling different methods. Once a unique ore specific EMC method was established and validated using complimentary quantitative mineralogical analysis, it proved to be a straightforward and elegant means of including mineralogy into the framework. The unbalanced data obtained from EMC was initially validated by comparing it with the unbalanced data from QEMSCAN. The results were comparable as the $\mathrm{R}^{2}$ value was above 0.95 , which this confirmed that the data was reliable and this successfully answers the first key question.

b) Does the element to mineral conversion (EMC) methodology provide a suitable means of including the first level of mineralogical data in the development of the integrated framework, which can be used to assess metallurgical performance (mineral grade and recovery) as well as an associated environmental indicator (acid rock drainage potential) for the polymetallic sulfide ore case study? The mineralogical data was used to assess 
metallurgical performance by evaluating grade and recovery of each valuable mineral (chalcopyrite, sphalerite and galena). The data was able to highlight that pyrrhotite was the cause of dilution in the copper (chalcopyrite) concentrate. In keeping with the overarching objectives, the initial development of the framework focused on the application of simple methodology that is able to account for whether material is likely to generate ARD or not. The mass balanced mineralogy results determined from the EMC were used to calculate the acid rock drainage (ARD) potential of the tailings using a combination of the Paktunc (1999) and Lawrence and Scheske (1997) approaches. The AP calculation was based on the mineral grade of pyrrhotite, chalcopyrite, sphalerite and galena. The neutralising potential was assessed considering the mineral grade of potentially neutralising minerals containing non-oxidisable cations. On this basis, the calculation of NP was redundant for this particular sample. The method calculated the difference between theoretical acid producing potential (AP reported as $\mathrm{kg} \mathrm{H}_{2} \mathrm{SO}_{4}$ equivalent per tonne) and acid neutralising potential (NP, reported as $\mathrm{kg} \mathrm{H}_{2} \mathrm{SO}_{4}$ equivalent per tonne) based on quantitative mineralogy. The results showed that the waste was potentially acid forming, but a full complement of ARD characterisation tests (static and kinetic tests) are required to inform whether the material is in fact acid generating and what the time scales are. The mass balanced mineralogy results determined from the EMC were an integral in building the framework, as the data was used to evaluate metallurgical performance as well as estimate the potential of acid formation.

c) Can the developed integrated framework be used for different scenario analyses that take into account both techno-economic and environmental indicators? Two different scenarios were evaluated to monitor the relationship between metallurgical performance and acid formation (environmental indicator). A sensitivity analysis was also conducted to assess the effect of feed ore variability on the two scenarios. Scenario I assessed the impact of improving the $\mathrm{Cu}$ (chalcopyrite) concentrate by rejecting pyrrhotite. The scenario showed that upgrading the concentrate resulted in an increased mineralogical calculated ARD when compared to the base case study. The increased in ARD formation motivated a scenario analysis of installing a magnetic separator, to assess the possibility of minimising ARD formation. Scenario II evaluated under the same conditions as scenario I, with the addition of a magnetic separator to treat final tailings. Scenario II achieved a net acid producing potential lower than scenario I. A sensitivity analysis on scenario I and II was conducted to evaluate the consequence of the feed ore variability in relation to the ARD formation. The pyrrhotite feed grade was varied between 10 and $100 \%$ of the base case and there was direct correlation between the grade and ARD formation. The sensitivity analysis of scenario II resulted in an overall decrease in ARD formation when compared to the sensitivity analysis of scenario I. Application of the integrated modelling framework for scenario analysis demonstrated the value of the approach in allowing 
simultaneous evaluation of techno-economic and environmental factors at an operational level. The motivation of installing a magnetic separator further demonstrates that the framework can be used for different scenario analysis.

\subsection{Concluding remarks}

This research has presented the first step in the development of an integrated modelling framework underpinned by mineralogy, using a case study of a polymetallic sulfide ore around flotation circuit. The initial stages of the development focus solely on the interface between techno-economic and environmental aspects. The framework used a mineralogical input that was simple, cost effective, and applicable by using a technique known as element to mineral conversion. The downfall of this technique was developing the recipe was time consuming and expensive due to the usage of QEMSCAN and different trials had to performed to come up with the recipe for the specific ore. As soon as the recipe has been established, the technique can be used routinely. Mineralogy proved to be a very important input as it was used to evaluate both metallurgic performance (grade and recovery) and to characterise the waste for the potential of acid rock drainage formation. A simple model known as the mineral splitter function was considered to be adequate since the development of the conceptual framework had to be simple and cost effective. This demonstrates how the minerals split across the flotation streams based on their recoveries. The output of the framework was the ability to simultaneously assess metallurgical performance (grade and recovery) and characterise the waste for the potential of acid rock drainage. The waste was characterised as either non-acid forming (NAF) or potentially acid forming (PAF). Figure 6.1 presents the overview of the framework.

\section{Inputs}

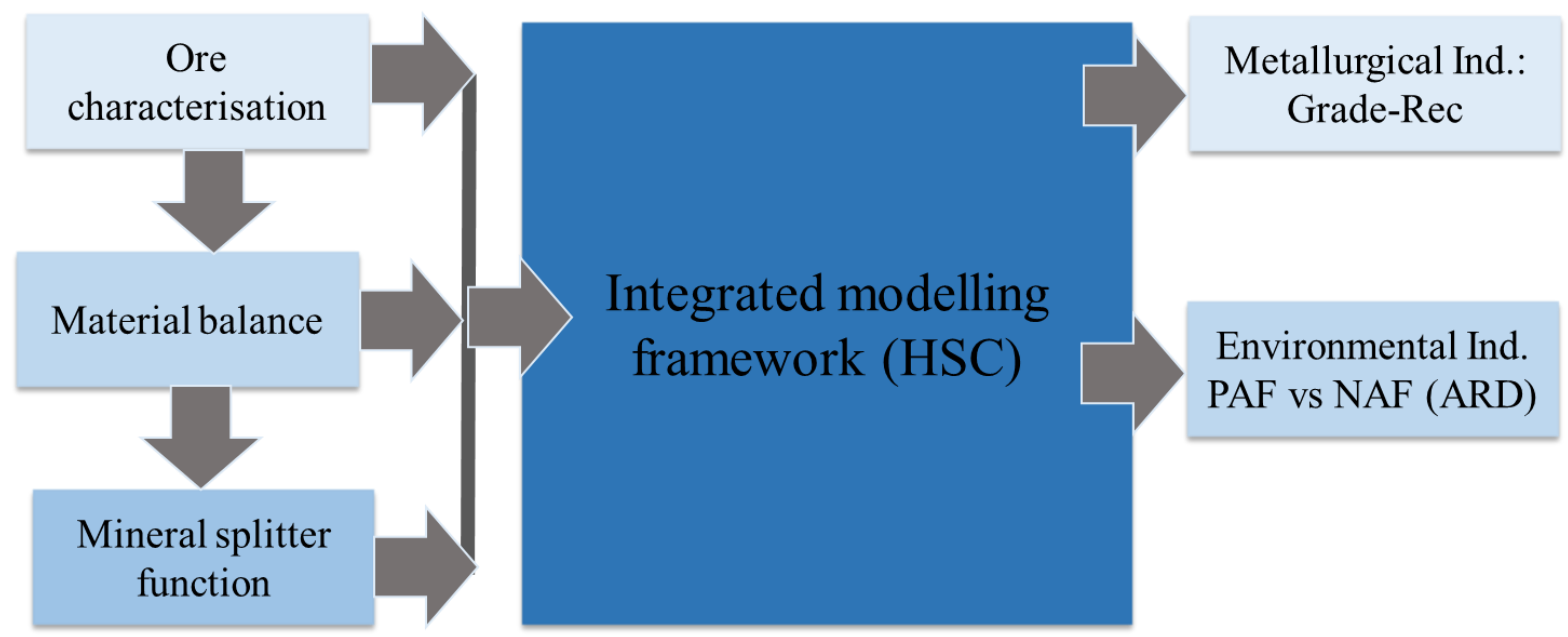

Figure 6.1: Overview of the integrated framework development. 
The value of the framework was the approach to simultaneously evaluate techno-economic and environmental factors at the operational level. This was demonstrated by the hypothetical scenarios which considered; benefits of improving copper concentrate quality at the expense of increasing tailings ARD potential mitigating ARD by installing a magnetic separator and a sensitivity analysis was also conducted to assess the effect of feed ore variability on the two scenarios. The scenarios demonstrated the possibility of improving the net smelter return (NSR) by upgrading the concentrate which in turn minimises penalty costs. The consequence of improving the grade was an increase in ARD formation, which can be potentially be mitigated by installing a magnetic separator. Ultimately the integrated modelling framework has demonstrated the potential for including sustainability principles at an operational level. Further development has to investigate the incorporation of a suitable social indicator in order to achieve the overall aim of the study and to meet the criteria of sustainable development. The overarching aim is to develop an integrated modelling framework of the entire minerals value that assess techno-economic, environment and social indicators. The purpose of this framework is to address the challenges of the mining industry within techno-economic, environment and social spheres. This can be achieved by having a holistic approach to address all aspects of sustainability at the operational level.

At the moment the integrated modelling framework has been presented as a conceptual approach - such that its potential value can be demonstrated. Further development will require more detailed analysis to validate the models. Detailed mineralogical data such as size by size liberation will have to be conducted, perform more static and kinetic tests and integrate complex models that can predict the trajectory of ARD formation. Pilot scale testing and further modelling has to be performed on the magnetic separator to determine, if the equipment can efficiently recover pyrrhotite and minimise ARD formation. In this case study, the magnetite was recovered together with the pyrrhotite, future work will have to determine the best process to separate the two minerals. Micro and nano particles of magnetite have a market value in biomedical and environmental areas (Mayo et al., 2007;Carretero and Pozo, 2009). The work should also evaluate appropriate prevention or control measures to deal with pyrrhotite to avoid the formation of acid rock drainage. Predicting the downstream impacts of optimising pyrrhotite recovery allows decision makers to assess objectively the enviro-techno-economic value proposition for and also in terms of installing additional capacity to actively recover the pyrrhotite from the tailings (Hesketh et al., 2010; Harrison et al. 2015). The study only focused on improving $\mathrm{Cu}$ concentrate grade and the payable $\mathrm{Cu}$ content, in future the framework has to be developed, to balance increasing the net smelter revenue of $\mathrm{Cu}, \mathrm{Pb}$ and $\mathrm{Zn}$.

In conclusion, the scenario analyses have provided an aerial view of different options and context as to which options should be investigated in more detail. 


\subsection{Recommendations}

- Further development of the integrated framework will focus on the inclusion of more detailed mineralogy data (size-by-size, and liberation), more ore extremes of ore variability and additional unit operations. This give more indication of whether the minerals were recovered due to mineralogical properties or operational conditions. The data can also be used to validate the models used in the study.

- In further developing the integrated framework, the next phase must focus on more empirical models that factor in changes on operating parameters, equipment settings and ore characteristics, ARD complex models and biokinteics test that considers the trajectory of acid formation.

- A magnetic separator should be used as an alternative mitigation tool, as it proved to be able to minimise ARD formation. An added advantage is an opportunity a saleable magnetite product and small volume pyrrhotite stream that can be disposed of accordingly. Research should be conducted to determine the best process route to separate magnetite and pyrrhotite including measures to implement in dealing with pyrrhotite to avoid formation of ARD.

- $\quad$ The framework provides a means to explore the implications of different scenarios, but additional operational knowledge would still be required to effect the changes of the scenarios (for example, how to proactively improve pyrrhotite rejection from a flotation chemistry perspective).

- $\quad$ This modelling approach has been shown to be a valid initial first step in identifying scenarios for further detailed investigation. However further investigation of scenarios would require flotation models which will require extensive plant data for calibration.

- $\quad$ Robust measures of quantifying scenario analysis should be considered as this will enable the generation of more possible operating scenarios. This will allow the framework to be used as a tool for optimising plant performance and minimising environmental impacts.

- The framework should consider to simultaneously increase the net smelter revenue of $\mathrm{Cu}$, $\mathrm{Pb}$ and $\mathrm{Zn}$.

- The framework should investigate the development and incorporation of more suitable 'social indicators' in order to meet the criteria of sustainable development. 


\section{References}

Akabzaa, T. and Yidana, S., 2012. An Integrated approach to environmental risk assessment of cumulatively impacted drainage basin from mining activities in South-western Ghana. Environmental Earth Sciences, vol. 65, no. 1, pp. 291-312 ISSN 1866-6280. DOI 10.1007/s12665011-1090-0.

Akcil, A., Koldas, S., 2006. Acid Mine Drainage ( AMD ): causes, treatment and case studies. J. Clean. Prod. 14, 1139-1145. doi:10.1016/j.jclepro.2004.09.006.

Azapagic, A., Perdan, S., 2000. Indicators of sustainable development for industry: a general framework. Inst. Chem. Eng. 78, 243-261. doi:10.1205/095758200530763.

Azapagic, A., 2003. Developing a framework for sustainable development indicators for the mining and minerals industry. J. Clean. Prod. 12, 639-662. doi:10.1016/S0959-6526(03)00075-1.

Azapagic, A., Millington, A., Collett, A., 2006. A methodology for integrating sustainability considerations into process design. Inst. Chem. Eng. 2006, 439-452. doi:10.1205/cherd05007.

Baker, B.J. and Banfield, J.F., 2003. Microbial communities in acid mine drainage. FEMS Microbiology Ecology, 5/15, vol. 44, no. 2, pp. 139-152 ISSN 0168-6496. DOI 10.1016/S01686496(03)00028-X.

Bailie, R., Armstrong, R., Reid, D., 2007. The Bushmanland Group supracrustal succession, Aggeneys, Bushmanland, South Africa: Provenance, age of deposition and metamorphism. South African J. Geol. 110, 59-86. doi:10.2113/gssajg.110.1.59.

Barbier, E.B., 1987. The concept of sustainable economic development. Environ. Conserv. 14, 101110. doi:10.1017/S0376892900011449.

Baum, W., 2013. Ore characterization , process mineralogy and lab automation a roadmap for future mining. Miner. Eng. 60, 69-73. doi:10.1016/j.mineng.2013.11.008.

Baxter, R., 2016. Mining in South Africa: The challenges and the opportunities. Johannesburg, South Africa.

Becker, M., Villiers, J. De, Bradshaw, D., 2010. The flotation of magnetic and non-magnetic pyrrhotite from selected nickel ore deposits. Miner. Eng. 23, 1045-1052.

doi:10.1016/j.mineng.2010.07.002.

Becker, M., Dyantyi, N., Broadhurst, J.L., Harrison, S.T.L., Franzidis, J.-P., 2015. A mineralogical approach to evaluating laboratory scale acid rock drainage characterisation tests. Miner. Eng. 80, 33-36. doi:http://dx.doi.org/10.1016/j.mineng.2015.06.015.

Becker, M., Broadhurst, J.L., Bradshaw, D.J., 2017. Process mineralogy : the key to unlocking the provision of minerals and metals to a sustainable world. Cape Town, South Africa, pp. 1-17.

Becker, M., 2018. Mineralogy: Underpinning sustainable process and decision making. Published in: Digby, C., Bradshaw, D., Mostert, H., Chicksen, Green mining: Beyond the myth. Perspectives of the future mining.

Becker, M., Charikinya, E., Ntlhabane, S., Voigt, M., Broadhurst, J., Harrison, S., Bradshaw, D., 2018. An Integrated Mineralogy-based Modelling Framework For The Simultaneous Assessment Of Plant Operational Parameters With Acid Rock Drainage Potential Of Tailings, in:

Wolkersdorfer, C., Sartz, L., Weber, A., Burgess, J., Tremblay, G. (Eds.), Proceedings of the 11th International Conference on Acid Rock Drainage. Pretoria, South Africa, pp. 309-314. 
Blowes, D.W., Jambor, J.L., Hanton-fong, C.J., Lortie, L., Gould, W.D., 1998. Geochemical, mineralogical and microbiological characterization of a 13.

Blowes, D.W., Ptacek, C.J., Jambo, J.L. and Weisener, C.G., 2005. 9.05 The geochemistry of acid mine drainage: In treatise on geochemistry. Environmental Geochemistry, vol. 9, pp. 149-204.

Bowell, R.., Sapsford, D.., Dey, M., Williams, K.., 2006. Protocols affecting the reactivivty of mine waste during laboratory -based kinetic tests, in: International Conference of Acid Rock Drainage (ICARD). pp. 247-270.

Bradshaw, D., 2014. The role of ' process mineralogy' in improving the process performance of complex sulphide ores The role of ' process mineralogy' in improving the process performance of complex sulphide ores.

Brundtland, G.H., 1987, Our Common Future, Oxford University Press.

Caldentey, R., Mondschein, S., 2003. Policy model for pollution control in the copper industry, including a model for the sulfuric acid and market. Oper. Res. 51, 1-16.

Carretero, M.I., Pozo, M., 2009. Clay and non-clay minerals in the pharmaceutical industry. Part I. Excipients and medical applications. Appl. Clay Sci. 46, 73-80. doi:10.1016/j.clay.2009.07.017.

Charikinya, E., Robertson, J., Platts, A., Becker, M., Lamberg, P., Bradshaw, D., 2017. Integration of mineralogical attributes in evaluating sustainability indicators of a magnetic separator. Miner. Eng. 107, 53-62. doi:10.1016/j.mineng.2016.11.014.

Cohelo, A. (2007) Topas-Academic, Coelho Software, Brisbane, Australia.

Collins, G.L., Jameson, G.J., 1976. Experiments on the flotation of fine particles. The influence of particle size and charge. Chem. Eng. Sci. 31, 985-991.

Cropp, A., Goodall, W.R., Bradshaw, D.J., 2013. The Influence of Textural Variation and Gangue Mineralogy on Recovery of Copper by Flotation from Porphyry Ore - A Review. 2nd AUSIMM Int. Geometallurgy Conf. 279-291.

Cullinan, V.J., Grano, S.., Greet, C.., Johnson, N.., Ralston, J., 1999. Investigating fine galena recovery problems in the lead circuit of Mount Isa mines lead/zinc concentrator. Part 1: Grinding media effects. Miner. Eng. 12, 147-163.

Deglon, D.A., 2005. The effect of agitation on the flotation of platinum ores. Miner. Eng. 18, 839844. doi:10.1016/j.mineng.2005.01.024.

Deloitte, 2014. Tracking the trends 2014. The top 10 mining companies will face in the coming year.

Doherty, W., Reynolds, A., Kennedy, D., 2009. The effect of air preheating in a biomass CFB gasifier using ASPEN Plus simulation. Biomass and Bioenergy 33, 1158-1167. doi:10.1016/j.biombioe.2009.05.004.

Dold, B., 2010. Basic concepts in environmental geochemistry of sulfidic mine-waste management, Er Sunil Kumar (Ed.), ISBN: 978-953-7619-84-8, InTech, Available from: http://www.intechopen.com/books/waste-management/basic-concepts-in-environmentalgeochemistry-of- sulfidic-mine-waste-management.

Dold, B., 2014. Evolution of acid mine drainage formation in sulphidic mine tailings. Minerals 4 (2), 621-641.

Dold, B., 2016. Acid rock drainage prediction: A critical review. J. Geochemical Explor. 172, 120132. doi:10.1016/j.gexplo.2016.09.014.

Doherty, W., Reynolds, A., Kennedy, D., 2009. The effect of air preheating in a biomass CFB gasifier 
using ASPEN Plus simulation, in: Biomass and Bioenergy. pp. 1158-1167. doi:10.1016/j.biombioe.2009.05.004.

Dortmans, P., Eiffe, E., 2004. An examination of future scenarios using historical analogy. Futures 36, 1049-1062. doi:10.1016/j.futures.2004.03.011.

Duinker, P.N., Greig, L.A., 2006. Scenario analysis in environmental impact assessment : Improving explorations of the future. Environ. Impact Assess. Rev. 27, 206-219. doi:10.1016/j.eiar.2006.11.001.

Durand, J.F., 2012. The impact of gold mining on the Witwatersrand on the rivers and karst system of Gauteng and North West Province, South Africa. J. African Earth Sci. 68, 24-43. doi:10.1016/j.jafrearsci.2012.03.013.

Edraki, M., Baumgartl, T., Manlapig, E., Bradshaw, D., Franks, D.M., Moran, C.J., 2014. Designing mine tailings for better environmental, social and economic outcomes: A review of alternative approaches. J. Clean. Prod. 84, 411-420. doi:10.1016/j.jclepro.2014.04.079.

Engelbrecht, C., 2011. XRF analysis of base metals prepared by fused bead method. MSc thesis, University of the Witwatersrand.

Enzweiler, J., Webb, P.C., 1996. Determination of trace elements in silicate rocks by X-ray fluorescence spectrometry on 15 glass discs : comparison of accuracy and precision with pressed powder pellet analysis. Chem. Geol. 2541, 195-202.

Evans, C.L., Wightman, E.M., Manlapig, E. V, Coulter, B.L., 2011. Application of process mineralogy as a tool in sustainable processing. Miner. Eng. 24, 1242-1248. doi:10.1016/j.mineng.2011.03.017.

Evans, C.L., Wightman, E.M., Manlapig, E. V, Coulter, B.L., 2011. Application of process mineralogy as a tool in sustainable processing. Miner. Eng. 24, 1242-1248. doi:10.1016/j.mineng.2011.03.017.

FEI, Available 2014. at: [Accessed 21 April 2015]. FEI. [Online] http://www.fei.com/products/sem/Qemscan/.

Feng, D., Aldrich, C., 1999. Effect of particle size on flotation performance of complex sulphide ores. Miner. Eng. 12, 721-731.

Freitas, A.H.A., Magrini, A., 2013. Multi-criteria decision-making to support sustainable water management in a mining complex in Brazil. J. Clean. Prod. 47, 118-128. doi:10.1016/j.jclepro.2012.10.043.

Fuerstenau, D.W., 2005. A Century of developments in the chemistry of flotation processing, in: Centenary of Flotation Symposium. Brisbane, Australia, pp. 1-47.

García, R., Báez, A. P., (2012). Atomic Absorption Spectrometry (AAS), Atomic absorption spectroscopy, Dr.Muhammad Akhyar Farrukh (Ed.), ISBN: 978-953-307-817-5, InTech, Available from:http://www.intechopen.com/books/atomic-absorption-spectroscopy/atomicabsorption-spectrometry-AAS.

Gaudin, A. M., Groh, J.O., and Henderson, H. B.,1931. The effect of particle size on flotation. AIME. Tech.Pub.,414, pp.3-23.

Ghorbani, Y., Becker, M., Petersen, J., Mainza, A.N., Franzidis, J.P., 2013. Investigation of the effect of mineralogy as rate-limiting factors in large particle leaching. Miner. Eng. 52, 38-51. doi:10.1016/j.mineng.2013.03.006.

Girardin, P., Bockstaller, C., Werf, H. Van Der, 1999. Indicators : Tools to evaluate the environmental impacts of farming systems. J. Sustain. Agric. 13, 5-21. doi:10.1300/J064v13n04 
Goldie, R., Tredger, P., 1991. Net smelting return models and their use in the exploration,evaluation and exploitation of polymetllic deposits. Geosci. Canada 18, 159-171.

Gu, Y., 2003. Automated scanning electron microscope based mineral liberation analysis. J. Miner. Mater. Charact. Eng. 2, 33-41.

Gu, Y., Schouwstra, R.P., Rule, C., 2014. The value of automated mineralogy. Miner. Eng. 58, 100103. doi:10.1016/j.mineng.2014.01.020.

Guerin, T.F., 2000. Can there be a win-win outcome in the sustainable mining debate? Asian J. Min. $11-14$.

Gunson, A.J., Klein, B., Veiga, M., Dunbar, S., 2010. Reducing mine water network energy requirements. J. Clean. Prod. 18, 1328-1338. doi:10.1016/j.jclepro.2010.04.002.

Hacking, T., Guthrie, P., 2007. A framework for clarifying the meaning of triple bottom-line , integrated and sustainability assessment. Environ. Impact Assess. Rev. 28, 74-89. doi:10.1016/j.eiar.2007.03.002.

Harrison, S.T.L., Franzidis, J.P., van Hille, R.P., Mokene, T., Broadhurst, J.., Kazadi Mbamba, C., Opitz, A.K.B., Chiume, R., Vries, E., Stander, H.-M., Jera, M., 2015. Minimising the formation of acid rock drainage through management of the disposal of sulphidic waste rock and tailings.

Henley, K.J., 1983. Ore-Dressing Mineralogy - A Review of Techniques, Applications and Recent Developments. Geol. Serv. Div. I, 175-200.

Hesketh, A.H., Broadhurst, J.L., Harrison, S.T.L., 2010. Mitigating the generation of acid mine drainage from copper sulfide tailings impoundments in perpetuity: A case study for an integrated management strategy. Miner. Eng. 23, 225-229. doi:10.1016/j.mineng.2009.09.020.

Hestnes, K.H., Sørensen, B.E., 2012. Evaluation of quantitative X-ray diffraction for possible use in the quality control of granitic pegmatite in mineral production. Miner. Eng. 39, 239-247. doi:10.1016/j.mineng.2012.06.006.

Holmes, R.J., 2004. Correct sampling and measurement - the foundation of accurate metallurgical accounting. Chemom. Intell. Lab. Syst. 74, 71-83. doi:10.1016/j.chemolab.2004.03.019.

Hope, G.A., Woodsy, R., Munce, C.G., 2001. Raman microprobe mineral identification. Miner. Eng. $14,1565-1577$.

Huggins, F.E. 2002. "Overview of analytical methods for inorganic constituents in coal", International Journal of Coal Geology, vol. 50, pp. 169-214. Hutton.

IFC, 2014. Sustainable and responsible mining in Africa. Retrieved from. http://www.ifc. Org/wps/wcm/connect/dfaac38043fea19b8f90bf869243d457/Sustainable+Mining +in+Africa.pdf?MOD=AJPERES. International Network for Acid Prevention (INAP), 2009. Global acid rock drainage guide (GARD guide).

Jambor, J.L., Dutrizac;, J.., Groat, L.A., Raudsepp, M., 2002. Static tests of neutralization potentials of silicate and aluminosilicate minerals. Environ. Geol. 1-17. doi:10.1007/s00254-002-0615-y

Jansen, W., Slaughter, M., 1982. Elemental mapping of minerals by electron microprobe. Am. Mineral. 67, 521-533.

Johnson, N., 1972. The flotation behaviour of some chalcopyrite ores. $\mathrm{PhD}$ thesis, University of Queensland.

Johnson, N.W., 1987. Application of kinetics and liberation data to an analysis of the industrial flotation process. CIM Bull. 80 (899), 113-117.

Jones, M.P. (1987) Applied mineralogy. A quantitative approach. Graham \& Trotman, London. 
Jurjovec, J., Ptacek, C.J. and Blowes, D.W., 2002. Acid neutralization mechanisms and metal release in mine tailings: A Laboratorycolumn experiment. Geochimica Et Cosmochimica Acta, vol. 66, no. 9, pp. 1511-1523.

Kaartinen, T. and Walstrom, M., 2009. Development of a European standard for the determination of acid potential and neutralization potential of sulfidic waste.

Kable, E., Becker, M., Gu, Y., 2016. Chemical assays, in: Becker, M., Wightman, E.M., Evans, C.L. (Eds.), Process Mineralogy: JKMRC Monograph Series in Mining and Mineral Processing, No 6. Julius Kruttschnitt Mineral Research Centre, Brisbane, Australia, pp. 97-107.

King, R.P., 2001. Modelling and simulation of mineral processing systems, Butterworth- Heinemann, pp 290.

Klimpel, R.R., 1997. Flotation kinetic studies going from laboratory to the plant. Proceedings - 29th annual meeting of the Canadian Mineral Processors. The Canadian Institute of Mining, Metallurgy and Petroleum, Ottawa, Ontario, Canada, pp. 352-365.

Kohad, V.P., 1998. Flotation of sulphide ores - HZL experience, Recent trends @ IIME, Jamshedpur.

Labuschagne, C., Brent, A.C., Erck, R.P.G. Van, 2007. Assessing the sustainability performances of industries. Pretoria, South Africa.

Lamberg, P., Hautala, P., Sotka, P., Saavalainen, S., 1997. Mineralogical balances by dissolution methodology. Proc.Short course 'Crystal Growth Earth Sci.1-29.

Lamberg, P., Vianna, S., 2007. A technique for tracking multiphase mineral particles in flotation circuits. VII Meet. South. Hemisph. Miner. Technol. Ouro Preto, Bras. 195-202.

Lamberg, P., Rosenkranz, J., Wanhainen, C., Lund, C., Minz, F., 2013. Building a geometallurgical model in iron ores using a mineralogical approach with liberation data.

Lapakko, K., 2002. Metal Mine Rock and Waste Characterization Tools : An Overview. Minnesota Department of Natural Resources, US: Acid drainage technology initiative - Metal mining sector.

Laurence, D., 2011. Establishing a sustainable mining operation: An overview. J. Clean. Prod. 19, 278-284. doi:10.1016/j.jclepro.2010.08.019.

Lawrence, R.W., Wang, Y. 1996. Determination of neutralization potential for acid rock drainage prediction. MEND Project 1.16.3. 38 p. plus figures, tables and appendices.

Lawrence, R.W., Scheske, M., 1997. A method to calculate the neutralization potential of mining wastes. Environ. Geol. 32, 100-106. doi:10.1007/s002540050198.

Lawson, V, Kerr, A.N., Shields, Y., Wells, P.F., Xu, M., Dai, Z. 2005. Improving pentlandite pyrrhotite separation at INCO's Clarabelle Mill. In: Centenary of Flotation Symposium. AusIMM, Brisbane, pp. 875-885.

Lindsay, M.B.J., Condon, P.D., Jambor, J.L., Lear, K.G., Blowes, D.W., Ptacek, C.J., 2009. Mineralogical, geochemical , and microbial investigation of a sulfide-rich tailings deposit characterized by neutral drainage. Appl. Geochemistry 24, 2212-2221. doi:10.1016/j.apgeochem.2009.09.012.

Liipo, J., Lang, C., Burgess, S., Otterstrom, H., Person, H., Lamberg, P., 2012. Automated mineral liberation analysis using INCAMineral. In: Process Mineralogy '12, Proceedings, Vineyard Hotel, Cape Town, South Africa, 7-9 November, pp. 1-7.

Liu, Y., Gupta, H., Springer, E., Wagener, T., 2008. Linking science with environmental decision making: Experiences from an integrated modeling approach to supporting sustainable water 
resources management. Environ. Model. Softw. 23, 846-858.

doi:10.1016/j.envsoft.2007.10.007.

Lotter, N.O., Bradshaw, D.J., Becker, M., Parolis, L.A.S., Kormos, L.J., 2008. A discussion of the occurrence and undesirable flotation behaviour of orthopyroxene and talc in the processing of mafic deposits. Miner. Eng. 21, 905-912. doi:10.1016/j.mineng.2008.02.023.

Lotter, N.O., 2011. Modern process mineralogy : An integrated multi-disciplined approach to flowsheeting. Miner. Eng. 24, 1229-1237. doi:10.1016/j.mineng.2011.03.004.

Lotter, .O., Baum, W., Reeves, S., Arrue, C., Bradshaw, D.J., 2017. The business value of best practice mineralogy, in: MEI Process Mineralogy 2017, Cape Town. pp. 1-24.

Lottermoser, B.G., 2010. Mine Wastes, in: Edition, 3rd (Ed.), . Springer, p. 392. doi:10.1007/978-3642-12419-8.

Lund, C., Lamberg, P., Lindberg, T., 2013. Practical way to quantify minerals from chemical assays at Malmberget iron ore operations - An important tool for the geometallurgical program. Miner. Eng. 49, 7-16. doi:10.1016/j.mineng.2013.04.005.

Magnusson, H., 2005. Process simulation in Aspen Plus of an Integrated Ethanol and CHP plant. University of UMEA.

Mahmoud, M., Liu, Y., Hartmann, H., Stewart, S., Wagener, T., Semmens, D., Stewart, R., Gupta, H., Dominguez, D., Dominguez, F., Hulse, D., Letcher, R., Rashleigh, B., Smith, C., Street, R., Ticehurst, J., Twery, M., van Delden, H., Waldick, R., White, D., Winter, L., 2009. A formal framework for scenario development in support of environmental decision-making. Environ. Model. Softw. 24, 798-808. doi:10.1016/j.envsoft.2008.11.010.

Malewski, J., Krzeminska, M., 2012. Dependence of mine revenue on the grade of copper concentrate. Physicochem. Probl. Miner. Process. 48, 545-554. doi:10.5277/ppmp120218.

Mandile, A.J., Hutton, A.C., 1995. Quantitative X-ray diffraction analysis of mineral and organic phases in organic-rich rocks. Int. J. Coal Geol. 28, 51-69. doi:10.1016/0166-5162(95)00004-W.

Mayo, J.T., Yavuz, C., Yean, S., Cong, L., Shipley, H., Yu, W., Falkner, J., Kan, A., Tomson, M., Colvin, V.L., 2007. The effect of nanocrystalline magnetite size on arsenic removal. Sci. Technol. Adv. Mater. 8, 71-75. doi:10.1016/j.stam.2006.10.005.

Mbamba, C.K., Harrison, S.T.L., Franzidis, J., Broadhurst, J.L., 2012. Mitigating acid rock drainage risks while recovering low-sulfur coal from ultrafine colliery wastes using froth flotation. Miner. Eng. 29, 13-21. doi:10.1016/j.mineng.2012.02.001.

McClung, C.R., Viljoen, F., 2011. Mineralogical assessment of the Metamorphosed Broken Hill Sulfide Deposit, South Africa Implications for Processing Complex Orebodies - Springer, in: 10th International Congress for Applied Mineralogy. pp. 1-5.

Miller, S., Robertson, A., and Donohue, T. 1997. Advances in acid drainage prediction using the Net Acid Generation (NAG) Test. p. 535-549. In: Proceedings of the 4th International Conference on Acid Rock Drainage (Vancouver, May 31-June 6, 1997), vol II.

Minz, F.E., 2016. Mineralogical controls on the recovery of antimony in base-metal flotation. Lulea University of Technology.

Mitchell, P.L., 1997. Misuse of regression for empirical validation of models. Agriculutural Syst. 54, 313-326.

Moen, K., 2006. Quantitative measurements of mineral microstructure. PHD thesis. Trondheim, Norwegian University of Science and Technology, 194p.

Moncur, M.C., Jambor, J.L., Ptacek, C.J., Blowes, D.W., 2009. Mine drainage from the weathering of 
sulfide minerals and magnetite. Appl. Geochemistry 24, 2362-2373. doi:10.1016/j.apgeochem.2009.09.013.

Montenegro, M.R., Bruckard, W.J., Gálvez, E.D., Cisternas, L.A., 2013. Arsenic-rejection flotation circuit design and selection based on a multiple-objective evaluation. Miner. Eng. 45, 22-31. doi:10.1016/j.mineng.2013.01.012.

Morin, K.A. and Hutt, N.M. Kinetic tests and risk assessment for ARD. Anonymous 5th Annual BC metal leaching and ARD workshop, 1998.

Mudd, G.M., 2009. The sustainability of mining in Australia : Key production trends and their environmental implications for the future. Clayton Victoria, Australia.

Mudd, G.M., 2010. The environmental sustainability of mining in Australia: Key mega-trends and looming constraints. Resour. Policy 35, 98-115. doi:10.1016/j.resourpol.2009.12.001.

Muketekelwa, S.L., 2017. Investigating the potential of using hydrocyclone-fine screen hybrid systems to improve the performance of classification circuits. University of Cape Town.

Multani, R.S., Waters, K.E., 2017. A Review of the physicochemical properties and flotation of pyrrhotite superstructures $(4 \mathrm{C}-\mathrm{Fe} 7 \mathrm{~S} 8 / 5 \mathrm{C}-\mathrm{Fe} 9 \mathrm{~S} \mathrm{10})$ in $\mathrm{Ni}-\mathrm{Cu}$ sulfide mineral processing. Can. J. Chem. Eng. 9999, 1-22. doi:10.1002/cjce.23099.

Naidoo, S., 2017. Acid mine drainage in South Africa. Development of actors, policy impacts and broader implications, Acid mine drainage in South Africa development actors, Policy Impacts, and Broader Implications.

Nikolopoulou, A., Ierapetritou, M.G., 2012. Optimal design of sustainable chemical processes and supply chains: A review. Comput. Chem. Eng. 44, 94-103. doi:10.1016/j.compchemeng.2012.05.006.

Norgate, T., Haque, N., 2009. Energy and greenhouse gas impacts of mining and mineral processing operations. J. Clean. Prod. 18, 266-274. doi:10.1016/j.jclepro.2009.09.020.

Oberteuffer, J., 1974. Magnetic separation: A review of principles, devices, and applications. IEEE Trans. Magn. 10, 223-238. doi:10.1109/TMAG.1974.1058315.

Ochieng, G., Seanego, E., Nkwonta, O., 2010. Impacts of mining on water resources in South Africa: A review. Sci. Res. Essays 5, 3351-3357.

Outotec, 2015. www.hsc-chemistry.com. [Online] Available at: http://www.hsc- chemistry.com/.

Paktunc, A.D., 1998. MODAN : An interactive computer program for estimating mineral quantites based on bulk composition. Comput. Geosci. 24, 425-431.

Paktunc, A.D., 1999. Mineralogical constraints on the determination of neutralization potential and prediction of acid mine drainage. Environ. Geol. 39, 103-112. doi:10.1007/s002540050440.

Paine, M., König, U., Staples, E., 2011. Application of rapid X-ray diffraction (XRD) and cluster analysis to grade control of iron ores. In: Proceedings, 10th International Congress for Applied Mineralogy (ICAM), Trondheim, Norway, 1-5 August, pp. 495-501.

Pallottino, S., Sechi, G.M., Zuddas, P., 2005. A DSS for water resources management under uncertainty by scenario analysis. Environ. Model. Softw. 20, 1031-1042. doi:10.1016/j.envsoft.2004.09.012.

Parbhakar-Fox, A.K., Edraki, M., Walters, S., Bradshaw, D., 2011. Development of a textural index for the prediction of acid rock drainage. Miner. Eng. 24, 1277-1287.

doi:10.1016/j.mineng.2011.04.019.

Parbhakar-Fox, A., Lottermoser, B.G., 2015. A critical review of acid rock drainage prediction 
methods and practices. Miner. Eng. 82, 107-124. doi:10.1016/j.mineng.2015.03.015.

Parian, M., 2015. Development of the mineralogical path for geometallurgical Modeling of Iron Ores. Lulea University of Technology.

Parian, M., Lamberg, P., Rosenkranz, J., 2016. Developing a particle-based process model for unit operations of mineral processing - WLIMS. Int. J. Miner. Process. 154, 53-65. doi:10.1016/j.minpro.2016.07.001.

Pease, J.D., 2004. Improving fines recovery by grinding finer, in: MetPlant 2004 AusIMM. pp. 1-17.

Pease, J.D., Curry, D.C., Young, M.F., 2006. Designing flotation circuits for high fines recovery. Miner. Eng. 19, 831-840. doi:10.1016/j.mineng.2005.09.056.

Petersen, L., Dahl, C.K., Esbensen, K.H., 2004. Representative mass reduction in sampling - a critical survey of techniques and hardware. Chemom. Intell. Lab. Syst. 74, 95-114. doi:10.1016/j.chemolab.2004.03.020.

Petruk, W., 2000. Applied mineralogy in the mining indusrty, 1st editio. ed. Ottawa,Ontario, Canada.

Pimentel, B.S., Gonzalez, E.S., Barbosa, G.N.O., 2015. Decision-support models for sustainable mining networks : Fundamentals and challenges. J. Clean. Prod. 112, 2145-2157. doi:10.1016/j.jclepro.2015.09.023.

Pitard, F.F., 1989. Pierre Gy’s Sampling theory and sampling practice, , vol. 2. CRC Press, Boca Raton Fl, US, 247p.

Plante, B., Bussière, B., Benzaazoua, M., 2012. Static tests response on 5 Canadian hard rock mine tailings with low net acid-generating potentials. J. Geochemical Explor. 114, 57-69. doi:10.1016/j.gexplo.2011.12.003.

Plumlee, G.S., Smith, K.S., Montour, M.R., Ficklin, W.H., Mosier, E.L., 1999. Geological controls on the composition of natural waters and mine waters draining diverse mineral-deposit types. Soc. Econ. Geol. 1-63.

Postma, T.J.B.M., Liebl, F., 2005. How to improve scenario analysis as a strategic management tool? Technol. Foreacasting Soc. Chang. 72, 161-173. doi:10.1016/j.techfore.2003.11.005.

Potts, P.J., 2015. Electron probe microanalysis, 1st editio. ed, Electron probe microanalysis. John Wiley \& Sons, Chichester, West Sussex, UK. doi:10.1007/978-94-015-3988-3_10.

Powell, M.S., 2013. Utilising orebody knowledge to improve comminution circuit design and energy utilisation, in: The Second AUSIMM International Geometallurgy Conference / Brisbane, QLD, 30 September - 2 October 2013. pp. 27-35.

Pownceby, M.I., MacRae, C.M., Wilson, N.C., 2006. Mineral characterisation by EPMA mapping. Miner. Eng. 20, 444-451. doi:10.1016/j.mineng.2006.10.014.

Price, W.A., 2009. Prediction manual for drainage chemistry from sulphidic geologic materials,CANMET Mining and Mineral Sciences Laboratories, 579p.

Prior, T., Giurco, D., Mudd, G., Mason, L., Behrisch, J., 2012. Resource depletion, peak minerals and the implications for sustainable resource management. Glob. Environ. Chang. 22, 577-587. doi:10.1016/j.gloenvcha.2011.08.009.

Rahman, R.M., Ata, S., Jameson, G.J., 2012. The effect of flotation variables on the recovery of different particle size fractions in the froth and the pulp. Int. J. Miner. Process. 106, 70-77. doi:10.1016/j.minpro.2012.03.001.

Rietveld, H.M., 1969. A profile refinement method for nuclear and magnetic structures. Journal of Applied Crystallography 2, 65-71. 
Runge, K.C., Tabosa, E., Jankovic, A., 2013. Particle size distribution effects that should be considered when performing flotation geometallurgical testing, in: The Second AUSIMM International Geometallurgy Conference. Brisbane, pp. 335-344.

Runge, K., Bradshaw, D., 2015. A review of entrainment : Mechanisms , contributing factors and modelling in flotation. Miner. Eng. doi:10.1016/j.mineng.2014.09.003.

Rudnick, Pers. Comm, 2018.

Ryan, P.J., Lawrence, A.L., Lipson, R.D., Moore, J.M., Paterson, A., Stedman, D.P., Van Zyl, D., 1982. The Aggeneys base metal sulphide deposits, Namaqualand, South Africa. Johannesburg.

Salomon-de-friedberg, H., Robinson, T., Way, H., teck.com., n.d. Tackling impurities in copper concentrates.

Schonewille, R.H., Rioux, D., Kreuh, M., 2012. Towards Clean Metallurgical Processing for Profit , Social and, in: Schonewille, R.H., Rioux, D., Kashani-Nejad, S., Kreuh, M., Muinonen, M.E.S. (Eds.), 51st Conference of Metallurgists, Held with Pressure Hydrpmetallurgy. A Publication of The Canadian Institute of Mining, Metallurgy and Petroleum, Niagara, Ontario,Canada.

Senshaw, D.A., 2014. Modeling and analysis of long-term energy scenarios for sustainable strategies of Ethiopia. European University Flensburg, Germany.

Skousen, J., Renton, J., Brown, H., Evans, P., Leavitt, B., Brady, K., Cohen, L., Ziemkiewicz, P., 1997. Neutralization Potential of Overburden Samples Containing Siderite. J. Environ. Qual. 26, 673-681. doi:10.2134/jeq1997.00472425002600030012x.

Shannon, L.K., Trahar, W.J., 1986. The role of collector in sulfide ore flotation. In: Somasundaran, P. (Ed.), Advances in Mineral Processing. SME, Littleton, Colorado, pp. 408-425.

Smart, R., Skinner, W.M., Levay, G., Gerson, A.R., Thomas, J.E., Sobieraj, H., Schumann, R., Weisener, C.G., Weber, P.A., Miller, S.D., Stewart, W.A., 2002. ARD test handbook: Project P387, A prediction and kinetic control of acid mine drainage. AMIRA, International Ltd, Ian Wark Research Institute, Melbourne, Australia.

Smith, P., Warren, L., 1989. Entrainment of particles into flotation froths. Miner. Process. Extr. M. 5 (1-4), 123-145.

Sobek, A.A., Schuller, W.A., Freeman, J.R. and Smith, R.M., 1978. Field and laboratory methods applicable to overburdens and mine soils. U.S. Environmental Protection Agency, Cincinnati, Ohio, 45268: EPA-600/2-78-054.

Stewart, W.A., 2005. Development of acid rock drainage prediction methodologies for coal mine Wastes. PhD thesis, University of South Australia.

Stewart, W.A., Miller, S.D., Smart, R., 2006. Advances in acid rock drainage (ARD) characterisation of mine wastes., in: 7th International Conference on Acid Rock Drainage (ICARD). St. Louis MO. R.I. Barnhisel, pp. 2098-2119.

Stewart, W., Schuman, R., Miller, S., Smart, R.St.C., 2009. Development of prediction methods for ARD assessment of coal process wastes. Securing the future and 8th ICARD, June 22-26th, 2009, Skelleftea, Sweden.

Sutherland, D.N., Gottlieb, P., Heyes, G.W., Jackson, B.R., 1988. The influence of mineral locking on flotation behaviour. In: Proc. XVI International Mineral Processing Congress, Stockholm, Sweden, June 5-10, 1988, pp. 535-545.

Sutherland, D.., Gottlieb, P., 1991. Application of automated quantitative mineralogy in mineral processing. Miner. Eng. 4, 753-762. doi:10.1016/0892-6875(91)90063-2 
Swart, R.J., Raskin, P., Robinson, J., 2004. The problem of the future: Sustainability science and scenario analysis. Glob. Environ. Chang. 14, 137-146. doi:10.1016/j.gloenvcha.2003.10.002.

Swaine, D.J., 1990. "Trace Elements in Coal". Butterworths, London.

Swart, R.J., Raskin, P., Robinson, J., 2004. The problem of the future: Sustainability science and scenario analysis. Glob. Environ. Chang. 14, 137-146. doi:10.1016/j.gloenvcha.2003.10.002.

Trahar, W.J. and Warren, L.J., 1976. The floatability of very fine particles. Int. J. Miner. Process, Vol.3, pp, 103-131.

Trahar, W.J., 1981. A rational interpretation of the role of particle size in flotation. Int.J.Miner.Proc.,Vol.8, pp.289-327.

The International Network for Acid Prevention (INAP), 2009. Global Acid Rock Drainage Guide (GARD Guide), http://www.gardguide.com/.

Tuazon, D., Corder, G., Powell, M., Ziemski, M., 2012. A practical and rigorous approach for the integration of sustainability principles into the decision-making processes at minerals processing operations. Miner. Eng. 29, 65-71. doi:10.1016/j.mineng.2011.10.017.

Tungpalan, K., Wightman, E., Manlapig, E., 2015. Relating mineralogical and textural characteristics to flotation behaviour. Miner. Eng. 82, 136-140. doi:10.1016/j.mineng.2015.02.005

Wang, L., Peng, Y., Runge, K., Bradshaw, D., 2015. A review of entrainment: Mechanisms , contributing factors and modelling in flotation. Miner. Eng. 70, 77-91. doi:10.1016/j.mineng.2014.09.003.

WBCSD, IIED, 2002. Breaking New Ground: The Report of the mining, minerals and sustainable development project. Earthscan Publications, London.

Weber, P.A., Stewart, W.A., Skinner, W.M., Weisner, C.G., Thomas, J.E. and Smart, R.St.C., 2004. Geochemical effects of oxidation products and framboidal pyrite oxidation in acid mine drainage prediction techniques. Applied Geochemistry, 12, vol. 19, no. 12, pp. 1953-1974 ISSN 08832927. DOI 10.1016/j.apgeochem.2004.05.002.

Welsh, W.D., Vaze, J., Dutta, D., Rassam, D., Rahman, J.M., Jolly, I.D., Wallbrink, P., Podger, G.M., Bethune, M., Hardy, M.J., Teng, J., Lerat, J., 2013. An integrated modelling framework for regulated river systems. Environ. Model. Softw. 39, 81-102. doi:10.1016/j.envsoft.2012.02.022.

West, J., 2011. Decreasing metal ore grades. Journal of Industrial Ecology 15, 165- 168, doi:10.1111/j. 1530-9290.2011.00334.x.

Weidenbach, M., Dunn, G., Yong Teo, Y., 2016. Removal of impurities from copper sulfide mineral concentrates, in: ALTA 2016 Nickel -Cobalt-Copper Proceedings. Perth,Australia, pp. 335-351.

Welsh, W.D., Vaze, J., Dutta, D., Rassam, D., Rahman, J.M., Jolly, I.D., Wallbrink, P., Podger, G.M., Bethune, M., Hardy, M.J., Teng, J., Lerat, J., 2013. An integrated modelling framework for regulated river systems. Environ. Model. Softw. 39, 81-102. doi:10.1016/j.envsoft.2012.02.022

Whiteman, E., Lotter, N.O., Amos, S.R., 2016. Process mineralogy as a predictive tool for flowsheet design to advance the Kamoa project. Miner. Eng. 96-97, 185-193. doi:10.1016/j.mineng.2016.05.004.

Whiteman, E., Lotter, N.O., Amos, S.R., 2016. Process mineralogy as a predictive tool for flowsheet design to advance the Kamoa project. Miner. Eng. 96-97, 185-193. doi:10.1016/j.mineng.2016.05.004.

Whiten, B., 2007. Calculation of mineral composition from chemical assays. Miner. Process. Extr. Metall. Rev. 29, 84-97. doi:10.1080/08827500701257860 
Wills, B.A., Napier-Munn, T., 2006. Mineral processing technology, 7th Edition. An introduction to practical aspects of ore treatment and mineral recovery.

Worrall, R., Neil, D., Brereton, D., Mulligan, D., 2009. Towards a sustainability criteria and indicators framework for legacy mine land. J. Clean. Prod. 17, 1426-1434. doi:10.1016/j.jclepro.2009.04.013.

World Economic Forum, 2015. Mining Metals in a Sustainable World 2050 (September).

Young, R.A. (Ed.). 1993. The Rietveld Method. Oxford University Press.

Young, M.F., Pease, J.D., Johnson, N.W., Munro, P.D., 1997. Developments in Milling Practice at the Lead / Zinc Concentrator of Mount Isa Mines Limited from 1990 ., in: AusIMM Sixth Mill Operators Conference. Madang, Papua New Guinea., pp. 6-8. 


\section{Appendix A - Process flow diagram}

Total Solids $(\mathrm{t} / \mathrm{h})$

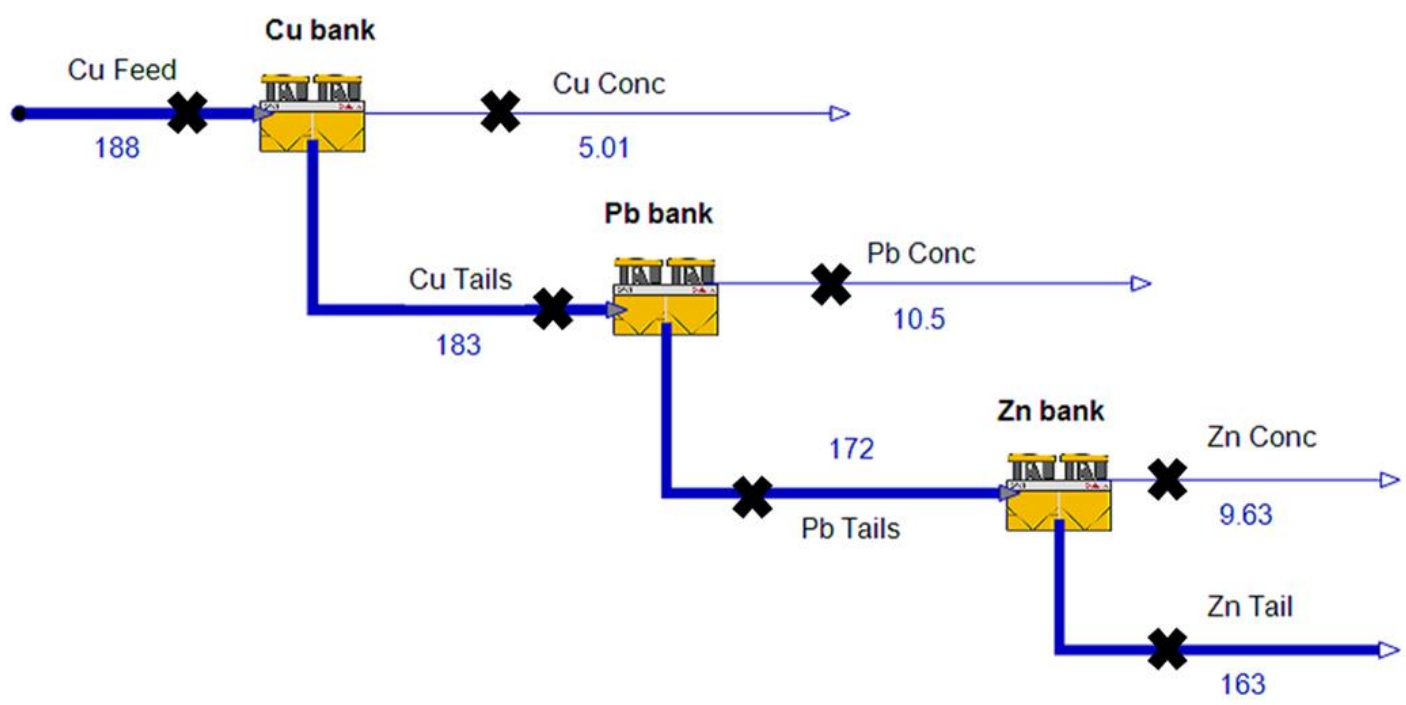

A1: Flowsheet of the case study flotation circuit with key sampling points annotated and solid flowrates for each stream. 


\section{Appendix B - Chemical characterisation}

Table B1: Elemental oxides of the different streams, obtained from XRF. Data is expressed as wt. \%

\begin{tabular}{|l|l|l|l|l|l|l|l|l|l|}
\hline \multirow{2}{*}{ Stream name } & \multicolumn{8}{|c|}{ Chemical assays (wt. \%) } \\
\cline { 2 - 12 } & $\mathbf{A l}_{\mathbf{2}} \mathbf{O}_{\mathbf{3}}$ & $\mathbf{B a O}$ & $\mathbf{C u O}$ & $\mathbf{F e}_{2} \mathbf{O}_{3}$ & $\mathbf{M n O}$ & $\mathbf{P b O}$ & $\mathbf{S O}_{3}$ & $\mathbf{S i O}_{2}$ & $\mathbf{Z n O}$ \\
\hline Copper feed & 2.9 & 0.5 & $<0.1$ & 57.0 & 2.7 & $<0.1$ & 0.4 & 29.5 & 2.7 \\
\hline Copper concentrate & 0.8 & 0.1 & 12.8 & 61.6 & 0.5 & 2.6 & 0.6 & 4.1 & 2.4 \\
\hline Copper tails & 2.7 & 0.7 & 0.7 & 56.3 & 2.6 & $<0.1$ & 0.3 & 31.5 & 2.8 \\
\hline Lead concentrate & 0.8 & $<0.1$ & 0.2 & 8.2 & 0.5 & 24.8 & $<0.1$ & 11.6 & 3.6 \\
\hline Lead tails & 2.8 & 0.4 & 0.3 & 58.5 & 3.4 & $<0.1$ & 0.3 & 28.8 & 2.3 \\
\hline Zinc concentrate & 0.8 & $<0.1$ & $<0.1$ & 11.4 & 0.9 & 1.1 & 0.2 & 1.5 & 56.5 \\
\hline Zinc tails & 2.6 & 0.3 & 0.0 & 57.7 & 2.6 & 0.1 & 0.1 & 29.9 & 3.2 \\
\hline
\end{tabular}

Table B2: Elemental assay of the different streams, obtained from ICP-OES. Data is expressed as wt. $\%$.

\begin{tabular}{|l|l|l|l|l|l|l|l|l|l|}
\hline \multirow{2}{*}{ Stream name } & \multicolumn{9}{|l|}{ Chemical assays (wt. \%) } \\
\cline { 2 - 12 } & Al & Ba & Cu & Fe & Mn & Pb & S & Si & Z \\
\hline Copper feed & 1.5 & 0.5 & 0.6 & 39.9 & 1.9 & 2.6 & 4.7 & 13.7 & 2.6 \\
\hline Copper concentrate & 0.4 & $<0.1$ & 20.7 & 36.8 & 0.2 & 1.9 & 30.4 & 1.9 & 1.3 \\
\hline Copper tails & 1.1 & $<0.1$ & 0.2 & 38.9 & 2.0 & 1.3 & 4.1 & 14.7 & 2.6 \\
\hline Lead concentrate & 0.2 & $<0.1$ & 1.7 & 5.9 & 0.4 & 1.9 & 11.9 & 5.4 & 4.0 \\
\hline Lead tails & 1.6 & 0.6 & 0.2 & 45.5 & 2.6 & 0.5 & 3.4 & 13.5 & 2.5 \\
\hline Zinc concentrate & 0.1 & $<0.1$ & 0.6 & 9.0 & 0.6 & 2.6 & 28.4 & 0.7 & 50.3 \\
\hline Zinc tails & 1.8 & 0.6 & 0.1 & 46.2 & 2.8 & 0.4 & 2.3 & 14.0 & 0.9 \\
\hline
\end{tabular}

Table B3: Chemical composition of the different streams samples, given in wt. \%. (Balanced data).

\begin{tabular}{|l|l|l|l|l|l|l|l|l|l|}
\hline \multirow{2}{*}{ Stream name } & \multicolumn{9}{|l|}{ Chemical assays (wt. \%) } \\
\cline { 2 - 11 } & $\mathbf{A l}$ & $\mathbf{B a}$ & $\mathbf{C u}$ & $\mathbf{F e}$ & $\mathbf{M n}$ & $\mathbf{P b}$ & $\mathbf{S}$ & $\mathbf{S i}$ & $\mathbf{Z n}$ \\
\hline Copper feed & 2.3 & 0.6 & 0.8 & 41.7 & 1.5 & 4.4 & 4.9 & 13.9 & 3.1 \\
\hline Copper concentrate & 0.2 & $<0.1$ & 22.8 & 36.8 & 0.1 & 2.3 & 34.5 & 0.6 & 1.2 \\
\hline Copper tails & 2.3 & 0.6 & 0.2 & 41.8 & 1.6 & 4.5 & 4.1 & 14.3 & 3.1 \\
\hline Lead concentrate & 0.3 & $<0.1$ & 1.8 & 4.1 & 0.2 & 73.4 & 13.0 & 1.0 & 2.5 \\
\hline Lead tails & 2.5 & 0.7 & 0.1 & 44.2 & 1.7 & 0.3 & 3.5 & 15.1 & 3.1 \\
\hline Zinc concentrate & 0.1 & $<0.1$ & 0.5 & 8.6 & 0.4 & 2.2 & 33.4 & 0.2 & 54.1 \\
\hline Zinc tails & 2.6 & 0.7 & 0.1 & 46.3 & 1.7 & 0.1 & 1.8 & 16.0 & 0.1 \\
\hline
\end{tabular}




\section{Appendix C - Mineralogical characterisation}

Table C1: Unbalanced data from Element to mineral conversion. Data expressed as wt. \%.

\begin{tabular}{|l|l|l|l|l|l|l|l|}
\hline Mineral & $\begin{array}{l}\text { Copper } \\
\text { feed }\end{array}$ & $\begin{array}{l}\text { Copper } \\
\text { concentrate }\end{array}$ & $\begin{array}{l}\text { Copper } \\
\text { tails }\end{array}$ & $\begin{array}{l}\text { Lead } \\
\text { concentrate }\end{array}$ & $\begin{array}{l}\text { Lead } \\
\text { tails }\end{array}$ & $\begin{array}{l}\text { Zinc } \\
\text { concentrate }\end{array}$ & $\begin{array}{l}\text { Zinc } \\
\text { tails }\end{array}$ \\
\hline Chalcopyrite & 2.0 & 67.6 & 0.7 & 5.4 & 0.5 & 1.5 & 0.5 \\
\hline Galena & 3.0 & 2.6 & 3.2 & 84.7 & 0.6 & 2.5 & 0.4 \\
\hline Sphalerite & 4.5 & 1.9 & 4.5 & 4.1 & 3.3 & 93.2 & 1.7 \\
\hline Barite & 0.9 & $<0.1$ & 1.1 & 0.0 & 0.9 & 0.0 & 0.8 \\
\hline Garnet & 7.3 & 0.6 & 7.8 & 0.9 & 10.4 & 0.2 & 11.0 \\
\hline Biotite & 3.1 & 0.3 & 3.4 & 0.5 & 3.0 & 0.2 & 2.9 \\
\hline Quartz & 22.5 & 0.5 & 22.1 & 1.0 & 20.7 & 0.3 & 23.1 \\
\hline Pyrrhotite & 4.9 & 25.0 & 4.1 & 0.5 & 3.1 & 0.6 & 3.2 \\
\hline Magnetite & 49.3 & 0.9 & 50.4 & 1.8 & 54.4 & 0.5 & 53.5 \\
\hline
\end{tabular}


Table C2: Mineralogical unbalanced data from QXRD. Data expressed as wt. \%.

\begin{tabular}{|l|l|l|l|l|l|l|l|}
\hline Mineral & $\begin{array}{l}\text { Copper } \\
\text { feed }\end{array}$ & $\begin{array}{l}\text { Copper } \\
\text { concentrate }\end{array}$ & $\begin{array}{l}\text { Copper } \\
\text { tails }\end{array}$ & $\begin{array}{l}\text { Lead } \\
\text { concentrate }\end{array}$ & $\begin{array}{l}\text { Lead } \\
\text { tails }\end{array}$ & $\begin{array}{l}\text { Zinc } \\
\text { concentrate }\end{array}$ & $\begin{array}{l}\text { Zinc } \\
\text { tails }\end{array}$ \\
\hline Augite & 2.5 & 1.6 & 3.1 & 3.9 & 3.0 & 1.0 & 2.7 \\
\hline Apatite & $<0.1$ & 2.5 & $<0.1$ & 0.9 & 7.1 & 6.0 & 0.0 \\
\hline Pyrite & 0.3 & 0.32 & 0.4 & 0.3 & 0.2 & 0.2 & 0.3 \\
\hline Pyrrhotite & 2.5 & 22.9 & 2.5 & 3.0 & 1.5 & 0.3 & 2.3 \\
\hline Biotite & 1.6 & 0.9 & 3.0 & 1.1 & 3.5 & $<0.1$ & 2.0 \\
\hline Galena & 1.6 & 1.1 & 1.9 & 54.0 & 1.0 & 0.9 & 0.6 \\
\hline Magnetite & 37.0 & 0.7 & 46.4 & 2.2 & 45.0 & 0.2 & 52.3 \\
\hline Quartz & 17.9 & 0.7 & 23.2 & 1.7 & 19.2 & 0.4 & 24.0 \\
\hline Sphalerite & 1.0 & 0.5 & 1.2 & 1.5 & 0.8 & $<0.1$ & $<0.1$ \\
\hline Bornite & 2.2 & 1.5 & 2.5 & 3.4 & 2.2 & 1.1 & 0.2 \\
\hline Chalcocite & 0.1 & 0.5 & 0.0 & 0.3 & 0.5 & 1.2 & 0.6 \\
\hline Chalcopyrite & 1.3 & 56.6 & 0.8 & 2.3 & 0.7 & 80 & 1.7 \\
\hline Pyroxmangite & 1.3 & 0.5 & 1.6 & 2.7 & 1.3 & 1.2 & 0.2 \\
\hline Cordierite & 6.9 & 4.4 & 2.0 & 11.8 & 3.4 & 5.0 & 1.0 \\
\hline Chlorite & 4.1 & 2.4 & 3.0 & 0.6 & 2.2 & 0.6 & 2.2 \\
\hline Orthoclase & 6.6 & 2.9 & 6.3 & 10.0 & 6.6 & 4.0 & 7.7 \\
\hline Spessartine & 12.7 & 0.0 & 1.7 & 0.4 & 1.9 & $<0.1$ & 2.3 \\
\hline
\end{tabular}




\section{Appendix D - Monte Carlo Simulation}

Table D1: Monte Carlo Simulation without magnetic separator for scenario I.

\begin{tabular}{|c|c|c|c|c|c|c|c|}
\hline Scenario 1 & Rounds & & & & & & \\
\hline Unit Name & - & $\mathrm{Cu}$ bank & $\mathrm{Cu}$ bank & $\mathrm{Cu}$ bank & $\mathrm{Cu}$ bank & Zn bank & Zn bank \\
\hline Variable Name & - & Sp Tails & Po Tails & Gn Tails & Ccp Tails & Po Tails & Tails \\
\hline $\begin{array}{c}\text { Measurement } \\
\text { Unit }\end{array}$ & - & $\operatorname{Rec} \%$ & $\operatorname{Rec} \%$ & $\operatorname{Rec} \%$ & $\operatorname{Rec} \%$ & wt $\%$ & $\mathrm{t} / \mathrm{h}$ \\
\hline SET / GET & - & GET & SET & GET & GET & GET & GET \\
\hline Cell Reference & - & 99.04 & 88.87 & 98.62 & 22.87 & 4.06 & 163.3 \\
\hline Monte Carlo & - & & $\mathrm{ON}$ & & & & \\
\hline Dist. Type & - & & Uniform & & & & \\
\hline Min & - & 99.04 & 82.0 & 98.62 & 22.87 & 3.79 & 162.8 \\
\hline Max & - & 99.04 & 100.0 & 98.62 & 22.87 & 4.50 & 164.0 \\
\hline Mean & - & 99.04 & 91.0 & 98.62 & 22.87 & 4.12 & 163.4 \\
\hline $\mathrm{SD}$ & - & 0 & 5.20 & 0 & $1.45039 \mathrm{E}-14$ & 0.22 & 0.37 \\
\hline $\mathrm{b}$ & - & & & & & & \\
\hline $\mathrm{c}$ & - & & & & & & \\
\hline Round to Nearest & - & & & & & & \\
\hline Run 1 & 4 & 99.04 & 84.33 & 98.62 & 22.87 & 3.86 & 163.8 \\
\hline Run 2 & 4 & 99.04 & 92.72 & 98.62 & 22.87 & 4.23 & 163.4 \\
\hline Run 3 & 4 & 99.04 & 88.74 & 98.62 & 22.87 & 4.06 & 163.6 \\
\hline Run 4 & 4 & 99.04 & 95.06 & 98.62 & 22.87 & 4.33 & 163.2 \\
\hline Run 5 & 4 & 99.04 & 87.88 & 98.62 & 22.87 & 4.02 & 163.3 \\
\hline Run 6 & 4 & 99.04 & 89.65 & 98.62 & 22.87 & 4.10 & 163.0 \\
\hline
\end{tabular}


Appendix D - Monte Carlo Simulation

\begin{tabular}{|c|c|c|c|c|c|c|c|}
\hline Run 7 & 4 & 99.04 & 86.03 & 98.62 & 22.87 & 3.94 & 162.8 \\
\hline Run 8 & 4 & 99.04 & 89.95 & 98.62 & 22.87 & 4.11 & 164.0 \\
\hline Run 9 & 4 & 99.04 & 85.14 & 98.62 & 22.87 & 3.90 & 163.5 \\
\hline Run 10 & 4 & 99.04 & 98.38 & 98.62 & 22.87 & 4.48 & 163.2 \\
\hline Run 11 & 4 & 99.04 & 83.64 & 98.62 & 22.87 & 3.83 & 163.5 \\
\hline Run 12 & 4 & 99.04 & 94.85 & 98.62 & 22.87 & 4.32 & 163.2 \\
\hline Run 13 & 4 & 99.04 & 94.57 & 98.62 & 22.87 & 4.31 & 163.7 \\
\hline Run 14 & 4 & 99.04 & 95.33 & 98.62 & 22.87 & 4.34 & 163.7 \\
\hline Run 15 & 4 & 99.04 & 95.69 & 98.62 & 22.87 & 4.36 & 164.0 \\
\hline Run 16 & 4 & 99.04 & 84.90 & 98.62 & 22.87 & 3.89 & 163.7 \\
\hline Run 17 & 4 & 99.04 & 92.66 & 98.62 & 22.87 & 4.23 & 163.0 \\
\hline Run 18 & 4 & 99.04 & 94.39 & 98.62 & 22.87 & 4.30 & 163.1 \\
\hline Run 19 & 4 & 99.04 & 86.50 & 98.62 & 22.87 & 3.96 & 163.0 \\
\hline Run 20 & 4 & 99.04 & 98.85 & 98.62 & 22.87 & 4.50 & 163.7 \\
\hline Run 21 & 4 & 99.04 & 94.04 & 98.62 & 22.87 & 4.29 & 163.7 \\
\hline Run 22 & 4 & 99.04 & 92.78 & 98.62 & 22.87 & 4.23 & 163.6 \\
\hline Run 23 & 4 & 99.04 & 92.09 & 98.62 & 22.87 & 4.20 & 163.5 \\
\hline Run 24 & 4 & 99.04 & 93.11 & 98.62 & 22.87 & 4.25 & 163.6 \\
\hline Run 25 & 4 & 99.04 & 87.14 & 98.62 & 22.87 & 3.99 & 163.2 \\
\hline
\end{tabular}


Table D2. Monte Carlo Simulation with magnetic separator for scenario II.

\begin{tabular}{|c|c|c|c|c|c|c|c|c|c|c|c|c|c|}
\hline Scenario 1 & $\begin{array}{c}\text { Roun } \\
\text { ds }\end{array}$ & & & & & & & & & & & & \\
\hline Unit Name & - & $\begin{array}{c}\mathrm{Cu} \\
\text { bank }\end{array}$ & $\begin{array}{c}\mathrm{Cu} \\
\text { bank }\end{array}$ & $\begin{array}{c}\mathrm{Cu} \\
\text { bank }\end{array}$ & $\begin{array}{c}\mathrm{Cu} \\
\text { bank }\end{array}$ & $\begin{array}{c}\mathrm{Zn} \\
\text { bank }\end{array}$ & $\begin{array}{c}\mathrm{Zn} \\
\text { bank }\end{array}$ & $\begin{array}{c}\text { Magnetic } \\
\text { Sep }\end{array}$ & $\begin{array}{c}\text { Magnetic } \\
\text { Sep }\end{array}$ & $\begin{array}{c}\text { Magnetic } \\
\text { Sep }\end{array}$ & $\begin{array}{c}\text { Magnetic } \\
\text { Sep }\end{array}$ & $\begin{array}{c}\text { Magnetic } \\
\text { Sep }\end{array}$ & $\begin{array}{l}\text { Magnetic } \\
\text { Sep }\end{array}$ \\
\hline $\begin{array}{l}\text { Variable } \\
\text { Name }\end{array}$ & - & $\begin{array}{c}\text { Sp } \\
\text { Tails }\end{array}$ & $\begin{array}{c}\text { Po } \\
\text { Tails }\end{array}$ & $\begin{array}{c}\text { Gn } \\
\text { Tails }\end{array}$ & $\begin{array}{l}\text { Ccp } \\
\text { Tails }\end{array}$ & $\begin{array}{c}\text { Po } \\
\text { Tails }\end{array}$ & Tails & Po Tails & Mgt Tails & Po Tails & Mgt Tails & Po Conc & Mgt Conc \\
\hline $\begin{array}{c}\text { Measurement } \\
\text { Unit } \\
\end{array}$ & - & $\begin{array}{c}\operatorname{Rec} \\
\%\end{array}$ & $\begin{array}{c}\mathrm{Rec} \\
\%\end{array}$ & $\operatorname{Rec} \%$ & $\operatorname{Rec} \%$ & wt $\%$ & $\mathrm{t} / \mathrm{h}$ & $\operatorname{Rec} \%$ & $\operatorname{Rec} \%$ & $\mathrm{wt} \%$ & $\mathrm{wt} \%$ & $\mathrm{wt} \%$ & $\mathrm{wt} \%$ \\
\hline SET / GET & - & GET & SET & GET & GET & GET & GET & GET & GET & GET & GET & GET & GET \\
\hline $\begin{array}{c}\text { Cell } \\
\text { Reference }\end{array}$ & - & 99.04 & 82.85 & 98.62 & 22.87 & 3.80 & 162.8 & 4.11 & 2.16 & 0.84 & 12.59 & 6.22 & 93.06 \\
\hline $\begin{array}{c}\text { Chart } \\
\text { numbers }\end{array}$ & - & & & & & & & & & & & & \\
\hline Monte Carlo & - & & $\mathrm{ON}$ & & & & & OFF & OFF & & & & \\
\hline Dist. Type & - & & $\begin{array}{c}\text { Norm } \\
\text { al }\end{array}$ & & & & & & & & & & \\
\hline Min & - & 99.04 & 82.85 & 98.62 & 22.87 & 3.88 & 163.0 & 10.0 & 10.0 & 0.86 & 12.57 & 6.36 & 91.93 \\
\hline Max & - & 99.04 & 100.0 & 98.62 & 22.87 & 4.51 & 164.1 & 10.0 & 10.0 & 1.01 & 12.59 & 7.36 & 92.93 \\
\hline Mean & - & 99.04 & 91.0 & 98.62 & 22.87 & 4.14 & 163.4 & 10.0 & 10.0 & 0.92 & 12.58 & 6.77 & 92.51 \\
\hline SD & - & 0 & 5.0 & 0 & $\begin{array}{c}1.45 \mathrm{E}- \\
14 \\
\end{array}$ & 0.15 & 0.26 & 0 & 0 & 0.04 & 0.004518 & 0.25 & 0.24 \\
\hline $\mathrm{b}$ & - & & & & & & & & & & & & \\
\hline $\mathrm{c}$ & - & & & & & & & & & & & & \\
\hline $\begin{array}{l}\text { Round to } \\
\text { Nearest }\end{array}$ & - & & & & & & & & & & & & \\
\hline Run 1 & 4 & 99.04 & 84.33 & 98.62 & 22.87 & 3.86 & 163.3 & 10.0 & 10.0 & 0.90 & 12.58 & 6.64 & 92.65 \\
\hline Run 2 & 4 & 99.04 & 92.72 & 98.62 & 22.87 & 4.23 & 163.0 & 10.0 & 10.0 & 0.87 & 12.59 & 6.37 & 92.91 \\
\hline Run 3 & 4 & 99.04 & 88.74 & 98.62 & 22.87 & 4.06 & 163.6 & 10.0 & 10.0 & 0.88 & 12.58 & 6.90 & 92.38 \\
\hline Run 4 & 4 & 99.04 & 95.06 & 98.62 & 22.87 & 4.33 & 163.2 & 10.0 & 10.0 & 0.92 & 12.59 & 6.52 & 92.76 \\
\hline Run 5 & 4 & 99.04 & 87.88 & 98.62 & 22.87 & 4.02 & 163.0 & 10.0 & 10.0 & 0.95 & 12.59 & 6.40 & 92.88 \\
\hline
\end{tabular}




\begin{tabular}{|l|l|l|l|l|l|l|l|l|l|l|l|l|l|}
\hline Run 6 & 4 & 99.04 & 89.65 & 98.62 & 22.87 & 4.10 & 163.6 & 10.0 & 10.0 & 0.99 & 12.58 & 6.92 & 92.37 \\
\hline Run 7 & 4 & 99.04 & 86.03 & 98.62 & 22.87 & 3.94 & 163.3 & 10.0 & 10.0 & 0.93 & 12.58 & 6.66 & 92.62 \\
\hline Run 8 & 4 & 99.04 & 89.95 & 98.62 & 22.87 & 4.11 & 163.6 & 10.0 & 10.0 & 0.91 & 12.58 & 6.96 & 92.33 \\
\hline Run 9 & 4 & 99.04 & 85.14 & 98.62 & 22.87 & 3.90 & 163.8 & 10.0 & 10.0 & 1.07 & 12.58 & 7.10 & 92.19 \\
\hline Run 10 & 4 & 99.04 & 98.38 & 98.62 & 22.87 & 4.48 & 163.1 & 10.0 & 10.0 & 0.92 & 12.59 & 6.48 & 92.81 \\
\hline Run 11 & 4 & 99.04 & 83.64 & 98.62 & 22.87 & 3.83 & 163.5 & 10.0 & 10.0 & 0.86 & 12.58 & 6.83 & 92.45 \\
\hline Run 12 & 4 & 99.04 & 93.52 & 98.62 & 22.87 & 4.22 & 163.6 & 10.0 & 10.0 & 0.91 & 12.58 & 6.27 & 90.29 \\
\hline Run 13 & 4 & 99.04 & 92.42 & 98.62 & 22.87 & 4.19 & 163.5 & 10.0 & 10.0 & 1.03 & 12.58 & 6.22 & 88.87 \\
\hline Run 14 & 4 & 99.04 & 91.83 & 98.62 & 22.87 & 4.11 & 163.4 & 10.0 & 10.0 & 1.0 & 12.58 & 6.19 & 89.14 \\
\hline Run 15 & 4 & 99.04 & 89.93 & 98.62 & 22.87 & 3.88 & 163.0 & 10.0 & 10.0 & 0.60 & 12.58 & 6.11 & 93.36 \\
\hline Run 16 & 4 & 99.04 & 84.76 & 98.62 & 22.87 & 4.40 & 163.9 & 10.0 & 10.0 & 0.97 & 12.58 & 6.88 & 88.59 \\
\hline Run 17 & 4 & 99.04 & 96.58 & 98.62 & 22.87 & 4.07 & 163.3 & 10.0 & 10.0 & 0.83 & 12.58 & 6.40 & 91.45 \\
\hline Run 18 & 4 & 99.04 & 89.10 & 98.62 & 22.87 & 4.08 & 163.3 & 10.0 & 10.0 & 0.97 & 12.58 & 6.07 & 89.23 \\
\hline Run 19 & 4 & 99.04 & 89.34 & 98.62 & 22.87 & 4.20 & 163.5 & 10.0 & 10.0 & 0.78 & 12.58 & 6.08 & 91.30 \\
\hline Run 20 & 4 & 99.04 & 91.97 & 98.62 & 22.87 & 4.29 & 163.7 & 10.0 & 10.0 & 1.06 & 12.58 & 6.20 & 88.51 \\
\hline Run 21 & 4 & 99.04 & 94.04 & 98.62 & 22.87 & 4.23 & 163.6 & 10.0 & 10.0 & 0.80 & 12.58 & 6.29 & 91.51 \\
\hline Run 22 & 4 & 99.04 & 92.78 & 98.62 & 22.87 & 4.20 & 163.5 & 10.0 & 10.0 & 0.99 & 12.58 & 6.23 & 89.44 \\
\hline Run 23 & 4 & 99.04 & 92.09 & 98.62 & 22.87 & 4.25 & 163.6 & 10.0 & 10.0 & 1.14 & 12.58 & 6.20 & 87.71 \\
\hline Run 24 & 4 & 99.04 & 93.11 & 98.62 & 22.87 & 3.99 & 163.2 & 10.0 & 10.0 & 1.06 & 12.58 & 6.25 & 88.71 \\
\hline Run 25 & 4 & 99.04 & 87.14 & 98.62 & 22.87 & 4.22 & 163.6 & 10.0 & 10.0 & 0.98 & 12.58 & 6.99 & 88.82 \\
\hline
\end{tabular}


Table D3: Varying pyrrhotite feed grade for sensitivity analysis for scenario I and II.

\begin{tabular}{|l|l|l|l|}
\hline \multirow{2}{*}{ Scenarios } & \multirow{2}{*}{ Pyrrhotite feed grade (wt. \%) } & \multicolumn{2}{|l|}{ Predicted pyrrhotite grade in the final tails (wt. \%) } \\
\cline { 3 - 4 } & & $\begin{array}{l}\text { Sensitivity analysis for } \\
\text { scenario I }\end{array}$ & $\begin{array}{l}\text { Sensitivity analysis for } \\
\text { scenario II }\end{array}$ \\
\hline Base Case & 4.0 & 3.8 & 0.98 \\
\hline 1 & 4.5 & 4.2 & 1.08 \\
\hline 2 & 4.9 & 4.6 & 1.18 \\
\hline 3 & 5.3 & 4.9 & 1.29 \\
\hline 4 & 5.7 & 5.3 & 1.39 \\
\hline 5 & 6.1 & 5.7 & 1.50 \\
\hline 6 & 6.5 & 6.1 & 1.61 \\
\hline 7 & 6.9 & 6.5 & 1.72 \\
\hline 8 & 7.3 & 6.9 & 1.84 \\
\hline 9 & 7.7 & 7.3 & 1.95 \\
\hline 10 & 8.1 & 7.7 & 2.19 \\
\hline
\end{tabular}

